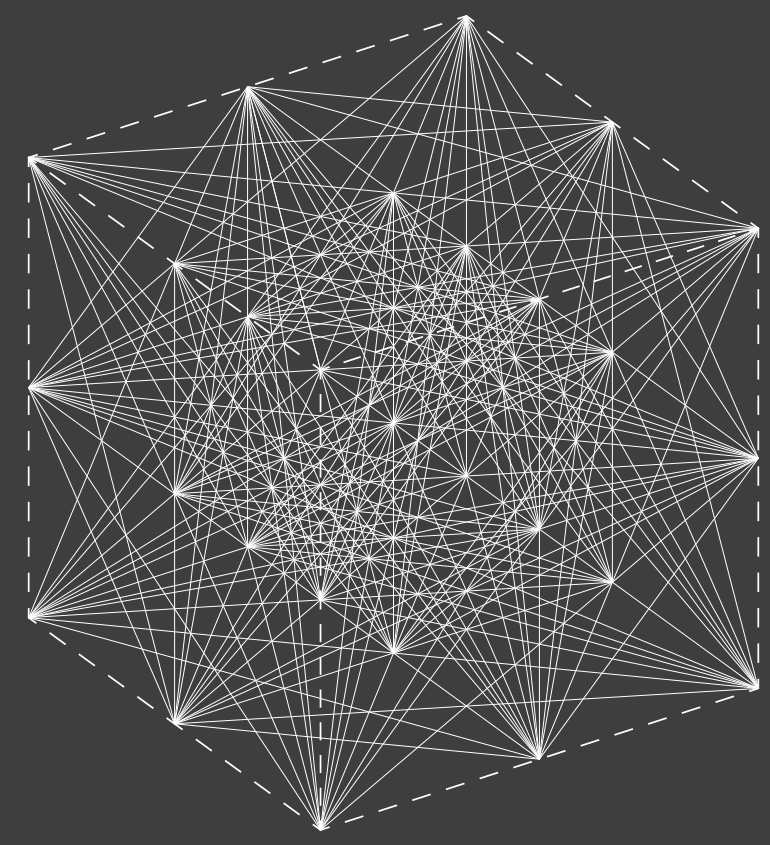

Formation Architecture Interactive Vertical Community 


\title{
Formation Architecture: Interactive Vertical Community
}

\author{
by \\ Benyi Hu \\ Bachelor of Architectural Science, Ryerson University, 2020 \\ A thesis \\ presented to Ryerson University \\ in partial fulfillment of the \\ requirements for the degree of \\ Master of Architecture \\ in the Program of \\ Architecture \\ Toronto, Ontario, Canada, 2020 \\ (C) Benyi Hu, 2020
}




\section{Author's Declaration}

I hereby declare that I am the sole author of this thesis. This is a true copy of the thesis, including any required final revisions, as accepted by my examiners.

I authorize Ryerson University to lend this thesis to other institutions or individuals for the purpose of scholarly research.

I further authorize Ryerson University to reproduce this thesis by photocopying or by other means, in total or in part, at the request of other institutions or individuals for the purpose of scholarly research.

I understand that my thesis may be made electronically available to the public. 


\section{Abstract}

Formation Architecture: Interactive Vertical Community

MArch 2020 | Benyi Hu | Master of Architecture | Ryerson University

High-density residential architecture under the influence of industrialization and mass production has developed a culture of design toward uniformity and standardization. This thesis deploys the parametrics approach to mass customization for a personalization culture in architecture. A systematic participatory design approach is developed to accommodate individual performance variability of the users and the changing demands of the social environment as part of the design solution. This design strategy allows the architect to balance the two separate forces of control between the collective and the individual, which transform the high-density residential living conditions from externally defined homogeneity towards individually initiated flexibility. A mixed-used vertical neighbourhood is designed to promote social intimacy and stability, and making the creation of community space an outcome of neighbourhood negotiation. The intention is to transform the monotonous and anonymous highdensity residential tower into a dynamic system that always maintains overall coherence. This personalization culture can incentivize people's emotional connection with the physical environment and making architecture more sustainable by establishing an enduring relationship with the user. 


\section{Acknowledgments}

I would like to express my gratitude to my supervisor Arthur Wrigglesworth and the rest of my committee for their unwavering support, guidance and insight throughout this thesis.

Special thanks to my wife Tingting Zhou and my father Xiaodong $\mathrm{Hu}$ for supporting and encouraging me throughout my degree. 


\section{Table of Contents}

$\begin{array}{lll}\text { Abstract } & \mathrm{VI}\end{array}$

Acknowledgments VIII

Table of Content IX

List of Figures XI

01 | Introduction 1

1.1 The Digital Machine 1

1.2 Design Participation 3

1.3 Personalization Culture 4

1.4 User Participatory Design 6

1.3 Balance of Forces 6

02 | Modernism and the Culture of Standardization 11

2.1 The Visionary Designer 11

2.2 Establishing a Standard 12

2.3 The Failure of Visionary Planning 13

$\begin{array}{lll}2.5 & \text { Star-chitect } & 17\end{array}$

03 | Bottom-Up Architecture: The Problems of Participation 21

3.1 Consensus Based Participation $\quad 21$

3.2 High Eesity Residential Without Architects 24

3.3 Japanese Metabolist Architecture 27

04 | Balance of Forces 29

4.1 Design With User 29

4.2 Separation of Control: Support, Allocation, Infill 30

4.3 The Allocation Level In Residential Open Building 32

4.4 Architect's Leadership Role in Design 34

4.4 Conceptual Design Study: A Dynamically Evolving 35

Elevation

05 | Digital Technology and Parametrics 41

5.1 Superusers 43

5.1 Design With Variables 46 
5.2 Rule Based Procedural Algorithm 47

5.3 Rule-Based Design Exploration 49

5.4 Façade Customization Exploration 51

5.5 Parametric Control of Allocation 53

5.6 Systematic Participatory Design 57

5.7 Role of Algorithm 69

06 | Unit Customization 71

6.1 Customization Through Neighbourhood Negotiation 71

6.2 Infill Customization 81

6.3 Facade Customization 83

07 | Design Study of Support Level 85

7.1 Core and Floor Plate Study 85

7.2 Support Level Design 93

08 | Vertical Community Design Investigation 97

6.1 Social Context of High-Density Residential Towers 97

6.2 Vertical Podium:

Commercial and Public Neighbourhood Activities $\quad 103$

6.3 Block Scale Residential Community 105

6.4 Social Dynamics Within The Vertical Community 107

$\begin{array}{lll}6.5 & \text { Feasibility } & 111\end{array}$

09 | Conclusion 117

$\begin{array}{ll}\text { Bibliography } & 121\end{array}$

$\begin{array}{ll}\text { Appendix } & 125\end{array}$ 


\section{List of Figures}

Figure No.1-1: Homeomorphic by Branko Kolarevic

Source: Kolarevic, B. (2004). Architecture in the Digital Age: Design and

Manufacturing. Taylor \& Francis.

Figure No.1-2: Soho Galaxy's public courtyard

Source: https://worldarchitecture.org/architecture-news/chmcp/galaxy-soho-

awarded-twice-for-design-excellence-in-china.html

Figure No.1-3: Guggenheim Bilbao Museum by Frank Ghery

Source: https://www.guggenheim.org/blogs/checklist/architects-critics-curatorsand-museum-directors-reflect-on-twenty-years-of-the-guggenheimmuseum-bilbao

Figure No.1.4: The Facade of Al Bahar tower

Source: https://www.theplan.it/eng/webzine/international-architecture/al-bahr. towers-en

Figure No.1-5: Customization options for car pre-order

Source: https://www.mercedes-benz.ca/en/vehicles/build/e-class/sedan/ e53w4?category=interior

Figure No.1-6: Support and Infill separation diagram

Source: https://www.brikbase.org/sites/default/files/PWRJ_Vol0701_02_

Developments_in_Residential_Open_Building.pdf

Figure No.1-7: High Control vs No Control

Source: https://www.straitstimes.com/business/property/worlds-priciest. housing-market-set-for-most-densely-packed-apartment-blocks https://www.cinemablend.com/news/1738399/13-most-bodaciouslybadass-moments-from-the-new-ready-player-one-trailer

Figure No.1-8: Conventional Method

Source: Benyi Hu

Figure No.1-9: Systematic Participatory Design

Source: Benyi Hu 
Figure No.2-1: Five Points Towards a New Architecture by Le Corbusier Source: http://3.bp.blogspot.com/-nPpdX95KILE/T43X-2h_COI/AAAAAAAAAes/ NzC_QOhWQNA/s1600/1.jpg

Figure No.2-2: Ford Motor Assembly Line in 1913

Source: https://www.assemblymag.com/articles/91581-the-moving-assemblyline-turns-100

Figure No.2-3: Dom-Ino House by Le Corbusier

Source: http://thecityasaproject.org/2014/03/the-dom-ino-effect/

Figure No.2-4: The Modulor System by Le Corbusier

Source: https://www.dezeen.com/2015/12/08/warsaw-beton-polish-film-festivalbrand-identity-graphic-design-references-le-corbusier-modulor-man/

Figure No.2-5: Aerial view of the Pruitt-Igoe

Source: https://99percentinvisible.org/episode/episode-44-the-pruitt-igoe-myth/

Figure No.2-6: Demolition of Pruitt-Igoe in 1972

Source: https://99percentinvisible.org/episode/episode-44-the-pruitt-igoe-myth/

Figure No.2-7: Masterplan of Bijlmermeer

Source: https://99percentinvisible.org/episode/bijlmer-city-future-part-1/

Figure No.2-8: Radiant City Model by Le Corbusier

Source: https://99percentinvisible.org/episode/bijlmer-city-future-part-1/

Figure No.2-9: Aerial View of Museum of Pop Culture, Seattle

Source: https://commons.wikimedia.org/wiki/File:Aerial_view_of_EMPSFM.jpg

Figure No.2-10: Illustrative floor-plan for Museum of Pop Culture

Source: https://www.mopop.org/visit/

Figure No.2-11: BMW Leipzig central building facade

Source: Spencer, D. (2016). The architecture of neoliberalism: How contemporary architecture became an instrument of control and compliance. Bloomsbury Academic.p.74 
Figure No.2-11: BMW Leipzig open plan design

Source: https://commons.wikimedia.org/wiki/File:BMW_Leipzig_MEDIA_050719_ Download_ZGB_2_max.jpg

Figure No.3-1: University of Oregon's Campus Planning

Source: Rudofsky, B. (1987). Architecture without architects: A short introduction to nonpedigreed architecture. Albuquerque: University of New Mexico Press.

Figure No.3-2: Marrakech, Morocco

Source: Lorenzo-Eiroa, P., \& Sprecher, A.(2013). Architecture in formation. p.19

Figure No.3-3: Aerial View of the Walled City in 1973

Source: Girard, G., \& Lambot, I. (1993). City of darkness: Life in Kowloon Walled City. Watermark.p.71

Figure No.3-4: Aerial View of the Walled City in 1989

Source: Girard, G., \& Lambot, I. (1993). City of darkness: Life in Kowloon Walled City. Watermark.p.5

Figure No.3.5: Interior corridor connecting the buildings

Source: Girard, G., \& Lambot, I. (1993). City of darkness: Life in Kowloon Walled City. Watermark.p.18

Figure No.3-6: Interior corridor connecting the buildings

Source: Girard, G., \& Lambot, I. (1993). City of darkness: Life in Kowloon Walled City. Watermark. p.25 p.26 p.55 p.115 p.127 p.204

Figure No.3-7: Plan of Tokyo Bay by Kenzo Tange, 1960

Source: https://archeyes.com/plan-tokyo-1960-kenzo-tange/

Figure No.3-8: Kisho Kurokawa's Nakagin Capsule Tower in Tokyo

Source: https://www.archdaily.com/110745/ad-classics-nakagin-capsule-tower-kishokurokawa

Figure No.4-1: Separation of levels and control for high density residential

Source: https://www.brikbase.org/sites/default/files/PWRJ_Vol0701_02_Developments_ in_Residential_Open_Building.pdf

Figure No.4-2: Stephen Kendall's Level of Control Diagram

Source: http://open-building.org/ob/concepts.html 
Figure No.4-3: Solid 11 in Amsterdam, Netherlands

Source: https://www.archdaily.com/207521/solid-11-tony-fretton-architects

Figure No.4-4: Next 21 in Osaka, Japan

Source: https://www.homes.co.jp/cont/press/reform/reform_00137/

Figure No.4-5: Diagram using building facades to represent the two separate forces in design Source: https://www.flickr.com/photos/domgarcia/9652975846/sizes/h/

https://www.textures.com/

Figure No.4-6: Diagram showing a combine of the two forces

Source: Benyi Hu

Figure No.4-7: A systematic design approach to encompass the changing demands of the Source: users

Benyi Hu

Figure No.5-1: Kilden Performing Arts Centre from design to fabrication - Digital Continuum Source: Burry, M., \& Burry, J. (2016). Prototyping for architects. London: Thames \& Hudson.p.106-109

Figure No.5-2: 2012 Renault Twizy EV with bobby form

Source: https://bgr.com/2015/03/25/renault-twizy-price-and-drivers-license/

Figure No.5-3: 2017 Tesla Model 3 EV that maintains the classic car appearance Source: https://www.tesla.com/model3

Figure No.5-4: Digital Water Pavilion by Carlo Ratti

Source: https://carloratti.com/project/digital-water-pavilion/

Figure No.5-5: Electronic Countermeasures by Tomorrow's Thoughts Today

Source: https://www.domusweb.it/en/news/2012/03/12/electronic-countermeasures. html

Figure No.5-6: Changing Coloumn geometries at La Sagrada Família

Source: https://moreaedesign.wordpress.com/2010/09/13/more-about-sagradafamilia/ 
Figure No.5-7: Construction details of a pinnacle in medieval period, 1486

Source: Schumacher, P. (Ed.). (2016). Parametricism 2.0: Rethinking Architecture's

Agenda for the 21st Century. London: Academy Press.p.28

Figure No.5-8: Rule-based design system formation progress

Source: Benyi Hu

Figure No.5-9: Rule-based design system adjustment

Source: Benyi Hu

Figure No.5-10 Grasshopper Script of Facade Exploration

Source: Benyi Hu

Figure No.5.11 User Customizable Facade System

Source: Benyi Hu

Figure No.5-12 Possible unit configuration with different cells combination

Source: Benyi Hu

Figure No.5-13 $4 \mathrm{~m} \times \mathbf{4 m}$ cell space study

Source: Benyi Hu

Figure No.5-14 Parametric System Logic

Source: Benyi Hu

Figure No.5-15 Paramteric generated Allocation options

Source: Benyi Hu

Figure No.5-16 Refined parametric system

Source: Benyi Hu

Figure No.5-17 Refined parametric system with vertically shifted massing

Source: Benyi Hu

Figure No.5.18 Refined parametric system with spaces partially carved out

Source: Benyi Hu

Figure No.5-19: Grasshopper script for Allocation system

Source: Benyi Hu 
Figure No.5-20: Relationship Diagram showing parametric spatial deployment

Source: Benyi Hu

Figure No.6.1 Unit customization through shifting of boundary

Source: Benyi Hu

Figure No.6.2 Simulation for shifting of boundary

Source: Benyi Hu

Figure No.6-3 Unit customization through sharing of space

Source: Benyi Hu

Figure No.6.4 Example of space sharing among students

Source: Benyi Hu

Figure No.6-5 Example of space sharing among trans-generational family

Source: Benyi Hu

Figure No.6-6 Tila Housing progress construction of Infill Level

Source: http://thematicdesign.org/wp-content/uploads/2017/05/Project_card\%20Tila.pdf

Figure No.6-7 Tila Housing Project Infill Options

Source: https://www.architonic.com/en/project/talli-architecture-and-design-tila-housing/5103963

Figure No.6.8 Three types of facade panel systems

Source: Benyi Hu

Figure No.6-9 Balcony customization based on user preferences

Source: Benyi Hu

Figure No.7-1 Single and double centre core design with block massing

Source: Benyi Hu

Figure No.7-2 Linear corridor design with scattered vertical circulation and means of egress

Source: Benyi Hu

Figure No.7-3 Axonometric sectional plan showing relation of programs and circulation

Source: Benyi Hu 
Figure No.7-4 Vertical Community design option of with double centre core

Source: Benyi Hu

Figure No.7-5 Vertical circulation of double core design

Source: Benyi Hu

Figure No.7-6 Axonometric sectional plan showing relation of programs and circulation

Source: Benyi Hu

Figure No. 7.7 Vertical Community design option of with single centre core

Source: Benyi Hu

Figure No. 7.8 Vertical circulation of single core design with single helix stairway

Source: Benyi Hu

Figure No. 7.9 Lower skip-stop level for residential entrance

Source: Benyi Hu

Figure No. 7-10 Upper skip-stop level for commercial and public space entrance

Source: Benyi Hu

Figure No. 7-11 Conventional Japanese residential structure system

Source: Kendall, S., \& Teicher, J. (2000). Residential Open Building. E\&FNSpon.

Figure No. 7.12 Inverted Slab/Beam Support structure

Source: Kendall, S., \& Teicher, J. (2000). Residential Open Building. E\&FNSpon.

Figure No. 7.13 Plumbing solutions for Open Building projects

Source: https://repository.tudelft.nl/islandora/object/uuid:c1a972a9-43f6-4043-aace04b323b2b4ed/datastream/OBJ2/download

Figure No. 7.14 Raised floor systems and products

Source: https://repository.tudelft.nl/islandora/object/uuid:c1a972a9-43f6-4043-aace. 04b323b2b4ed/datastream/OBJ2/download

Figure No. 7.15 3D illustration for the plumbing distribution of different raised floor systems Source: https://repository.tudelft.nl/islandora/object/uuid:c1a972a9-43f6-4043-aace04b323b2b4ed/datastream/OBJ2/download 
Figure No. 8-1 Shifting of urban territory classification due to increase of urban population Source: Benyi Hu

Figure No. 8.2 Plan showing division of blocks and standard high-rise building core Source: Benyi Hu

Figure No. 8.3 Perspectival Plan showing relationship of small public space and residential units Source: Benyi Hu

Figure No. 8.4 Perspectival Plan showing relationship of Large public space and residential units Source: Benyi Hu

Figure No. 8.5 Design Process Diagram

Source: Benyi Hu

Figure No. 8.6 Diagram showing vertical circulation and distribution of public space Source: Benyi Hu

Figure No. 8.7 Grouping residents with similar interest within a block Source: Benyi Hu

Figure No. 8.8 Corner Aerial View

Source: Benyi Hu

Figure No. 8.9 Perspective elevation showing design strategy of helix stairs Source: Benyi Hu

Figure No. 8-10 Park and Shared Office Perspective Elevation

Source: Benyi Hu

Figure No. 8-11 Perspective View of the Public Park

Source: Benyi Hu

Figure No. 8.12 Aerial Perspective of the Vertical Community within an urban environment Source: Benyi Hu 


\section{1 | Introduction}

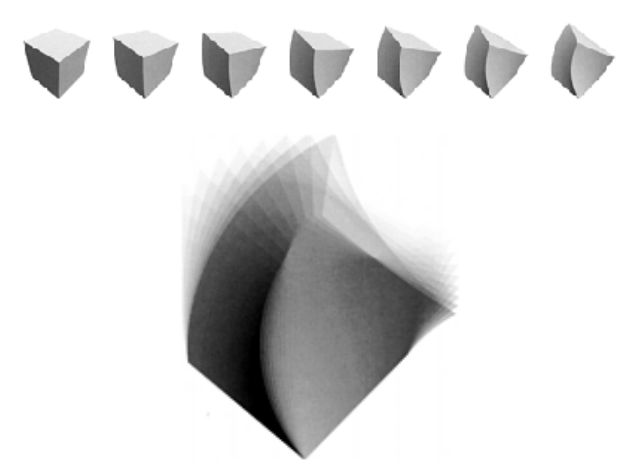

Figure No.1-1

Homeomorphic by Branko Kolarevic, 2003

Same topological structure have infinite number of geometrical manifestation

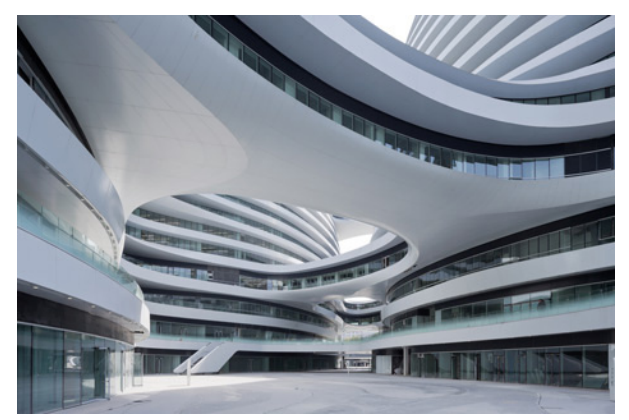

Figure No.1-2

Soho Galaxy's centre public courtyard by Zaha Hadid Architects, 2012, Beijing, China
The evolution of architecture is often accompanied by discoveries of technologies, techniques and knowledge. In the mid1400s, Leon Battista Alberti introduced a mathematical approach to graphic representation, which created precision drafting as a form of architectural representation. In the industrial age, the invention of the machines and assembly line to produce with high efficiency became the source of innovation for modernist architecture. Le Corbusier's "Five Points of Architecture" manifesto and his depiction of the house as a machine suggested a modular strategy of architecture design that could be mass-produced (Le Corbusier, 1927). It revealed a transformation of architecture based on technological innovation. In the contemporary era, the technological transformation from an analog to a digital way of processing, storing and transferring of information is imposing continuous changes in architecture, from design to construction and operation.

\section{The Digital Machine}

The difference between a mechanical machine and a digital machine is that mechanical machines produce identical copies of objects; and digital machines, according to Gilles Deleuze, produce "objectile", which does not have a definitive form but an open. ended mathematical function (Poster \& Savat, 2009). Consequently, architects working within the digital context are capable to design with variables. The fundamental power of digital technology is its flexibility; it provides the control of variables to create many solutions. Most parametric designers have mastered the technique to control the variables but they failed to recognize its flexible nature in design; architects are using these flexible technologies to create visually complex but static designs that are incapable of adapting to future changes. The Soho Galaxy by Zaha Hadid Architects used mass 
customization techniques to fabricate the continuously changing surface geometry of the façade panels to construct the biomorphic form. Digital technologies have made drawing and construction of complex non-orthogonal geometries such as the nave of Basílica de la Sagrada Família much more efficient and practical through computation. However, the complexity of construction and fabrication does not permit any future customization of the building. Once the building is out of style or does not meet the future needs, it will have to be demolished to make room for a new building. Therefore, most contemporary architects are using mass customization technology to produce non-customizable architecture, which becomes obsolete in a short time period.

In the early 1990s, when architects first started to engage with digitally designed form and variations through changing parameters, the explorations were form-based. Various projects, such as Frank Gehry's iconic Guggenheim Museum Bilbao or the BMW Bubble by Bernhard Franken, suggest the use of digital variables to create a new aesthetic for irregular and organic buildings known as "blobby" architecture. The contemporary uses of digital variables to design, known as parametrics, enables form configuration in response to specific design parameters such as the climatic, structural, or programmatic performance drivers. This design method can create an infinite number of design options by changing the input values, but only one option can be built, and there is a limited number of parameters that can be addressed. Unfortunately, most architects have only conceptualized their deployment of mass customization technology from the point of view of conventional mechanical machines, with the goal of generating complex geometries. The technology's intrinsic value of relational computation for performance variability is neglected. Performance-related parameters are an essential part of
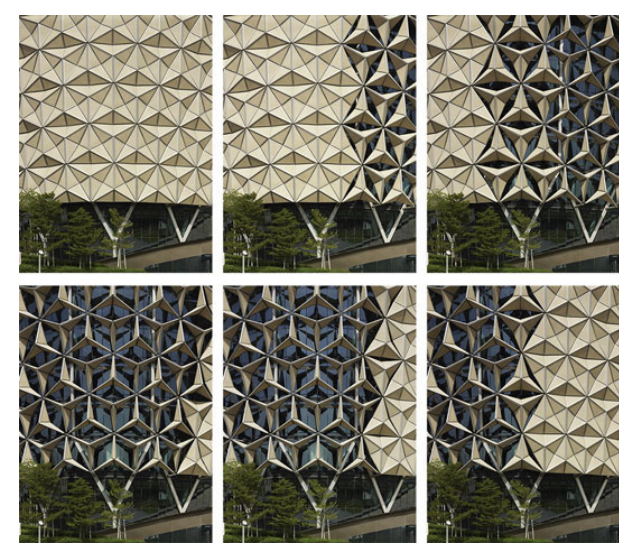

Figure No.1-4

The Facade of Al Bahar Tower, 2012, Abu Dhabi Using parametric technology to control the transformation of the facade to respond to solar parameters 
architecture that is often being reduced to a standard size or number in conventional architecture design. Performance variability through relational computation enables architecture to incorporate design variations as part of the design solution. Performance parameters can be used with mass customization technology to support the architect's design process and realization of the form. Therefore, architects should investigate ways to use mass customization technology for achieving performance variability.

\section{Design Participation}

Architectural explorations with digital variables are
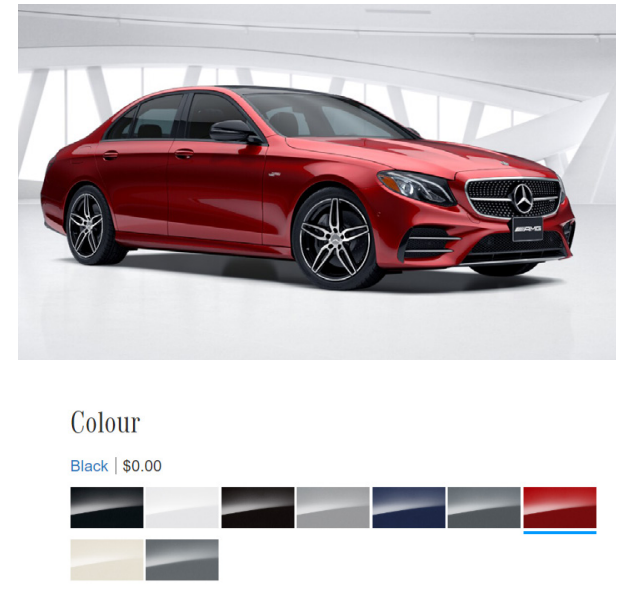

Wheels

19-inch AMG twin 5-spoke, bicolour | $\$ 0.00$

\section{(1)}

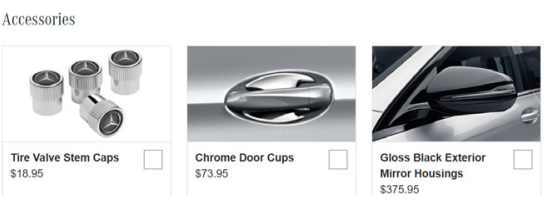

Figure No.1-5

Mercedes-Benz E-Class

Customization options for car pre-order minantly form-based with the desire of generating visual complexity. However, digital technology can be better integrated with architecture for the purpose of achieving social dynamic in design. According to Mario Carpo, "All that is digitally variable is potentially open to interaction, communality and participation" (Lorenzo-Eiroa, Sprecher, \& McClintock, 2013, p. 47). Digital technology has been developed to allow users to connect, collaborate and share content. Through user participation, websites like Twitter and Facebook have become a continuously evolving system with constantly updating content. The fundamental characteristic of Web 2.0 websites is its participatory culture that emphasizes user-generated content and interaction within the virtual community. A framework is typically designed by the website developer to structure user engagement and to constrain the published contents within defined limits. For example, Wikipedia allows users to submit and modify the article contents, but new and unregistered users are required to be reviewed by established users before publishing (Frewin, 2010). Digital technology can be deployed in architecture to incorporate the diverse performance needs of users as part of the design process. User participation 
through digital technology can help develop an architecture system that is capable of constantly evolving to reflect the changing needs of its inhabitants.

\section{Personalization Culture}

Design customization is a technique for supporting personalization culture in many aspects of the economy, often presenting product or service selection "choices" as being in the customers' control and able to meet their individual needs or desires. For example, car manufacturers provide the buyer options for the colour, the styling of wheels, or the interior trim. Fast-food restaurants offer their customers choices of toppings, sauces, and drinks with diverse flavours. This product customization culture recognizes the fact that every individual has preferences, and a single design solution cannot satisfy all demands. Clare Cooper Marcus said that "personalization is the inherent emotional connection people carry with the physical environment" (Marcus, 1995, p.11).

Home customization is an essential part of identity development. The furniture layout, wall paint colour, or even choices of window blinds are all reflections of the user's living habits. Through the different stages of an individual's life, our home would be customized or configured to respond to our needs and living habits. Therefore, the physical living environment should always suit ourselves and not the reverse. The Modernist architects' fantasy of using a single design scheme to resolve the living needs of all the users can no longer be a desirable method of design.

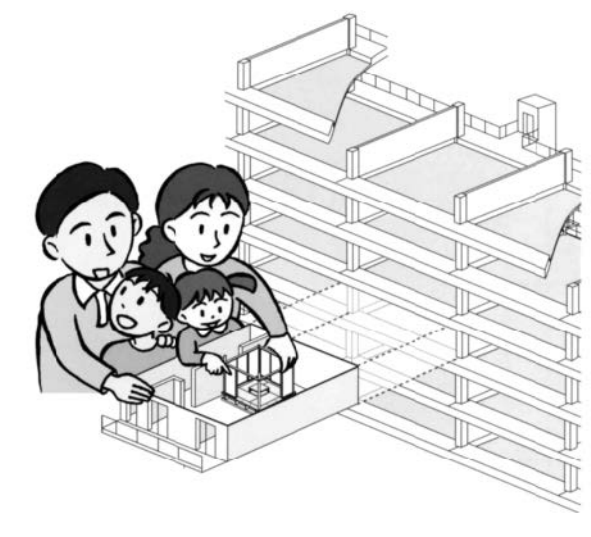

Figure No.1-6

Support and Infill separation diagram by HUDC Japan 


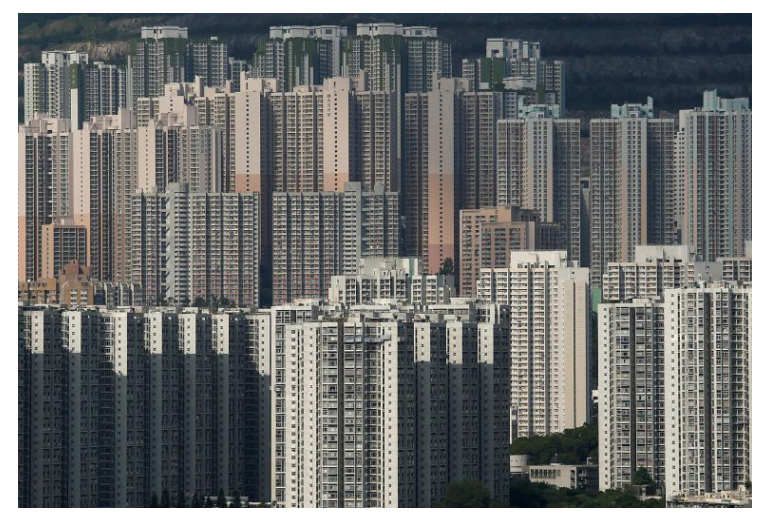

High Control = Uniformity

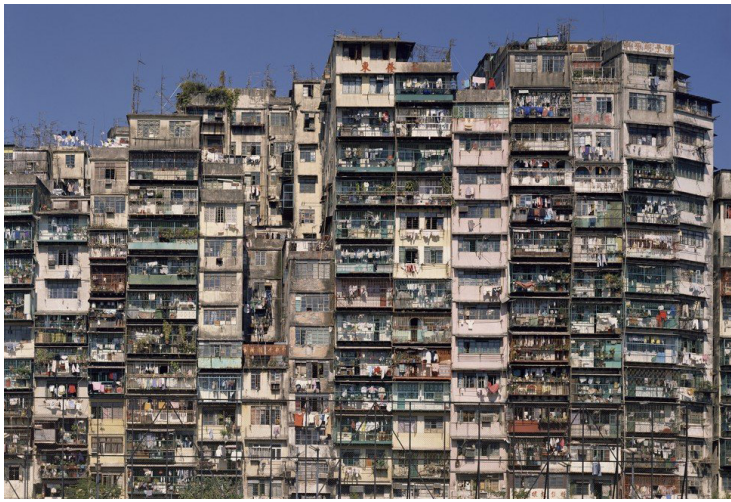

Balance $=$ ?

No Control $=$ Chaotic

Figure No.1-7

High Control vs No Control 


\section{User Participatory Design}

The idea of user participatory design can be linked to Structuralism and the "Support and Infill" approach initiated by John Habraken (Habraken \& Teicher, 1972). Structuralism investigated the interrelationships of social and built structures. The goal of Structuralism was to create self-contained, flexible communities. Nevertheless, most projects are unbuilt grand visionary designs with the concept of an organically growing city, but they adopted a modular system. Therefore, regardless of the overall form, most projects are designed as mass-produced environments that offer the same living experience to all its users. Residential architecture since the 20th century adopted modernist ideas of functionalism and a large-scale, centrally controlled method. This top-down notion in designing high-rise residences neglected the future need to change or adapt; therefore, the design often became obsolete in a short time frame.

\section{Balance of Forces}

The built outcomes of contemporary architecture design does not usually involve the actual users or occupants; it is determined by a small group of designers (architects, engineers, etc.), their clients (developers, institutions, etc.), and constructors make the majority of the design decisions on any building project. The reason for such a high degree of control is to prevent unpredictable and contradictory

results, but also leads to a homogeneous and monotonous uniformity. On the other hand, personalization can accommodate individual needs. Nevertheless, in a built environment without any control or standards, the result would be chaotic and conflicting. According to 
Juhani Pallasmaa, "Strong strategy and principles create the sense of distant control, whereas weak principles give rise to intimacy and participation" (Pallasmaa, 2000, p. 79). Therefore, architects should search for a balance between the two separate forces of control, allowing the architect to maintain their leadership role in the design but offering flexibility for users to customize their personal space.

John Habraken's "Support and Infill" concept initiated a flexible design method that addresses the spontaneous variety of user preferences and the unpredictability of future use (Habraken \& Teicher, 1972). Habraken demonstrated the necessity to include two forces of control for the successful design of a high-rise residences project: control by the community, and control by individuals. Without control by the individuals, the design becomes standardized and uniform. Without the community, the design will become completely random. A separation of the two levels can offer a certain degree of freedom for both parties. However, freedom is limited due to the lack of a systematic design strategy.

Parametrics can be deployed to create an open-ended design system that allows iteration in design. However, in contemporary parametric design, both the creation of the system and adjustment of the variable values are either directly controlled by the architect or performance factors set by the architect. Thus, parametrics in architecture design have remained tools to serve the centralized decision-making process. While its intrinsic capacity to create openended and iterative systems to guide design decision-making has not been widely implemented, there is great potential for parametric to serve as a tool for user participation through establishing rules and an interconnected relationship, providing users the possibility to operate within a predefined range far more sophisticated than 
simple colour or menu choices. The role of parametrics can then be redefined as a catalyst for social engagement and interaction.

Humanity's achievement is based on the invention of technologies and tools to respond to the needs for survival and development. Architecture, as a cultural practice of humankind, should continuously discover new ways to implement technology that could support and improve the design process, but not be abducted by it. Parametrics, through computation, is a relatively new technology that has been implemented into the field of architecture within the last two decades. Most architects have been attracted by its flexible nature to generate forms from a top-down point of view. However, this deployment of the mass customization technology has neglected its rich potential in systematic and iterative design. This thesis explores the possibility of deploying parametrics for a systematic participatory design that allows the designer to balance the two separate forces of control between the collective and the individual. This approach could maintain the architect's role as the designer and planner of the built environment, but also fosters a culture of personalization through user customization and social interaction. As a result, a combination of technology and design strategies is in response to the changing need of social environments and transforms the living condition of high-density residential designs from homogenized towards flexible. 


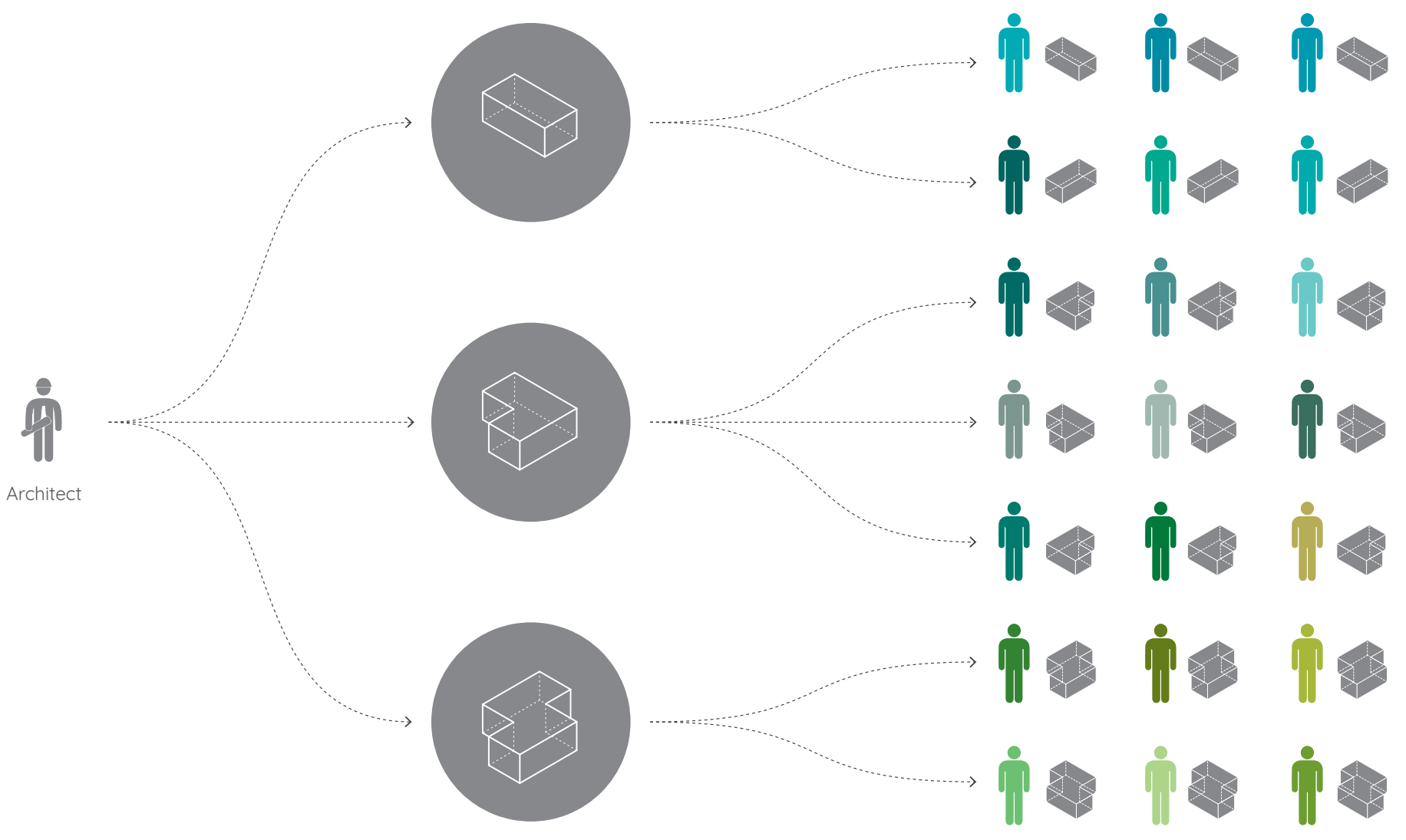

Limited design Variations based on programs, functions or size

Various user demands with few design solution

Figure No.1-8

Conventional Top-Down Design Method

The conventional architecture design is a top-down and linear method. The architect uses a singular scheme with limited variations to address the needs of a greater whole, creating a mass-produced environment with uniform spacial condition and experiences. 


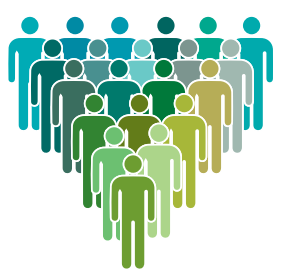

Users with their demands

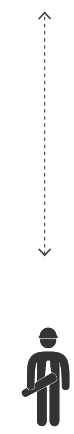

Architect

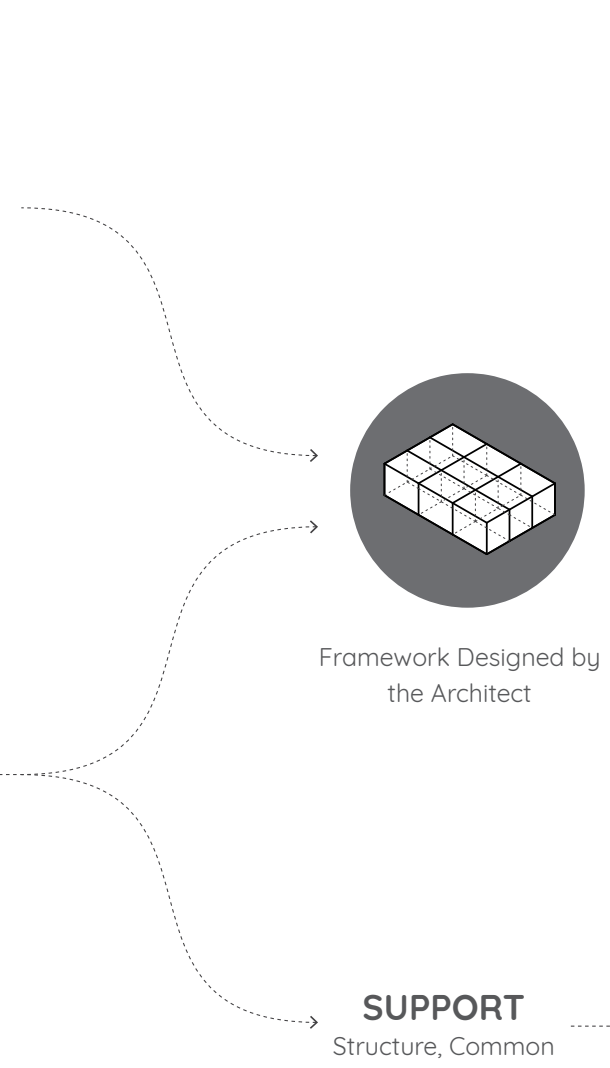

Spaces and Utilities

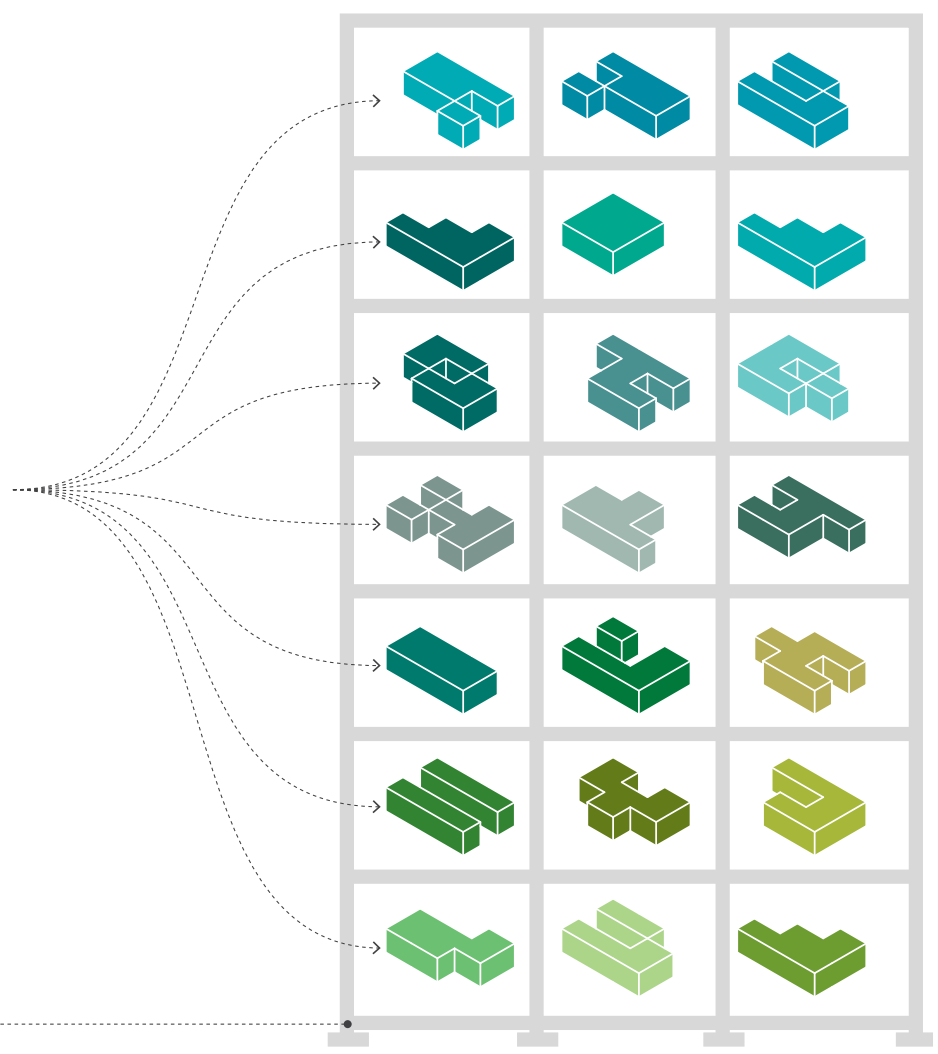

Design Customized for User's Need

Figure No.1-9

Systematic Participatory Design

In a Systematic Participatory Design, the architect can create a parametric framework based on architecture knowledge and users' performance variability that provides individuals the freedom to customize and personalize their space within the set limit. It challenges the architect to balance two separate forces of control between the collective and the individual. It is a flexible approach for architecture design that uses rules and relation to guide future changes. 


\section{2 | Modernism and the Culture of Standardization}

Modernist architecture emerged from the background of industrialization, fostering a revolutionary movement based on the new technologies in construction materials such as reinforced concrete and efficient fabrication methods using mass production. The movement has nurtured an architectural culture of efficiency and uniformity. Le Corbusier's renowned phrase, "The house is a machine for living in," along with his manifesto, "Five Points of Architecture," suggest a functionalist notion for future design that laid the foundation of modernist architecture (Le Corbusier, 1927). Architectural design methods under the influence of modernism standardized, embracing a functionalist and minimalist ideology with the notion of creating an international style suitable for any territory and cultural background (RIBA, 2019). Therefore, modernism incentivized the globalization phenomenon that has promoted a trend toward cultural homogeneity.

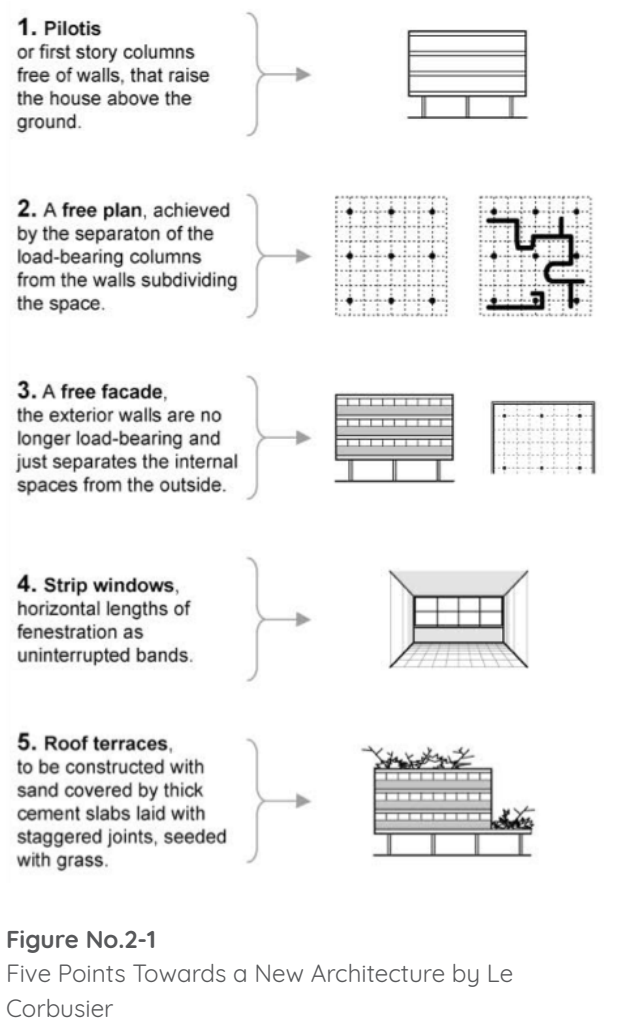

The Visionary Designer

In the early days of industrialization prior to modernism, architects had already begun to adopt the top-down mindset in design, seeing themselves as visionary designers for social orchestration. Architects were using a single-minded vision to impose an "order" into society. An example of this is the Royal Saltworks at Arc-etSenans, France, designed in the 18th century by Claude-Nicolas Ledoux who used architecture to illustrate French philosophy at the time. The saltworks were designed in a pure semicircle form within a forest, revealing an anthropocentric vision for man's dominance over nature. Architecture was being used to create a social hierarchy within the complex. Ledoux called it "speaking architecture," which uses form and built relationships to describe the different social classes (Ledoux, 1804). The administrative directorship was located in the centre of the semicircle that has the appearance of the hierarchical 
authority. The workers' houses were arrayed along the perimeter in smaller fragments to depict their lower social level. The project reveals a comprehensively designed environment influenced by the architect's preconceived notion of social order with a centralized decision-making process. The social relation of the saltworks is greatly influenced by the architect's own belief in societal hierarchy.

\section{Establishing a Standard}

In the early 20th century, the electrification of factories revolutionized fabrication methods, exemplified by the assembly lines developed by Ford Motor Company. Mass production of commodities through electric motor-driven machinery and conveyor belts significantly increased the efficiency of the manufacturing process, resulting in less human labor, a higher rate of production and higher accuracy. Mass production lowered the cost for the manufacturing of identical commodities but offered less variety compared to traditional fabrication methods (Hounshell, 1984). The culture of mass production influenced the standardization and efficiency aspects of modernism architecture.

Le Corbusier, one of the most influential modern architects, was fascinated with machines and engineering. In his book Towards a New Architecture published in 1927, he rejects art deco and ornaments in architecture and embraces the efficiency-driven machines designed by engineers. His famous quote, "A house is a machine for living in," depicts an architecture associated with functionalism and efficiency that performs like a machine (Le Corbusier, 1927, p. 95). The book showed images of grain silos, airplanes, cruise ships, and cars, which are all products of engineering designed to serve their primary function without additional decorations. By showing those images,

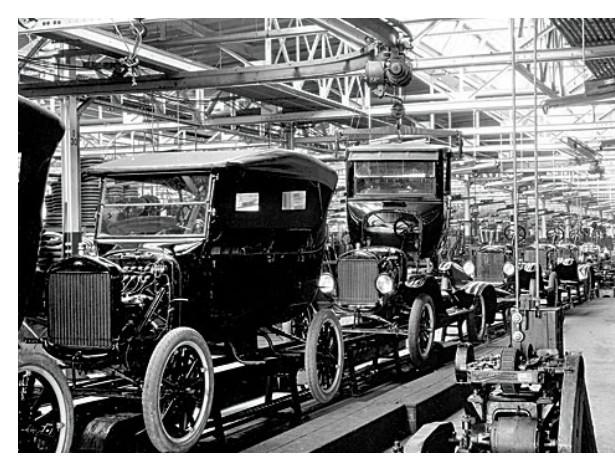

Figure No.2-2

Ford Motor Assembly Line in 1913 


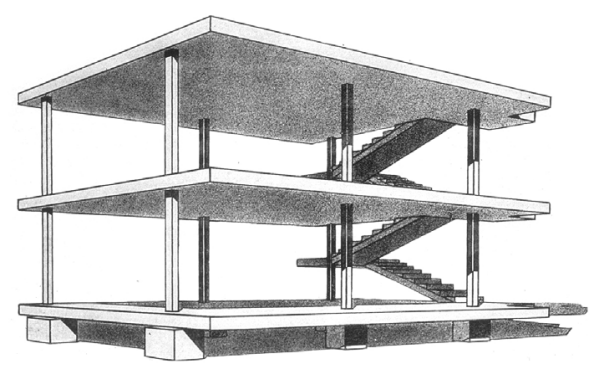

Figure No.2-3

Dom-Ino House by Le Corbusier, 1914

Suggesting an modular structure system with reinforced concrete that can be used for mass production of housing

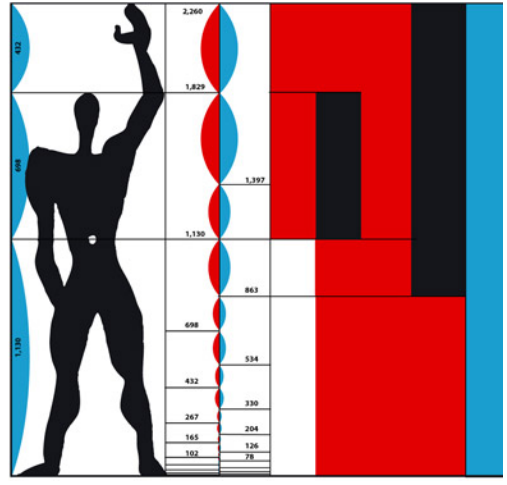

Figure No.2-4

The Modulor System by Le Corbusier
Le Corbusier was promoting a transformation in architecture towards functionality.

Machines such as aircraft and passenger ships are efficiently manufactured because they carry a standardized design, which can be mass-produced. As an attempt to standardize modernist architecture, Le Corbusier developed the Dom-Ino House and "Five Points of Architecture" as an attempt to create a prototype and dogma for mass production of housing (Sennott, 2004, p. 366). His design strategies and high density residential proposals were developed in response to the extreme shortage of housing in France following WWI and WWII. However, by creating a standard, Le Corbusier treated the public as a generic user. In The Modulor diagram (Fig. 2.4), Le Corbusier was using a single male's body ratio as the standard measuring system for his design. However, the human body is not only individually different but also transforms through a person's life cycle. By creating a single standard, Le Corbusier disregarded the diversity of the public. The living condition then becomes homogenized, which ignored the different needs of the users. Unité d' Habitation apartment building (completed 1952) that had a major influence on the design of high density residential in the second half of the 20th century, used stacked floor plans and repetition of apartment units to achieve high efficiency in production (see Chapter 4 Conceptual Design Diagram).

\section{The Failure of Visionary Planning}

Architecture's influence goes beyond the physical built form and the image of a city but also impacts the social and cultural aspects of society. It determines the living quality of the general public as well as how people interact with each other. Architects who 
adopt the role of a 'visionary planner' tend to impose a preconceived idea rather than addressing problems at the fundamental level, which will inevitably generate conflict with reality. The following two examples, Pruit Igoe and Bijlmer are both examples of architectural social orchestration driven by the architect's preconceived ideas which segregated these high density residential developments from the existing physical, economic and social urban fabric. As a result, these projects produced social monocultures for the lower income class and absence of economic activity.

The Pruitt-Igoe (1954) in St. Louis implemented the modernist ideas of design and planning to resolve a housing crisis for the lower-income population. Like many modernist high density residential projects at the time, the Pruitt-Igoe was a mass production of a standardized design based on the principles of modernism - a visionary solution for the urban poor. Without any consideration of the social aspects and by simply secluding all the lower-income households into a single community, the problems became exacerbated. The excessive amount of common vacant space became a centre for criminal activity, causing living conditions to decline rapidly. The project quickly became uninhabitable and was demolished in 20 years (Luke, 2017).

A similar high density residential project called Bijlmermeer (1933) in Amsterdam implemented the model of Le Corbusier's Radiant City (see p.15) and other modernist design principles. Like other modernist housing projects, the buildings were massproduced on a pure geometric grid, unrelated to the local site conditions or urban context (Mingle, 2018). The expression of the overall concept through the building massing was prioritized over all other design factors. By giving the highest priority to modernism's

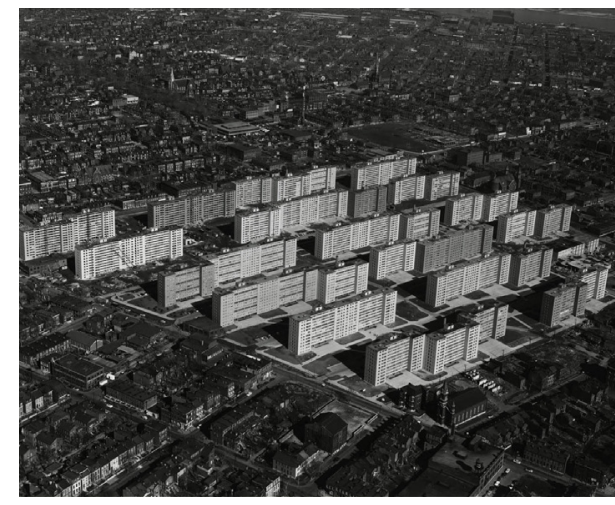

Figure No.2-5

Aerial view of the Pruitt-Igoe thirty-three buildings by Minoru Yamasaki, 1972, St. Louis

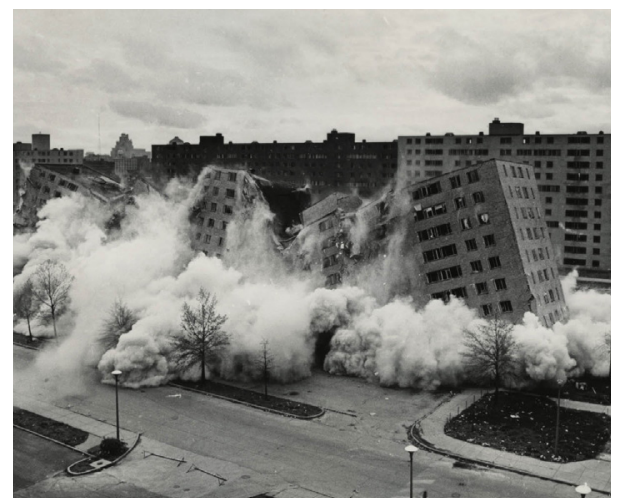

Figure No.2-6

Demolition of Pruitt-Igoe in 1972, St. Louis 


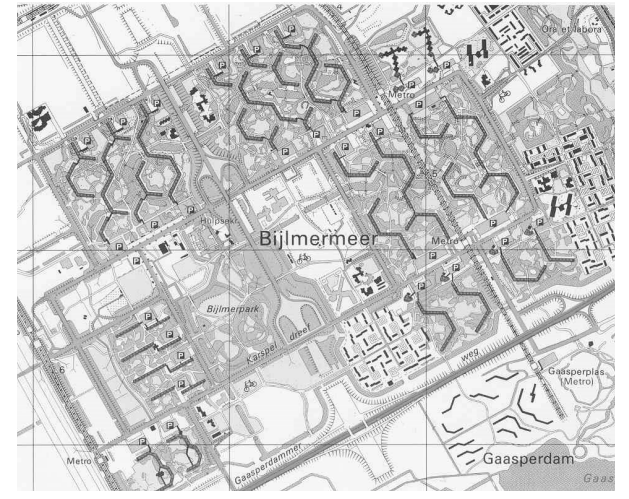

Figure No.2-7

Masterplan of Bijlmermeer showing massive hexagonal grid massing

by Siegfried Nassuth, 1969, Amsterdam

dogmatic principles, the project distanced itself from the public and failed to deliver a convenient and active habitation for its users (Mingle, 2018). The project occupies five city blocks with thrity-one buildings which is almost the size of an entire district, containing over 13,000 apartment units and thirty-one large parking garages, but is all residential occupation. The lack of integration with public transportation and planning for commercial and retail spaces made the housing inconvenient to live or access. The community became physically segregated from the rest of the city (Mingle, 2018). The identical concrete buildings also made navigation extremely difficult. The elevated streets, one hundred and ten kilometres of indoor corridors, and hundreds of elevators are mostly empty due to lack of residences and commercial activities (Mingle, 2018). The modernist goal of using strong principles as an urban planning strategy to resolve disorder, congestion, and pollution inevitably failed to achieve its initial purpose. Architect as a 'visionary planner' became isolated from the public they should serve. Rather than design from the perspective of individual users to promote convenience and social interaction, the project became a simple expression of the architect's power of control over the environment and the society.

In the 1920s, the Modernist architects thought that the urban

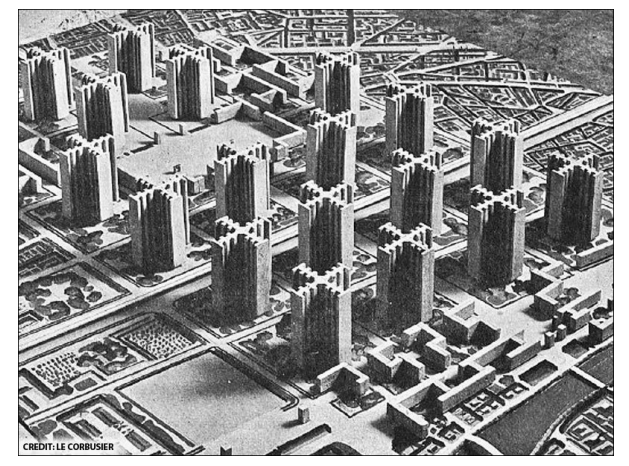
condition was too congested, noisy, and polluted. Le Corbusier's Radiant City, split the city into strict divisions of residential, commercial, and business zones, was a proposal for a linear and ordered metropolis; these core principles of modernism informed all urban planning in post-war Europe and North America, and later, throughout the colonial world. Le Corbusier envisioned a prototype city that could be mass-produced and standardized like machines. The design adopted a top-down urban planning strategy based on Figure No.2-8 Radiant City Model by Le Corbusier, 1920 The unbuilt urban masterplan his preconceived ideas and inspiration from the arrangement and 
roles of the human body (Kohlstedt, 2018). The plan was heavily focused on the idea of creating an efficient city with pure forms. The towers are aligned orthogonally and separated without examining the actual living conditions or social implications. While its concepts were adopted and deployed globally, this project has been more recently critiqued, including with regard to its lack of human scale and failure to relate to its site (Kunstler, 1993). Cities are formed by diverse fields of social and cultural interrelations that are constantly in transformation. Design without any consideration of social interactions will inevitably become an arrangement of static objects that are alienated from society.

Modernist architecture's extensive use of standardization and mass production restricted architecture design intention toward capacity-driven efficiency. Rem Koolhaas, the avant-garde architect and urbanist, describes this phenomenon using the words "bigness" and "junkspace." Bigness is a chapter of the $S, M, L, X L$ book published in 1992 that critiques contemporary urbanism and building design. Bigness reveals the issues of large-scale architecture projects within a high density urban environment. The problems include uncontrollable mass, large floor plates that disassociate the interior activities from the exterior façade, and disengagement from its context (Koolhaas, Mau, Werlemann, \& Sigler, 1992, pp. 495-502). These problems can be associated to the top-down urban planning strategies influenced by modernism principles.

Junkspace was published in 2002. It criticizes the "modular, unitary, and standardized" design of spaces that are continuously connected, such as airports and shopping malls, to promote consumerism (Koolhaas, 2002, pp. 175-190). Junkspace and Bigness reveal architectural products under the influence of capitalism to 
maximize efficiency and productivity. Both utilize the repetition of space to reduce the necessity for individual design. This repetition is achieved through technological supports such as air conditioning, elevators and artificial lighting (Koolhaas, 2002, p. 175). Profit is amplified by multiplying the number of floors and store units. Junkspace sacrifices the quality of architecture for its quantity. Covered by the minimalist and neutral modernism style, the same kind of junkspace is being replicated across the world with the influence of globalization. For instance, all McDonald's restaurants around the world have the same appearance and can be easily recognized. This is made possible through the low cost of mass produced materials that can be easily transported and assembled. In this circumstance, architecture has lost its original intention as a work of art and cultural representation and become a profit-driven product to be consumed like fast food. Koolhaas stated that "it was a mistake to invent modernism architecture for the twentieth century. Architecture disappeared in the twentieth century" (Koolhaas, 2002, p. 175). While at the time Koolhaas may have overstated the problem as a warning for future architects, he and many other architects accelerated this downward spiral through the emergence of the "star-chitect" and the rise of iconic buildings.

\section{Star-chitect}

The encounter with digital technology did not change architects' top-down notion in design, but exaggerated issues with regards to aesthetics-driven design and form expression. The prime role of the architect as a 'visionary planner' was unchanged since the rise of modernist architecture. With an unchanged mentality in design, the new tools would only offer complexity in geometrical forms, which promoted the rise in iconic buildings designed by idol 
architects or star-chitects.

Star-chitects tend to adopt an iconic style that could be implemented for all of their projects. For instance, Frank Gehry's irregular and folded geometries are a signature style that is extensively used in most of his projects, including the Guggenheim Museum Bilbao and The Museum of Pop Culture in Seattle. Most of Gehry's projects tend to offer visual complexity from the outside but do not introduce true dynamism to the users' overall experience within the

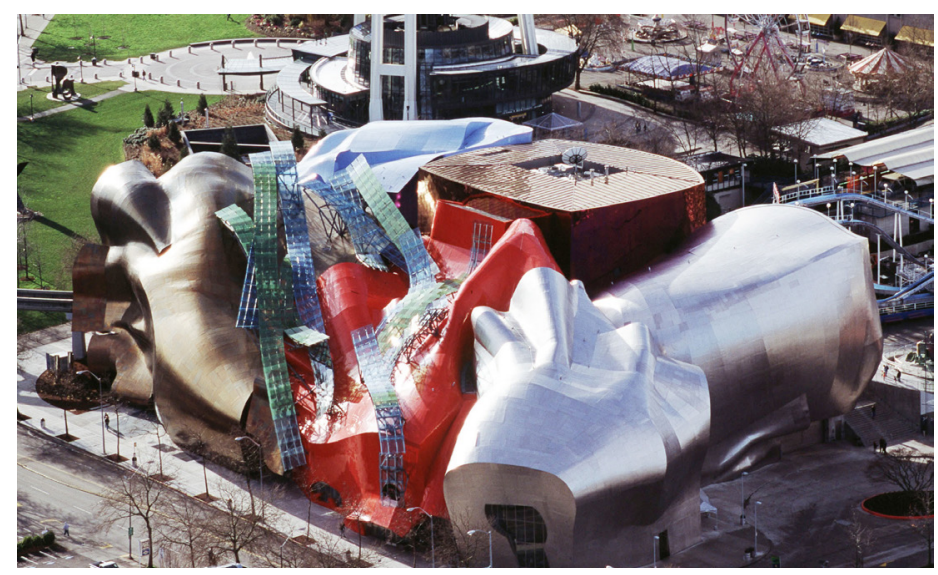

Figure No.2-9

Aerial View of Museum of Pop Culture,

by Frank Gehry, 2000, Seattle
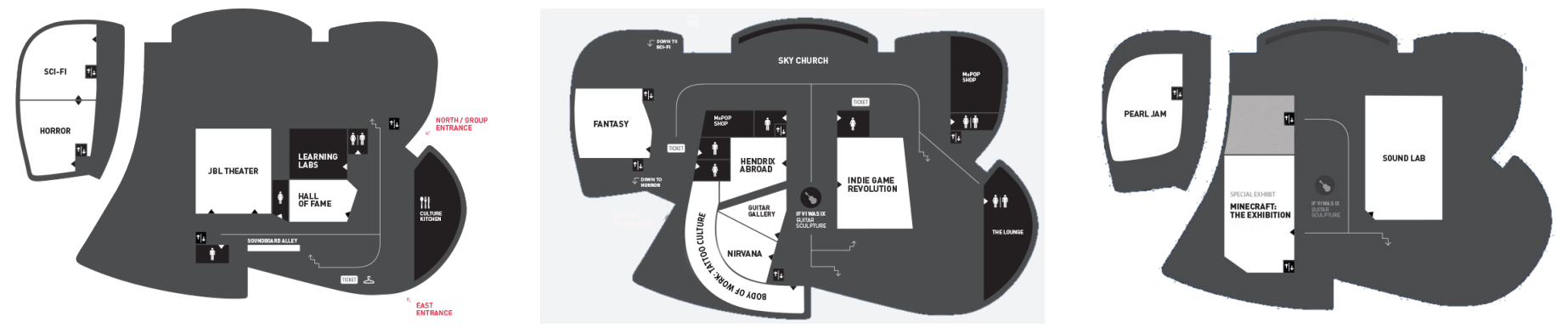

Figure No.2-10

Illustrative floor-plan for Museum of Pop Culture showing

disconnect between massing and interior layout 


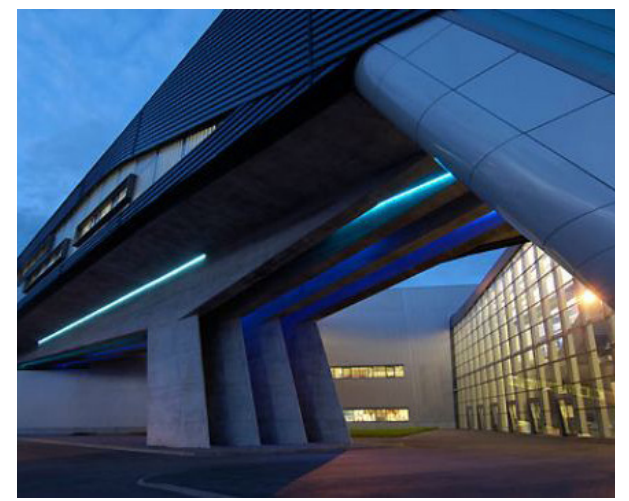

Figure No.2-11

BMW Leipzig central building facade

by Zaha Hadid Architects, 2005, Leipzig, Germany building (Ratti \& Claudel, 2016, p. 38). Moreover, the signature visual complexity may even reduce certain aspects of building performance. Therefore, architect's self-positioning as the "visionary planner" has blindfolded the profession into designs based on preconceived ideas that are distancing the profession from responding to the actual needs of the users, and abandoned architecture's social and cultural influence. As architectural historian Wouter Vanstiphout depicted, "Architecture has drifted into the stratosphere, where it's not even as simple as designs being produced which have no relationship to actual buildings, but it's even that the buildings that are being produced have no relationship to actual needs" (W. Vanstiphout, Australian Design Review, August 2011).

The contemporary star-chitect, who prioritizes iconic style over the social and cultural impact of their project, tends to be abducted by neoliberalism to work in favor of the privileged few. Douglas Spencer described this situation through his book The Architecture of Neoliberalism, published in 2016. The book reveals some of the projects by renowned architects who claim to use parametric techniques to "liberate architecture" and improve the working environment, but only offer their services in response to the particular demands of authority (the client and their peers) and neglect the social needs of the actual users or larger public. By doing so, the fancy curvilinear and freeform designs are simply camouflage to serve the capitalistic need for control and compliance, and for production efficiency. This "architectural phantasmagoria" is not focused on the actual work of architecture, but instead creates "a commodity" in service of "the neoliberal capitalism while mystifying its actual conditions of production" (Spencer, 2017, p. 74). 
Spencer used Zaha Hadid's Leipzig BMW design as an example. The building adopted an open plan design that connects three existing production facilities, and houses administrative and management functions in a single intertwining form. The architect claimed that this design strategy could promote a sense of community within the factory and improve communication, but the design actually works in favour of surveillance and managing the workers (Spencer, 2017, pp. 84-91). Like The Royal Saltworks (see p.11), the Leipzig BMW became a top-down design of social orchestration. Zaha Hadid's unique architectural style is adopted to only serve as a luxurious image for the company; the actual labour condition is concealed under the splendid skin.

Architects that practice in this manner fail to take a critical position in questioning the actual social condition for the majority of the building users. The advanced technologies adopted for the design have only benefited the privileged few. The solution is not to abandon the technology but to investigate and to deploy the technologies from the perspective of the users or the general public, as well as evaluate the design's social and cultural impact.

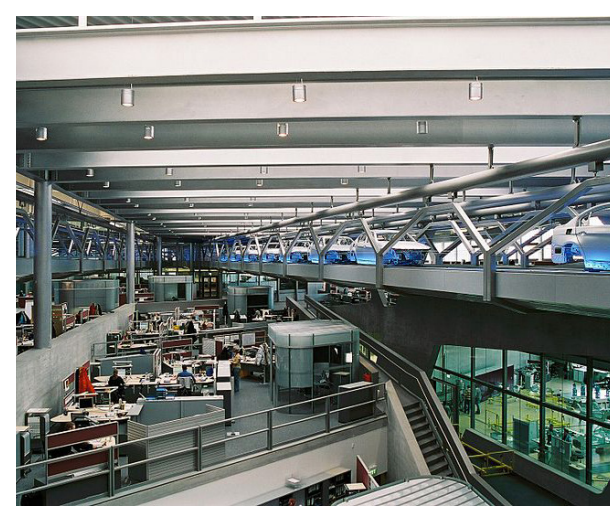

Figure No.2-12

BMW Leipzig open plan design with interconnected assembly line and office space

by Zaha Hadid Architects, 2005, Leipzig, Germany 


\section{3 | Bottom-Up Architecture: The Problems of Participation}

When architects adopted a mentality as a designer that could pre-plan the full extent of the society, the design would become a medium for the expression of power rather than a tailored service that responds to the users' needs. Therefore, architects who design in such a manner would disassociate the profession from the general public. Deyan Sudjic describes the immense power expressed by modernist architecture as "overwhelming of all cultural forms... it literally determines the way that we see the world and how we interact with each other" (Sudjic, 2005). Architects carry the duty for the success of the built environment and have significant influence over the social and cultural aspects of society. Such grand visionary projects lead to the creation of iconic buildings or masterpieces that project the importance of the client, but which have no relevance to the lives of their inhabitants. As described by Carlo Ratti, "The modus operandi has increasingly been to design buildings with as much visibility and cultural importance as possible, rather than addressing the questions at the root of human habitation" (Ratti \& Claudel, 2015, p.16). In reaction to the drawbacks of top-down decision-making, some architects and theorists began to investigate the direct opposite bottom-up approach: user participation as a driver for design.

\section{Consensus-Based Participation}

Christopher Alexander, an architect with a background in mathematics, is well known for his book A Pattern Language: Towns, Buildings, Construction. The book offers an innovative method of architectural design with a series of descriptions of problems and solutions that Alexander calls Pattern Language. The book is intended not only to guide professional architects but also to address the ordinary users of spaces, encouraging people to improve the 
living condition of their homes and neighbourhood themselves. His inspiration was drawn from the traditional development of villages that he calls a "timeless way of building." "A living world. A dynamic field of interrelated forces. The city as a collective art form" (Alexander, 1977). Villages are not products of master planning but a collective phenomenon of the users' demands. Alexander tried to apply his bottom-up theories in the Oregon Experiment but confronted multiple challenges (Miessen, 2010).

In the early 1970s, the University of Oregon appointed Alexander to design its campus with a bottom-up approach, to design a best-fit and comprehensive environment for a large community of students and faculty. The Pattern Language was used to prevent disorder and aimed to offer a democratic and collaborative design method. However, as the project progressed only a small number of students participated, causing the resulting design to be irrelevant to the needs of the majority of students, who were not involved in the design process. However, directly including the participation of large groups, who will include multiple objectives in a design process, is very unwieldy and will produce unpredictable and conflicting results. Alexander recalls the procedure of the project as a "political and administrative nightmare" (Alexander \& Alexander, 2005). Adopting a democratic process for planning also risks producing either a bland or chaotic result.

Markus Miessen illustrated the problems with "pseudoparticipation" in his book, The Nightmare of Participation. That the authority uses participation as a tool to offer an impression of openness but reserves the actual power of decision-making for themself. He described democratic consensus as an "empty concept" without content; therefore, it cannot lead to change or innovation 


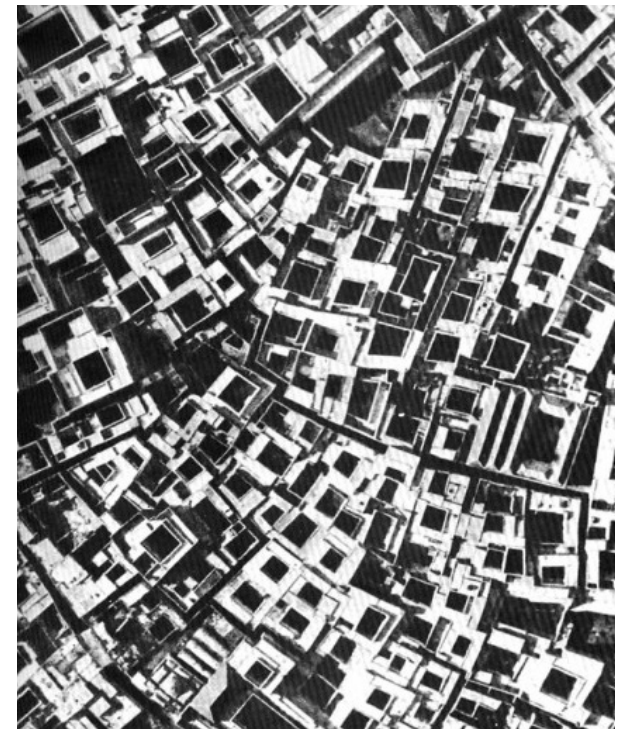

Figure No.3-2

Marrakech, Morocco

Vernacular architecture displayed in Architecture Without Architect by Bernard Rudofsky, 1965 but only generates conflict (Miessen, 2010, p. 46). Politicians, under the guise of equality, often use participation as a way of avoiding responsibility and ignoring the needs of minorities; choices apparently respond to the majority's desires. Miessen argues that "sometimes all-inclusive democracy must be avoided at all costs to make decisions within any given collaborative structure" (Miessen, 2010, p. 13).

Christopher Alexander's participatory model may have been largely unsuccessful in the Oregon Experiment, but his observations from the traditional development of villages as a "timeless way of building" remains valid. Villages are not designed or planned by a worldfamous architect but by anonymous individuals over an extended time, with intertwined social, cultural and economic relations. In the 1965 MoMA exhibition, Bernard Rudofsky presented a series of images of vernacular architecture with the title "Architecture Without Architect." The exhibition was a direct challenge to authoritative modernist architects. Rudofsky demonstrated an authorless architecture that is both functional and spontaneous. Forms are driven by the actual needs of the users and local climates. The communities are not designed or built in a linear process, but through trial and error, which formed a "locally and culturally optimized architecture" (Ratti \& Claudel, 2015, p.23).

In these vernacular architectures, the design and construction techniques are shared information among the community, but the layout of personal living space is correlated to individual preference. The benefit of such vernacular architecture is its flexibility and adaptability for a large group of users. However, the lack of a systematic structure would often cause a chaotic result that fails to maintain a minimum living standard. For instance, the maintenance 
and implementation of public space would be almost impossible, as everyone tries to maximize their personal living space. Therefore, Marrakech, Morocco (Fig. 3-2) had almost no public space between the buildings. The bottom-up approach, in this case, has maximized the benefit of individuals but offers no space for a community to thrive.

\section{High Density Residential Without Architects}

The Kowloon Walled City once had the highest population density in the world with thirty-three thousand residences and seven hundred businesses packed into only five acres of land (Girard \& Lambot, 1993, p. 38). The Walled City was an anarchist and selfregulating society due to a diplomatic glitch between the Chinese and the British Hong Kong governments. From 1947 to 1992, the Walled

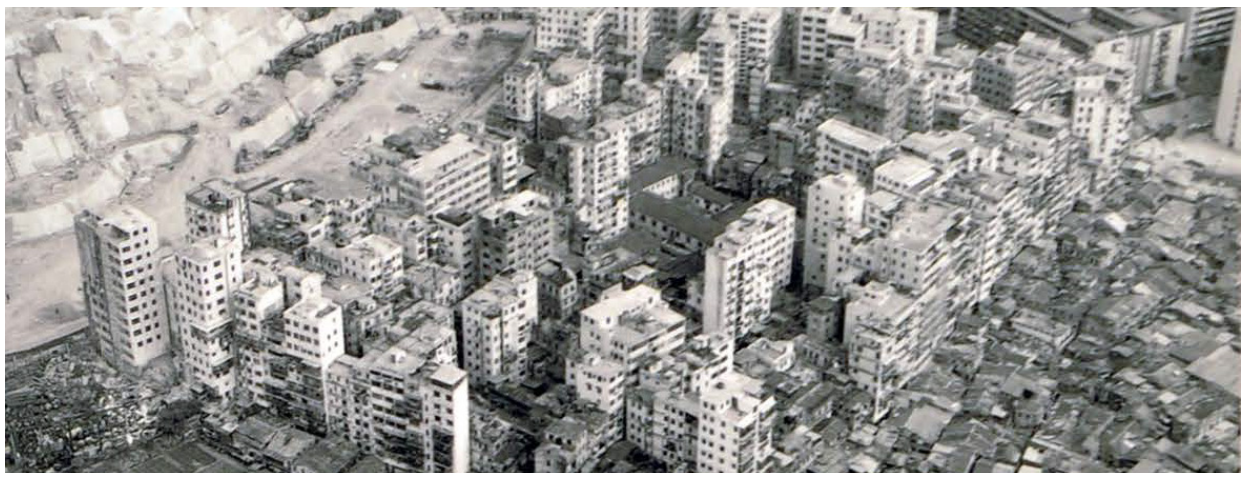

Figure No.3-3

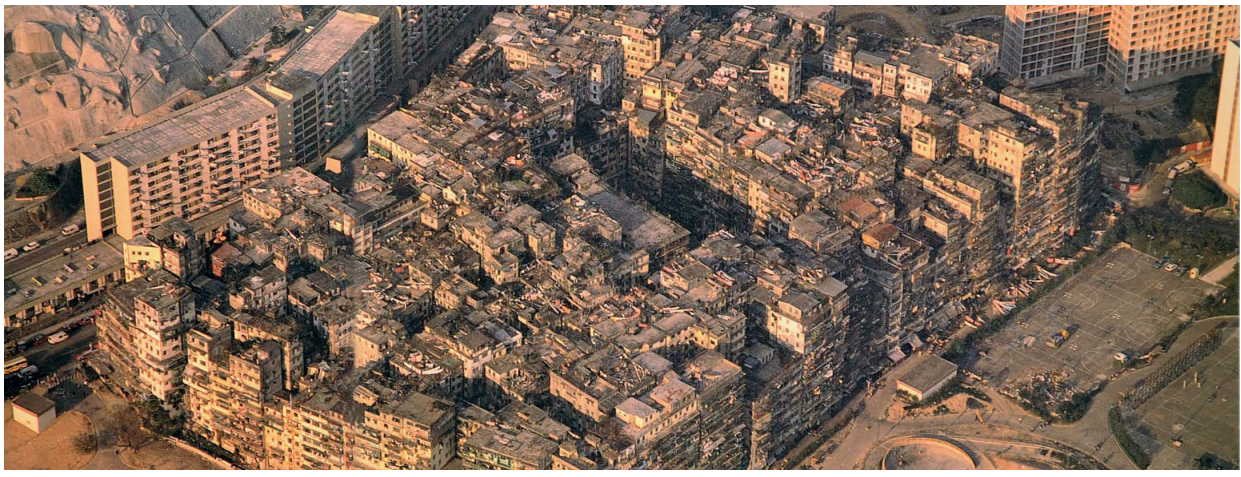

Aerial View of the Walled City in 1973, Hong Kong 


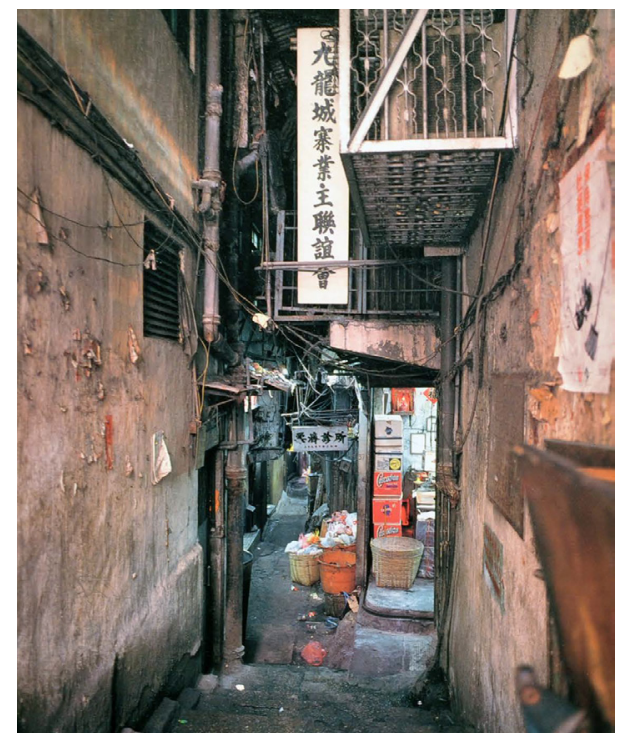

Figure No.3-5

Interior corridor connecting the buildings Kowloon Walled City, Hong Kong
City was not regulated by either of the two governments and became a home for poor families, refugees, illegal immigrants, unlicensed businesses, and even criminals (Girard \& Lambot, 1993, p. 9-11). As neither government was willing to impose top-down control on the Walled City, it developed its own unique society. The Walled City was originally a site with scattered multistory buildings built at different time periods. During this anarchist period, the Walled City encountered a significant rise in population and demand for living space. Therefore, self-initiated construction started to fill in the gaps between the existing towers without any regulation or building code. As time passed, the block became a dense megastructure that functioned as a single municipality. Without regulation, the living conditions for most parts of the city did not meet basic living standards. The individual buildings were connected by dark and damp corridors with exposed wires, rotten smells and scattered garbage (Lam, 2016). Poor living standards, such as the lack of public sanitary services, water leakage and lack of natural light, have made the place famous for its 'post-apocalyptic' appearance. The Walled City may seem unaesthetic or unlivable for most people. It was never abandoned but flourished as the city's life continued.

Although the majority of the Hong Kong population saw Kowloon Walled City as a dangerous place to be in, most residents of the Walled City portrayed the place as a relatively safe and convenient home. The social order was controlled by the local Triad gang organization; moreover, businesses and restaurants were scattered throughout the community (Lam, 2016). The Walled City offered a lively neighbourhood for its residents that most modern architecture failed to achieve. It may lack regulation, but it is a functional and self-evolving community. In the book City of Darkness, the author, Ian Lambot, described the Walled City as an "organic megastructure, not 
set rigidly for a lifetime but continually responsive to the changing requirements of its users, fulfilling every need from water supply to religion, yet offering the warmth and intimacy of a single household" (Girard \& Lambot, 1993, p. 13). This sense of intimacy within the community is driven by the interrelation of commercial, residential and public space, as convenience stores, dentist offices, workplaces or temples are dispersed across the neighbourhood as hotspots for social gathering. The long duration of residency also increased the chance for cross-connection between community members, thereby promoting the sense of a collective community instead of a cluster of separate residences. This anarchist city was indeed a bottom-up architecture that was gradually developed by responding to the needs of its individual users; however, the lack of systematic structure also made Kowloon Walled City the lowest living standard community in Hong Kong and was demolished in 1994 (Girard \& Lambot, 1993, p.2).
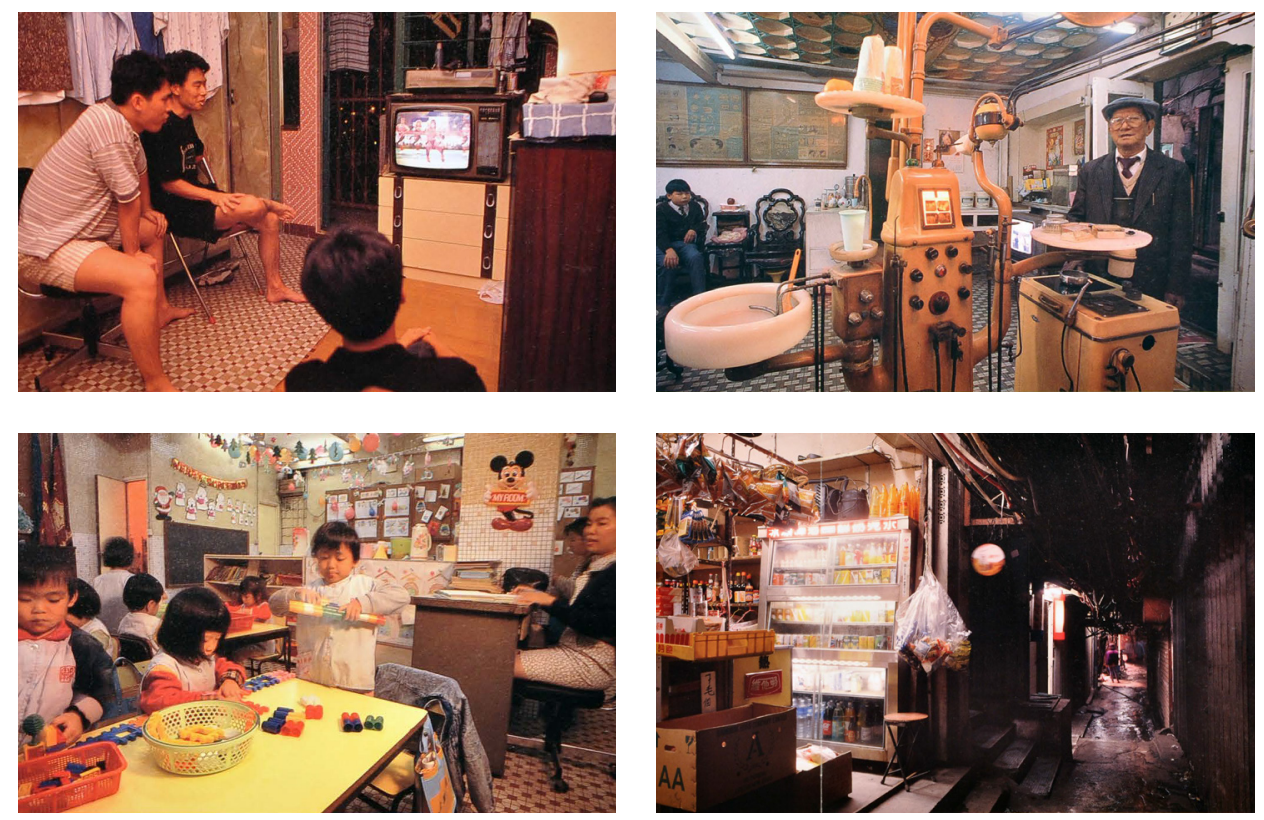
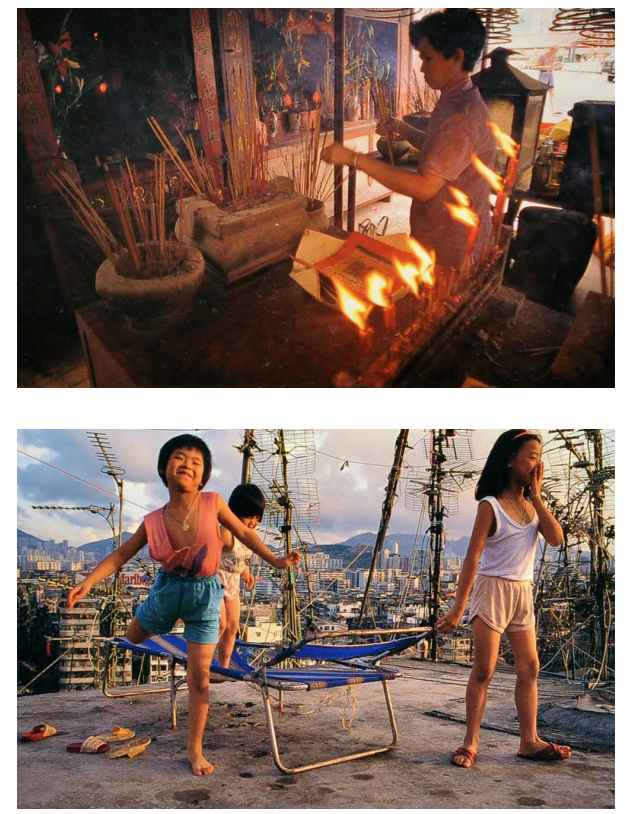

Figure No.3-6

Community life inside the Kowloon Walled City, Hong Kong 
Japanese Metabolist Architecture

The Kowloon Walled City example is a real case scenario of a organic megastructure that constantly evolved through the needs of its users without restrictions. On the contrary, the Metabolist Architecture can be seen as a 'visionary planner' version of the organic megastructure that expands in an orderly manner by combining urban growth and social structure. Metabolist Architecture is a Japanese architectural response to postwar urban growth. Japanese architects believed that the buildings could be shaped by societal forces and evolve over time through a spine and branch arrangement (Ratti \& Claudel, 2016, p.38).

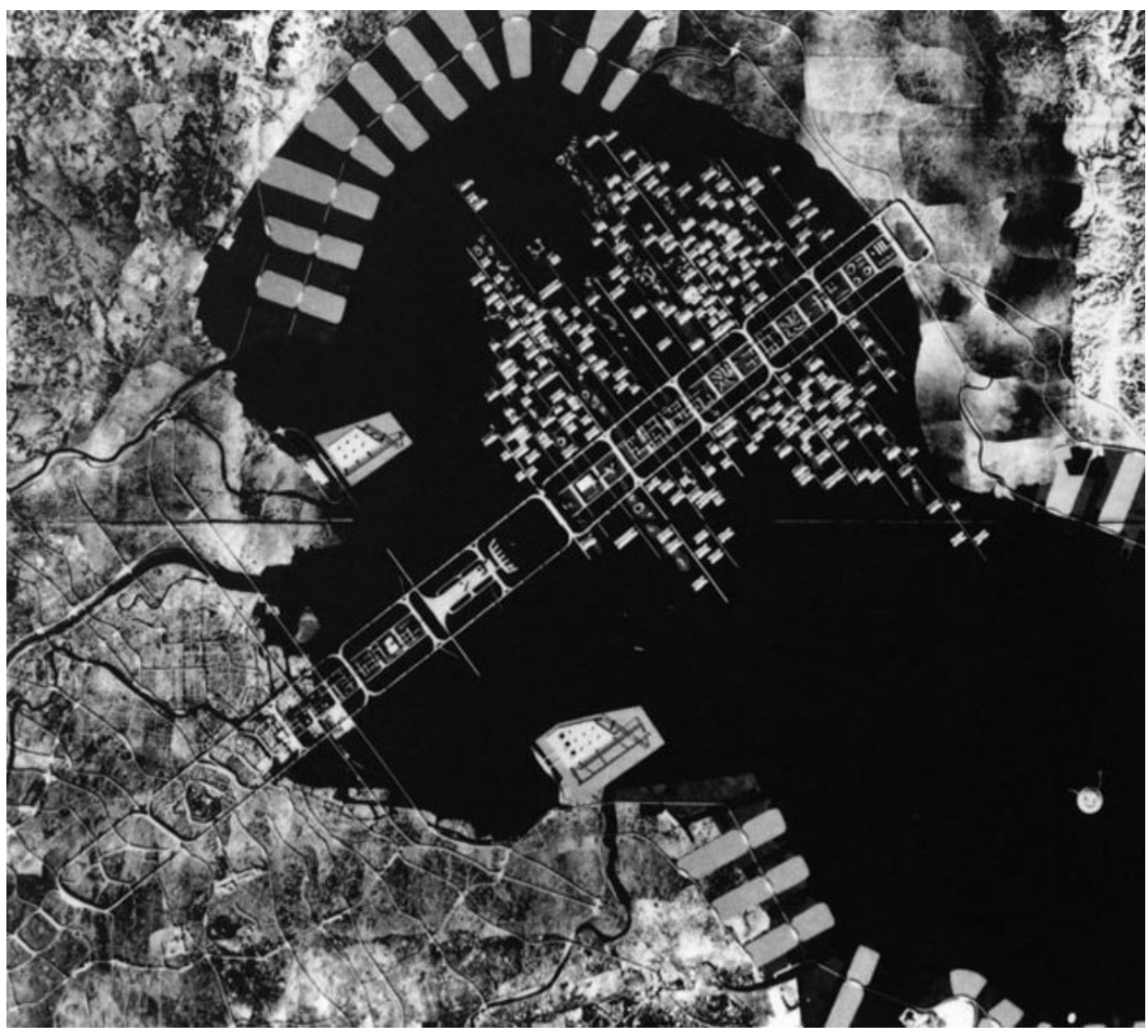


Most Metabolism projects are speculative projects at an enormous scale and claim to be able to expand in a systematic fashion. For example, the 1960 Tokyo Bay Plan by Kenzo Tange is a floating city-scale megastructure for a population of over ten million. The design adopted a modular system stretching eighty kilometers across Tokyo Bay. The modules were oriented according to the transportation grid, organized into linear strips of building zones connected by central looping highways (Koolhaas et al., 2011). This project is very similar to Le Corbusier's radiant city, as both offer a grand-vision city-scale design from the architect's perspective. The only difference is that the Tokyo Bay Plan offered a design that could transform over time. However, both designs failed in terms of lacking human scale and failing to address the problems in the context of a real urban environment. Organic growth or transformation, in this case, are not driven by true user demands like Kowloon City, but by the architect's preconceived ideas based on biological models. For this reason, most Metabolism Architecture remained a conceptual idea-only a few projects were ever built, the most renowned being Kisho Kurokawa's Nakagin Capsule Tower in Tokyo. The Capsule Tower can be seen as a prototype of the Metabolist theory, as it contains a central spine with rearrangeable modular units attached. However, none of the units were ever shifted or added since the project was built in 1972 (Sveiven, 2011). The absence of any substantial transformation since initial construction demonstrates the theory's lack of capacity to support project design from the user's functional perspective.

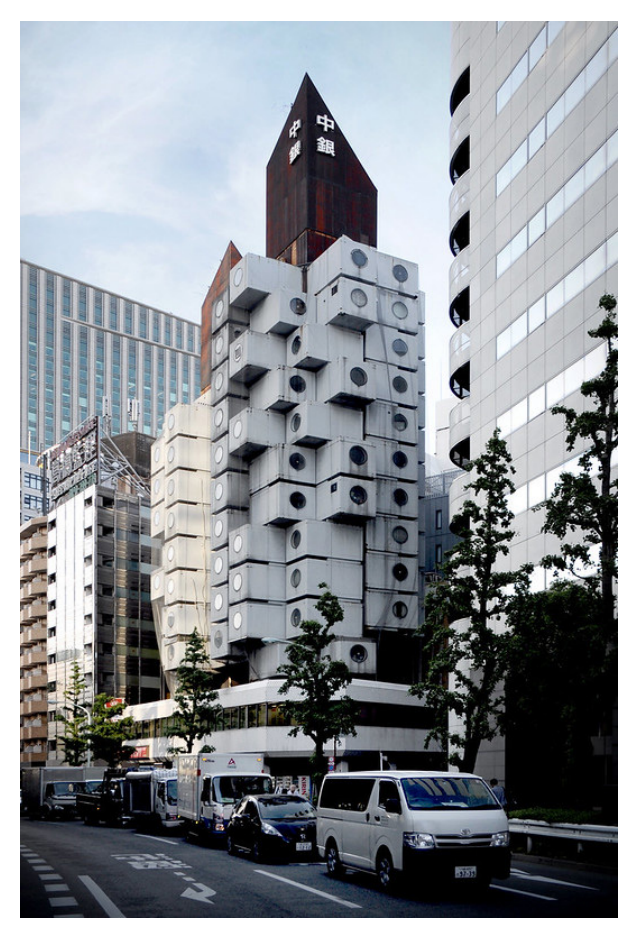

Figure No.3-8

Kisho Kurokawa's Nakagin Capsule Tower 1970, Tokyo, Japan 


\section{4 | Balance of Forces}

The creative and innovative aspects of architecture require the self-confidence of an individual, with requisite skills and expertise, to declare assumptions and make decisions based upon their knowledge and beliefs. It is necessary to accept some degree of authoritative leadership in the process of design in order to avoid bland outcomes, as demonstrated by the Oregon Experiment, or selfconflicting, chaotic failures of a completely bottom-up majority rule. However, architecture design should not merely be a self-reflection of the architect or a medium for architects to impose a characteristic style onto the society to gain popularity, or to serve a neoliberal agenda. It is an architect's obligation to recognize and address the diverse needs of individual users and provide opportunities for social interaction. "No one is more familiar with the user's needs than the users themselves, yet they are excluded from the process" (Ratti \& Claudel, 2015, p.107). Ultimately, neither extreme of the bottomup or the authoritarian top-down approaches have often provided an optimal result. Architects should search for a balance between the two separate notions of control and instead endeavour to achieve a more sophisticated outcome that offers flexibility and innovation.

\section{Design With User}

Giancarlo De Carlo states that the architect tends to stand on the side of the "bourgeois society," observing from a perspective of the elite. He invites architects to step out of their comfort zone and "stand on the other side: the side of the people-those who use and bear architecture" (Blundell-Jones, 2009, p. 6). He observed that an architecture with a top-down design notion that treats the users as generic would cause a lack of user support and quickly decay "because the users, not having participated in their planning, are unable to appropriate them and therefore have no reason to defend 
them" (Blundell-Jones, 2009, p. 13). Therefore, he asked architects to interrogate their design objectives and methods, shifting their perspective of design from preconceived "wise plan" towards engaging with the actual needs of the users. De Carlo suggested architects to "not plan 'for' the user, but plan 'with' the user" through three phases of "discovery of needs, formulation of hypotheses, and actual use" in a cyclical pattern (Blundell-Jones, 2009, p. 12). However, De Carlo encouraged users not to to only work at the drawing board and dictate an architecture design, but to collaborate through consultation.

While the approach of balancing the two separate forces of control, between the collective versus the individual, could be effective for with only a few users, without the addition of some significant new component to the process, building concensus among hundreds of users in the design of high-rise residences would remain an impossible task.

\section{Separation of Control: Support, Allocation, Infill}

John Habraken's idea to balance the separate forces of control is based on his theory of 'natural relation' where the "built environment resembles an organism more than an artifact" (Habraken \& Teicher, 1972, p.6). The word organism represents an organic system that is continuously evolving with different forces acting upon it, just like our built environment constantly upgrading to address multiple societal needs. The public engages with the built environment by acting on it rather than observing it. Habraken investigated the intrinsic hierarchical relations within the built environment. He illustrated the different parties associated with the control of each level and the distinct lifespan of the individual levels (Habraken \& Teicher,

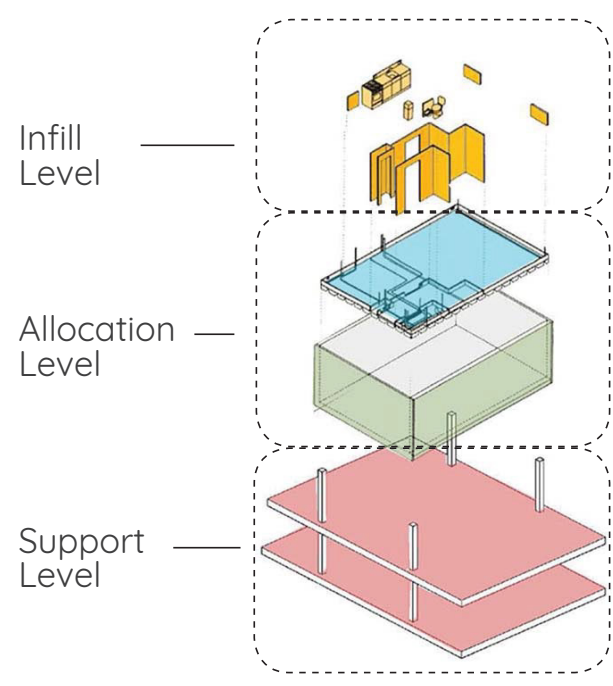

Figure No.4-1

Separation of levels and control for high density residentialby Stephen Kendall 
1972). For instance, the occupant of a room has control over the furniture layout of that room to reflect their personal living habits. Moreover, the municipal urban planning department has control over the design of city infrastructure to address future population growth. This separation of levels allows different actors to offer their unique perspectives.

Based on these distinct levels of intervention, Habraken suggested a separation of the 'support' and 'Infill' as two separate forces of control for residential design between the architect and users (Habraken \& Teicher, 1972, p. 59-61). This separation provides flexibility for the user to customize their living unit without interfering with the other fixed components of the building. This concept was subsequently expanded by Stephen Kendall in the Residential Open Building initiative, providing a further breakdown of the built environment with specified components and lifespans for each level. The Support Level encompasses the lifespan of the building, roughly one hundred years, controlled by the architect. It contains

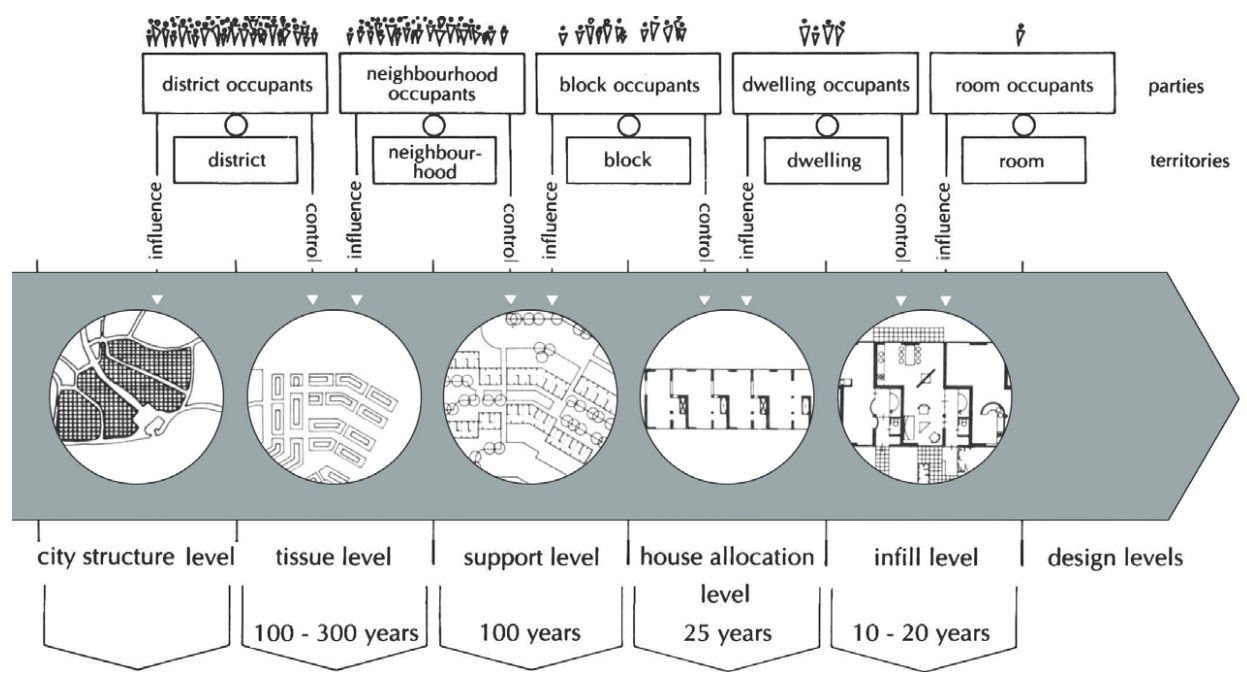


the unchanged and communal space for the building, which includes building structure, services and utilities (Kendall \& Teicher, 2000, p. 32-34). Between the 'Support Level' (architect control) and the 'Infill Level' (user control), the 'Allocation Level' defines the boundary of an individual living unit with a lifespan of roughly 25 years (Kendall \& Teicher, 2000, p.6). Lastly, the Infill comprises elements within the living unit, including partition walls, doors and fixtures with a lifespan of 10 to 20 years, controlled by the user (Kendall \& Teicher, 2000, p. 35-38).

\section{The Allocation Level in Residential Open Building}

Although Kendal illustrated the Allocation Level in his diagram in the book Residential Open Building, he did not provide further details about this intermediate layer and the relationship between the user and the architect, hence Kendal recognized the importance and the changing need of Allocation Level but did not offer a solution. While the Allocation Level points to a potential solution to
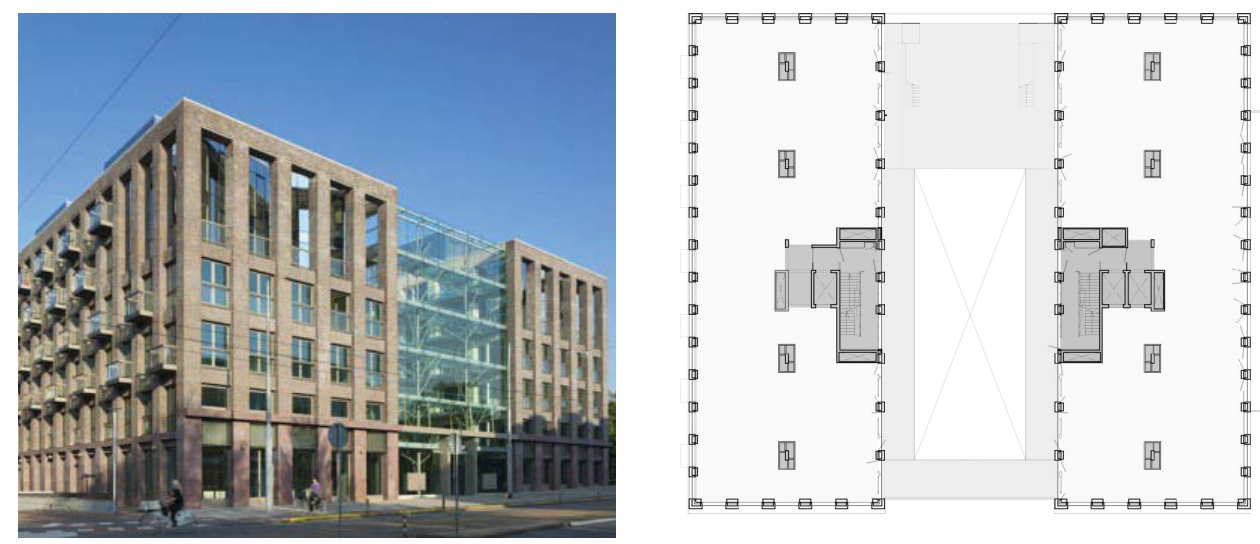

Figure No.4-3

Solid 11 Open-plan design, by Tony Fretton Architects, Netherlands, Amsterdam, 2011 
Figure No.4-4

Two-Step Supply System with fixed demising wall Next 21, by Yositika UTIDA, 1994, Osaka, Japan
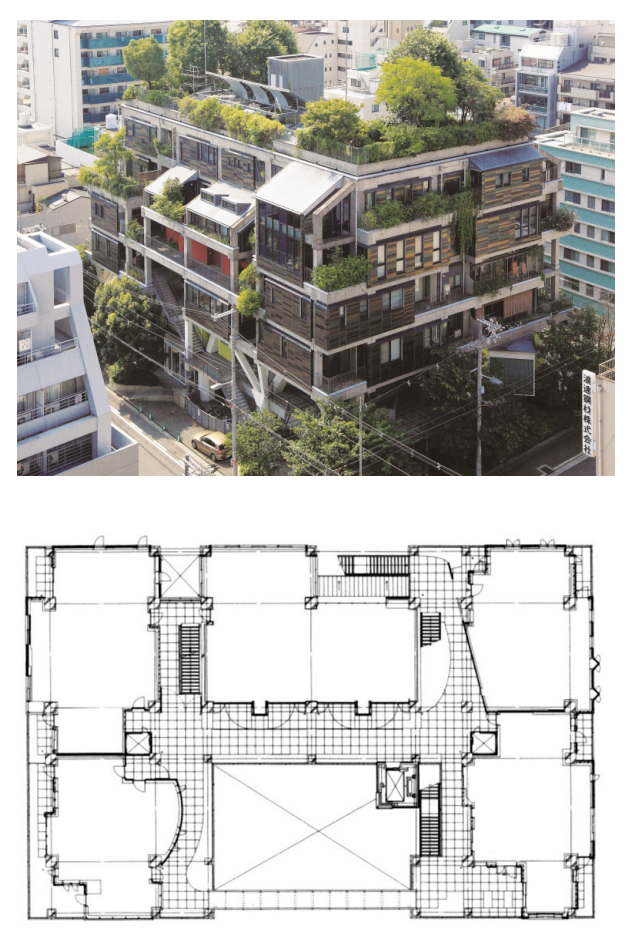

the tension between the individual and the collective, Kendal's lack of engagement with the Allocation Level allowed it to remain a layer of conflict between the two forces of control. The majority of the high-rise residences projects that adopted Kendal's Residential Open Building initiative are broken down into the two stages of design, "Support" and "Infill," initially presented by Habraken (Habraken \& Teicher, 1972). The Open Building projects became either a two-step supply system or an open plan. Next 21 in Osaka, Japan adopted the two-step supply system, designed with fixed demising walls and the users' control of the Infill. Solid 11 in Amsterdam, Netherlands is an open-plan, mixed-use building; the architect only provided the building shell, the vertical space division, and service utilities, then let the user determine their boundary of space. Neither of the two case studies provided the flexibility that the Open Building initiative claimed to have, as both approaches only offer flexibility over time of the interior layout of the individual apartment unit without an actual design solution for the continuously changing amount of space needed by individual users over time. As a result, most of the Open Building projects remained fixed after construction and failed to deliver the "natural relation" as a diverse built environment that accepts change and transformation, at least to the extent which Habraken intended.

However, current commercial office buildings deploy a version of the open plan concept; as much space as possible is provided between the building core and exterior envelope and tenants lease the floor area required, with demising walls and interior partitions and finishes constructed as required to support immediate needs. Changes within the tenant space and extent of lease space can be made easily and frequently. 


\section{Architect's Leadership Role in Design}

By balancing between the visionary planner and a bottomup approach, the architects' leadership role in design is certainly not undermined nor disappears. However, this paradigm requires architects to adjust their attitude and approach towards design. First of all, by recognizing social diversity and the need for support of ongoing change within the built environment, architects should aim for design results that are not static but embrace transformation and customization. Therefore, such design outcomes could not be single options but branches or classes of options that would address different scenarios; in addition, each design would promote and help guide each user's customization of his or her personal space. An alternative approach would emerge that is neither streamlined nor an isolation of each stage from design, to build, to occupancy, but an interrelated process similar to how a tree grows; the architect establishes the trunk and main branches according to its surrounding environment (Support Level), which allow diverse forms of smaller branches and leaves to grow out of them (Infill and Allocation Levels). In this systematic participatory design approach, the architect would be responsible for the outcome of some aspects of the project (especially the Support Level) and by defining guidelines and rules for the Infill and Allocation Levels. As well, classes of apartment unit prototypes to be parametrically deployed and customized for different scenarios would be designed. As a result, architects would transform

their leadership roles as the designers of the built environment, by incorporating the users' diversities into the process. 


\section{Conceptual Design Study:}

\section{A Dynamically Evolving Elevation}

Giancarlo De Carlo said "architecture is too important to be left to architects" (Zucchi \& De Carlo, 1992). Nobody knows the users better than the users themselves; however, most designs have excluded the users from the process. This conceptual design study uses the elevation of Le Corbusier's Unité d'Habitation as a base framework for community that constantly evolves to reflect the user's changing needs over time. The designer can then balance the two separate forces of control between the collective and the individual through the design of the building's Support Level systems. The project pursues an alternative to the top-down design process that produces one-size-fits-all solutions for the design of high-rise residences.

An abstract architecture rendering was developed for this design exploration. Collages of realistic images were used to form a relationship with the viewer. Unité d'Habitation by Le Corbusier is the prototype of modernism's high density residential design-a major influence on the 20th-century residential projects. A grid was created to reflect the typical apartment unit module: three floors and one bay. A catalogue of images of commercial and residential building façades was then created as an abstracted representation of different categories of user preferences or different programs. The images were then deployed onto the grid using a grasshopper software script. Various versions of designs were then generated with the same system by modulating the input data. This design strategy of incorporating variations in architecture through a system has inspired the design for the parametric spatial deployment and the facade of the final project. 


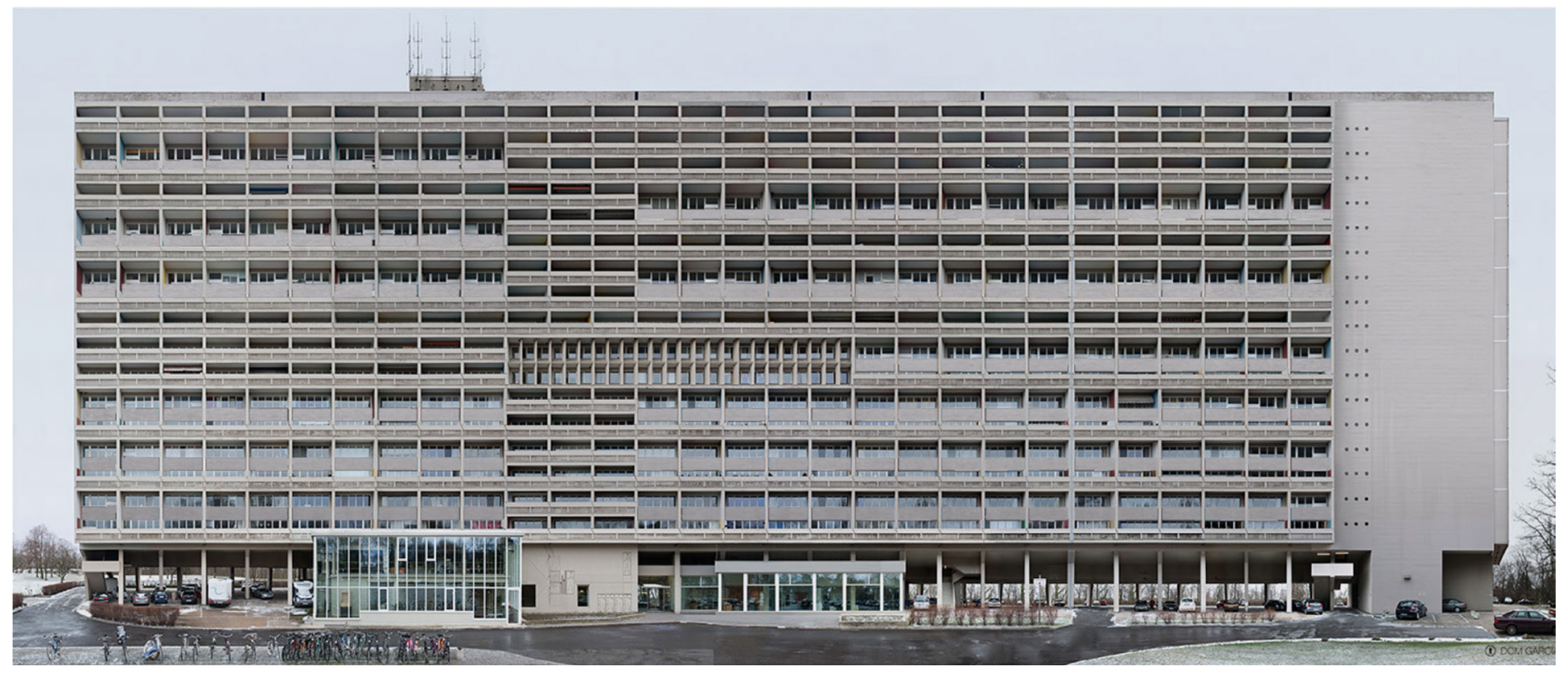

Elevation of Unite d' Habitation

by Le Corbusier, 1952, Marseille, France
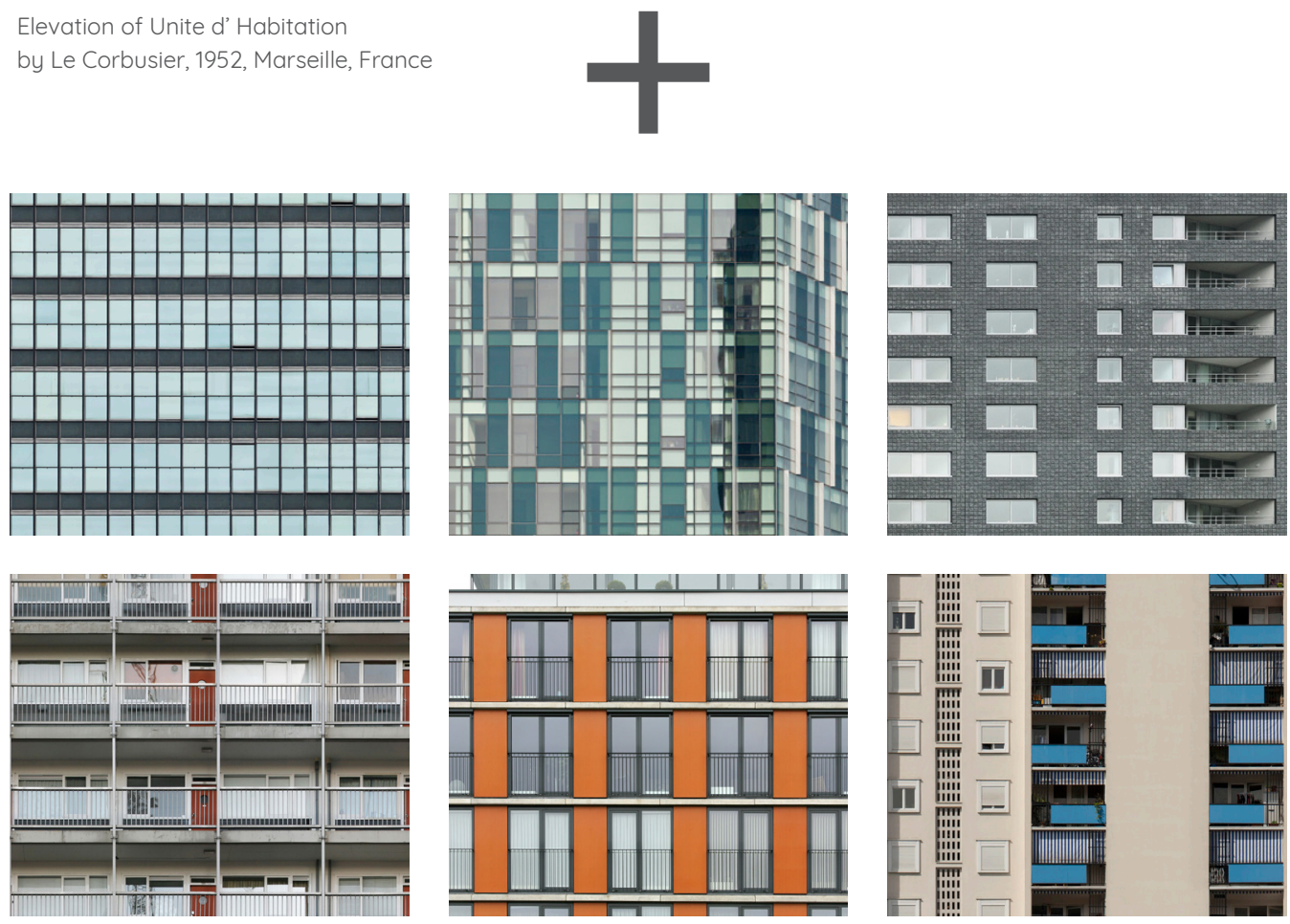

Catalog of building facade images as representation of diverse user's demand 


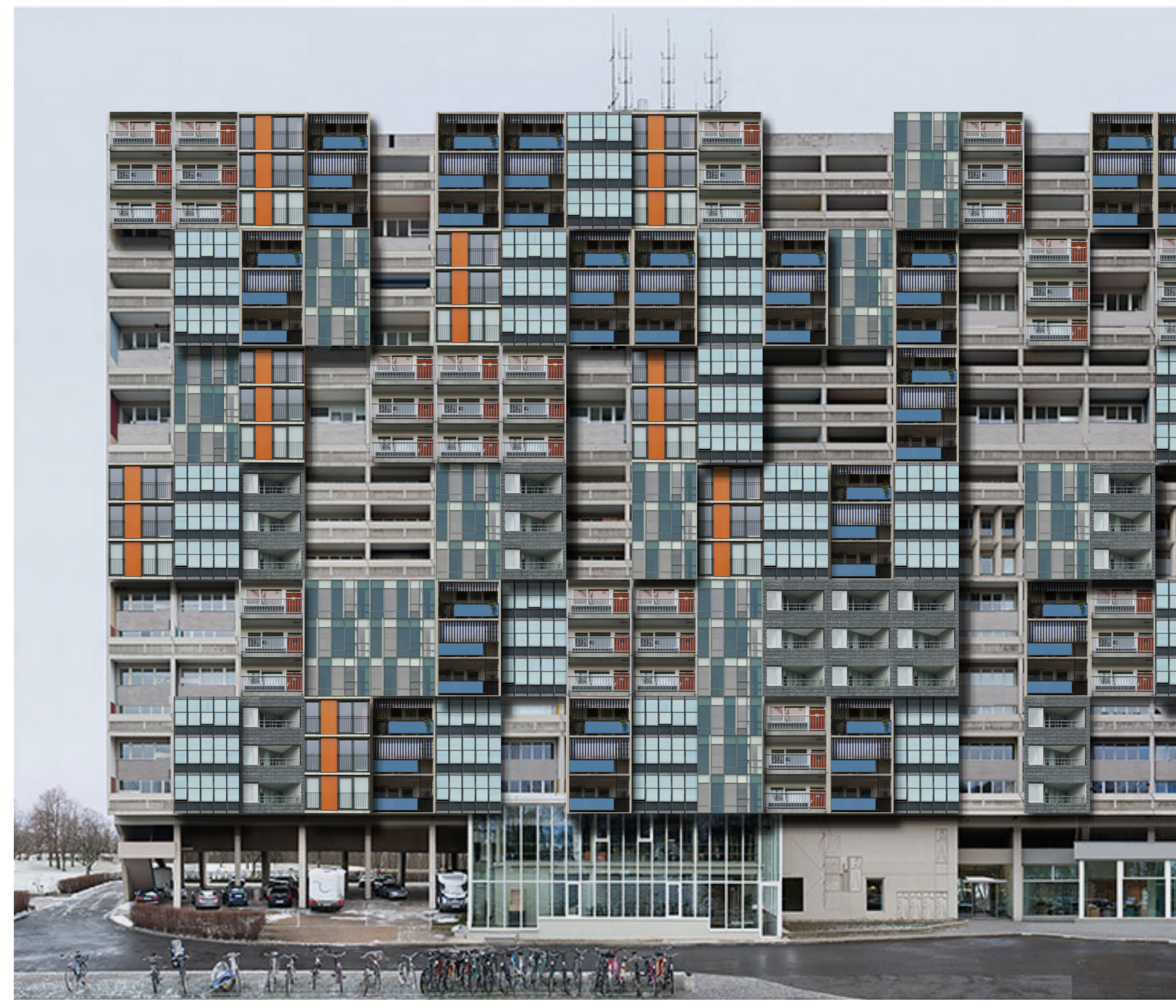



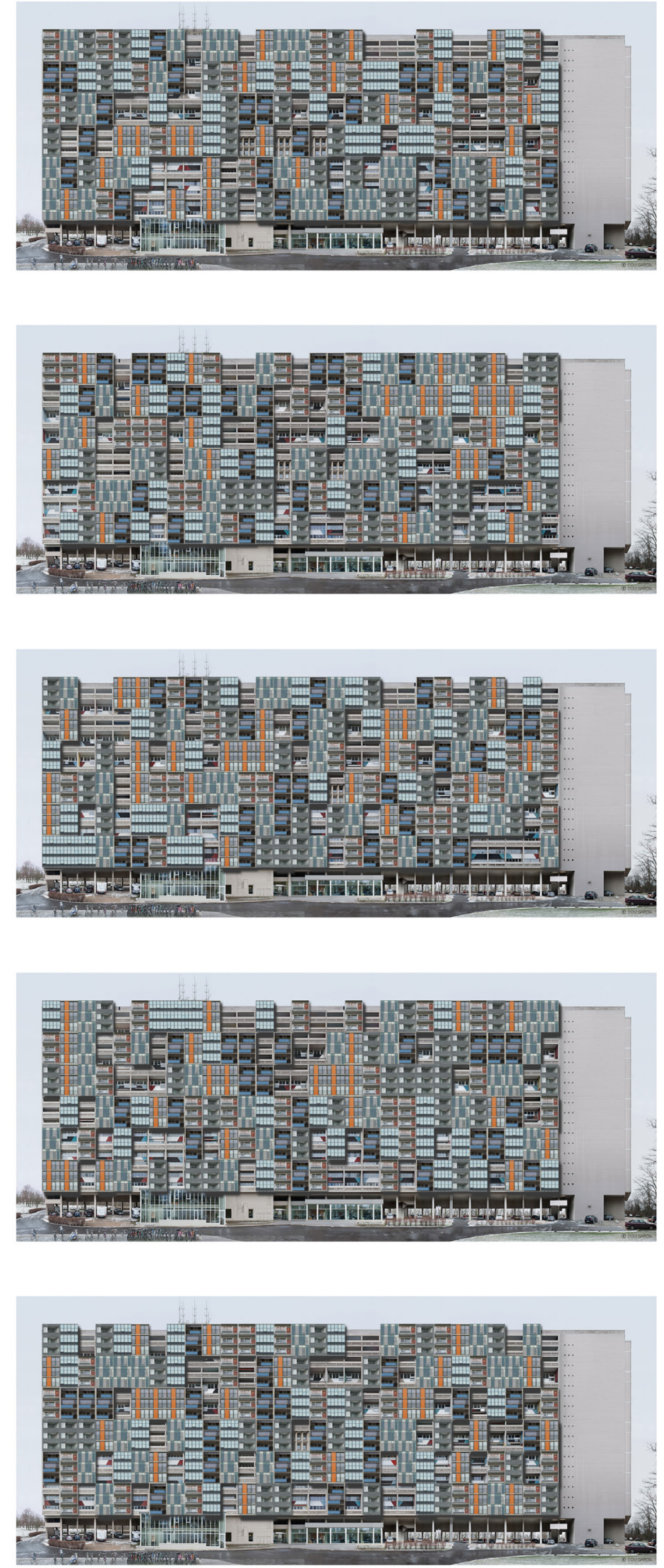
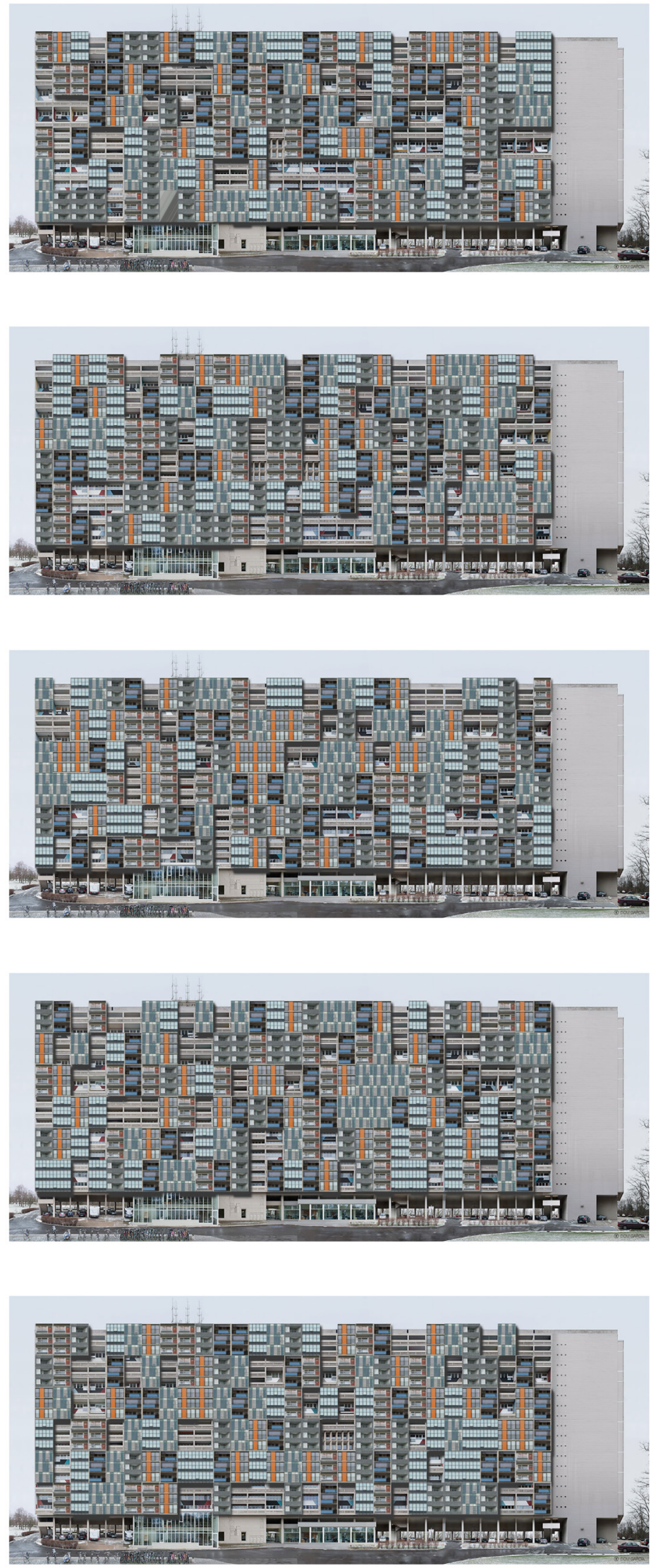

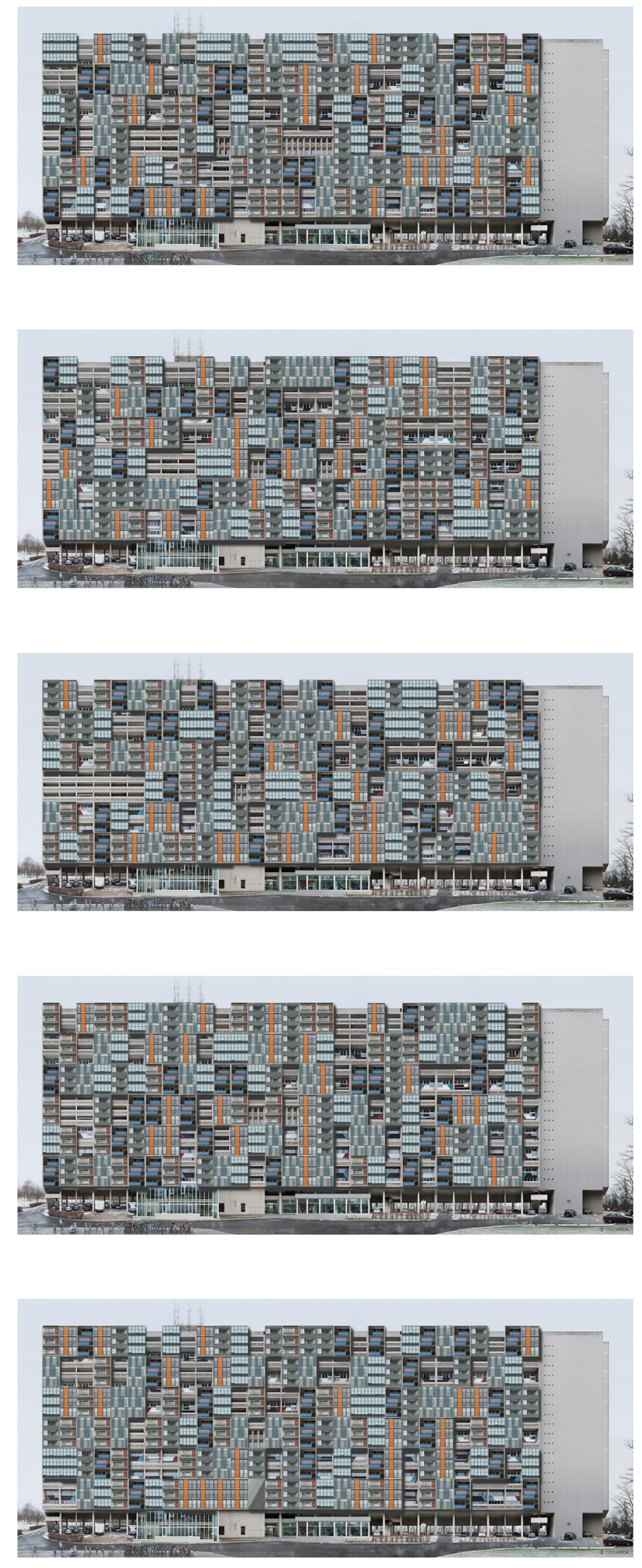
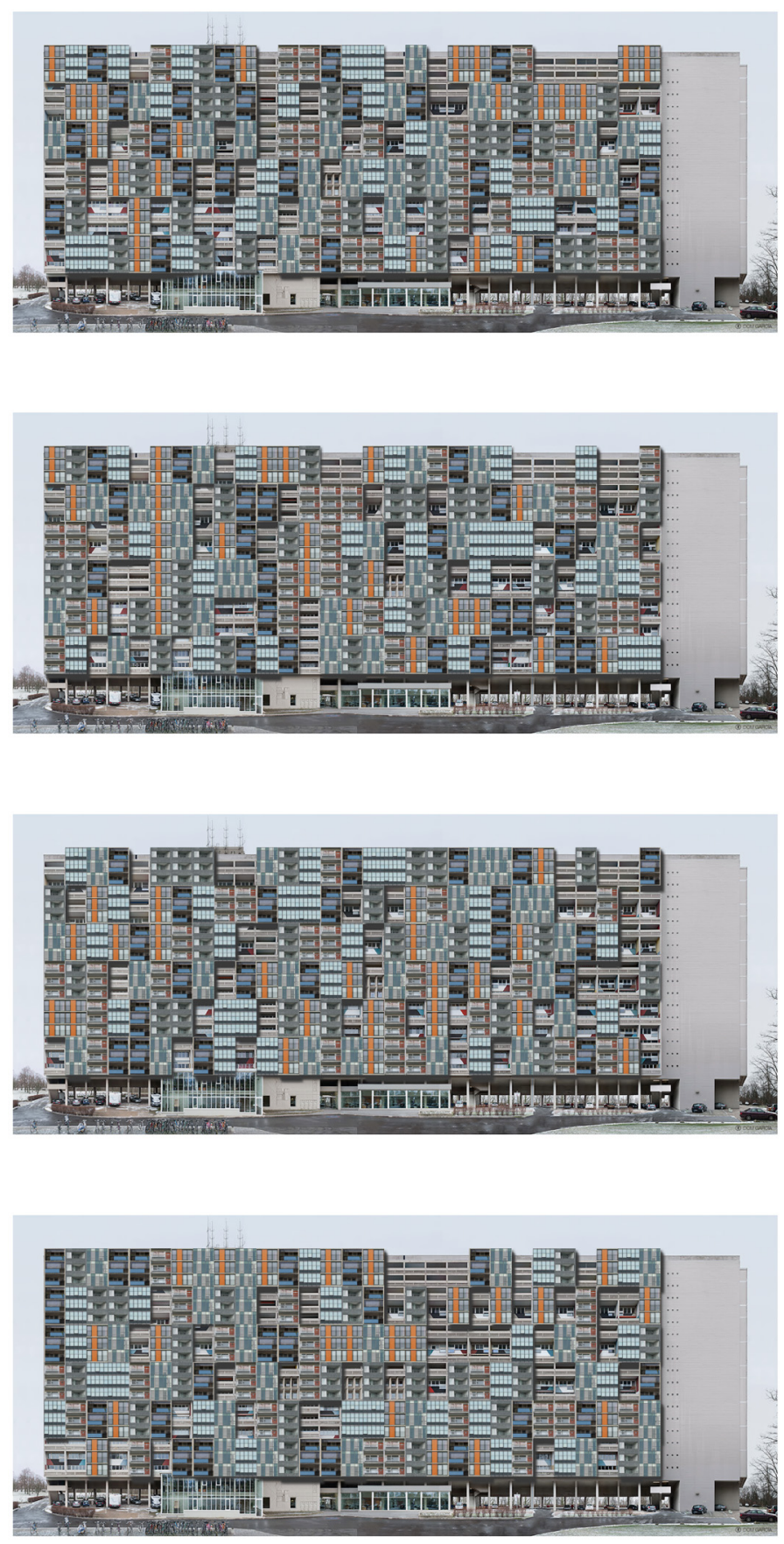

Figure No.4-7

Deployment of a systematic design demonstrating variation over time (individual) within a continuously coherent framework of (the collective) 


\section{5 | Digital Technology and Parametrics}

De Carlo and Habraken both recognized the necessity to balance the two separate forces of control between the collective and the individual, within a residential project and offered their version of the solution through two distinctive pathways. Habraken and Kendal separated the control of built environment design into separate levels of Support, Allocation and Infill, which allows the Infill Level to be controlled by the users. De Carlo's approach is based on consultation and consensus directly with the user. The two may seem conflicting, but in reality, they have been adopted concurrently as most of the 'Infill' level is designed by a separate architect who works directly with the unit owner. This design process can provide diversity and individual identity for the dwelling space but also suffers from a lack of collective control to support future changes. Consequently, this creates a complex relationship between the units that prevents future transformation. In order to promote changes in a high density housing environment, a system needs to be established, not to terminate diversity, but to enable diversity in a constrained way that permits future changes. The digital parametric systems are based on the control of variables, which offers the potential to regulate changes within a range of values, using technology to promote the transformation of the Allocation Level for a systematically controlled changing environment and building an effective "natural relation" between the user and the built environment (Habraken \& Teicher, 1972).

As has already been discussed, the evolution of architecture is often associated with technological innovation. Modernist architecture emerged from the background of industrialization and mass production. Over decades of technological evolution, digital technology has transformed the fabrication methods from mass production toward mass customization. A shift from an analog to 
a digital way of processing, storing and transferring information has transformed many industries. However, this technology has not been properly adopted in the construction industry and has been either used superficially or missed the conceptual opportunities the parametric offers. Therefore, parametrics has the potential to offer new possibilities to architecture design. According to Mario Carpo, digital technology and mass customization are part of a "new technological paradigm that is increasingly dealing with variations which can all be designed and fabricated sequentially... at the same unit cost as identical copies" (Carpo, 2011, pp. 92-93). The digital continuum presents a new degree of flexibility in design and fabrication. However,

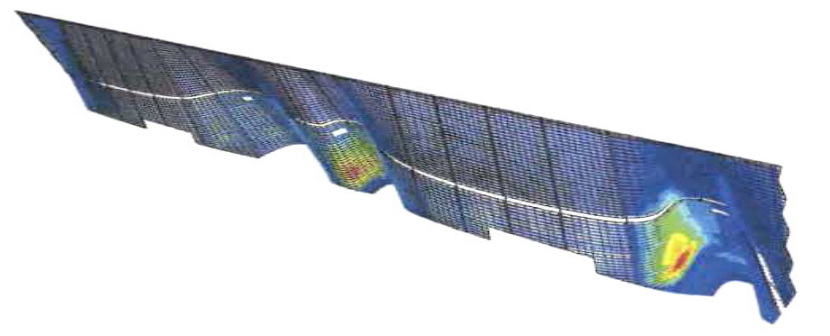

Digital Model

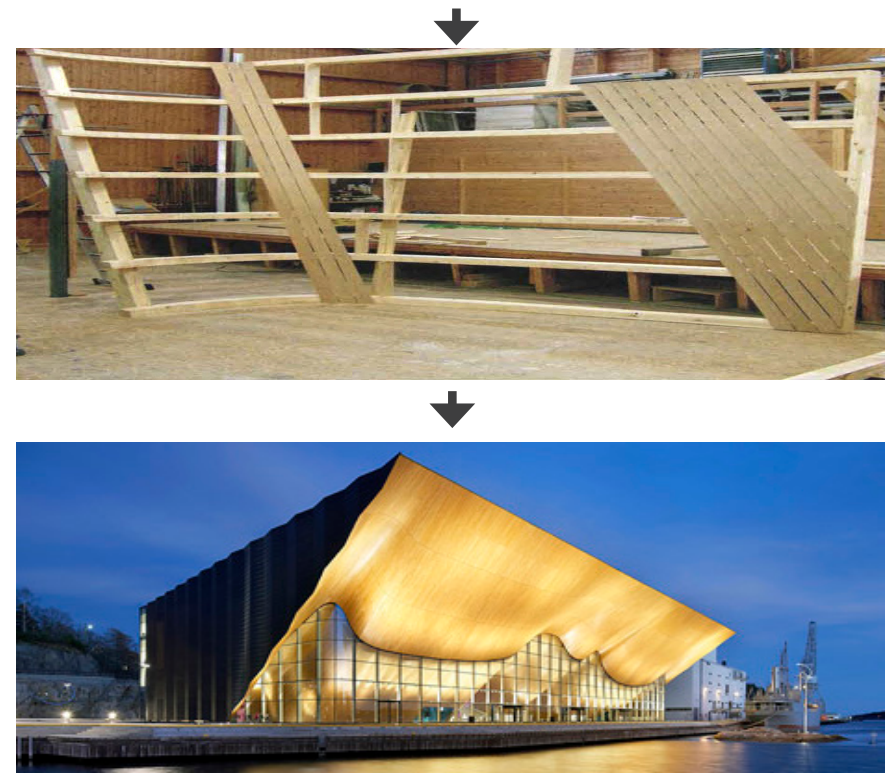

Physical Mock-Up

Realized Construction

Figure No.5-1

Kilden Performing Arts Centre from design to fabrication - Digital Continuum

by ALA Architects, 2012, Kristiansand, Norway 
this feature of technology is rarely being used to respond to the social diversity of the users but is mostly being applied to the conventional central decision-making process to achieve a wise plan imposed by the architect. Hence, it is necessary to deploy the advanced technology of mass customization and parametrics to promote social diversity and individual user preferences in architecture.

\section{Superusers}

As star-chitects deployed parametric technology to create an iconic style, many architects and field-related professionals started to question and critique the skin-deep application of the technology, finding ways to better integrate the technology with architecture beyond a stylistic facade treatment. Italian architect Carlo Ratti believes that digital systems can be united with architecture's design strategy and "become an integral and responsive part of human life. ... Architecture must do more than just look like a living organism: it should perform as a living system" (Ratti \& Claudel,

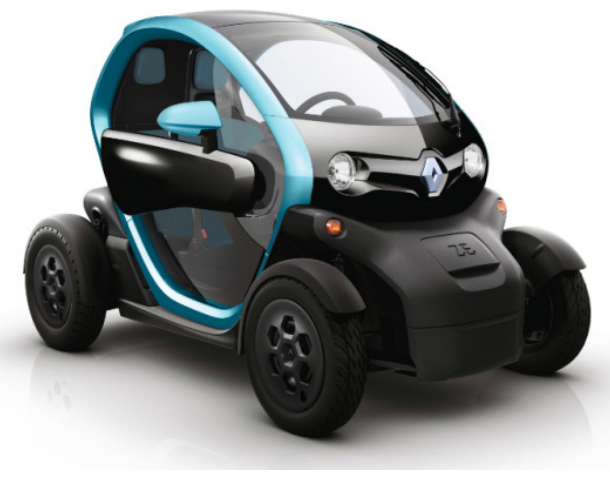

Figure No.5-2

2012 Renault Twizy EV with bobby form

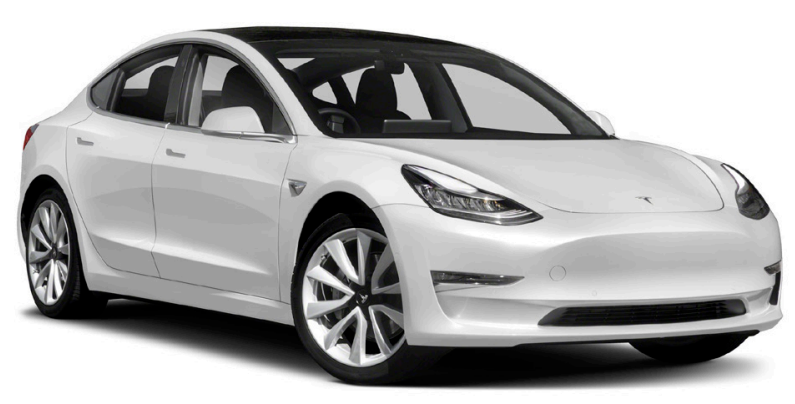

Figure No.5-3

2017 Tesla Model 3 EV that maintains the classic car appearance 
2016, p. 38). Using parametric technology superficially to achieve visual complexity in architecture is similar to the early design of EVs (electric vehicles), which involved using vibrant greens or blues or strange curvy body lines to distinguish EVs from normal combustion engine cars. However, a car design that looks futuristic is just like a blobby architecture form, which essentially does not add any additional function but only provides an unfamiliar appearance. The strange styling makes the car appear more like a toy than a serious vehicle that ensures the health and safety of its passengers. The automobile company Tesla recognized the shortcomings of this approach and instead focused on improving the performance of the car, while maintaining a classic appearance of normal vehicles, which allowed the brand to gain popularity and have some of the best-selling EV models on the market (Statista, 2020).

As digital technology become extensively used by the public, technologies that offer service to the architecture industry will evolve towards customizable design processes through parametric and automation to enrich the architectural experience of users. Randy Deutsch calls these professionals Superusers who can "leverage the tools and technology to do more" they are the "generalist architects of this era" (Deutsch, 2019, p. 2-3). By combining a diverse range of tools and working with an iterative workflow, Superusers can integrate or converge knowledge, data, and algorithms to develop the industry for public benefit.

Architect Carlo Ratti's Digital Water Pavilion demonstrated the use of technology to enrich the architecture's sensorial experiences with a combination of tools such as sensors, actuators, and software to offer a dynamic experience for the users. The pavilion is a multifunctional space that tracks human movements and uses 
pre-programmed software to control the water nozzles for a diverse range of water droplet patterns (Ratti \& Claudel, 2016, p. 41). Other similar projects enhance the overall architecture experience by finding new ways to utilize existing technologies from other fields such as electrical or mechanical engineering.

Some Superuser architects or practitioners are also deploying technologies with their architecture knowledge and design skills for speculative projects or critiques. Liam Young, professor at the AA (Architecture Association) in London, declares that architects have a broad range of skill sets; these skills are "wasted on making buildings as singular objects" (Hyde, 2013, p. 225). Instead of accepting the reactive and subservient role of working under a client to produce buildings that help generate profits, Liam runs a "think tank" research studio called Tomorrow's Thoughts Today (TTT). TTT "engages critically with contemporary culture" (Hyde, 2013, p. 225) and practice through speculative and research projects. Liam Young believes that building is a slow medium for expressing ideas; TTT uses digital technologies to form a more immediate response. For

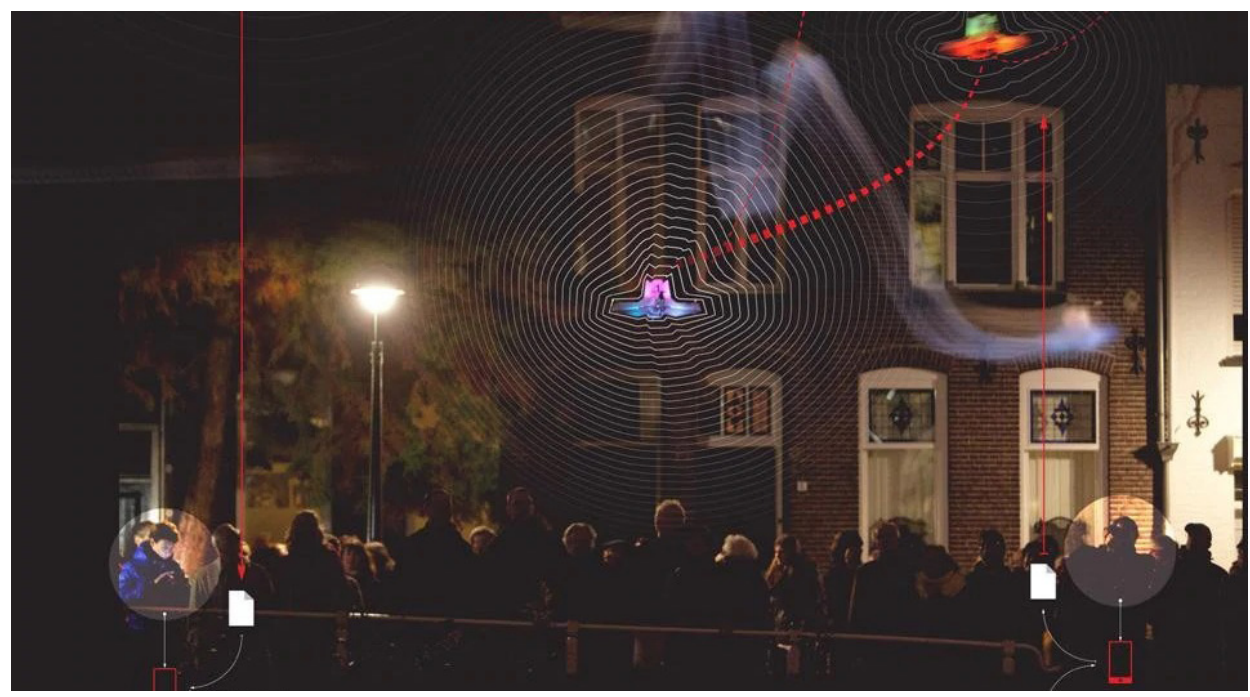


example, their project, Electronic Countermeasures, uses drones as an airborne infrastructure network to provide internet to the public during a protest (Hyde, 2013, p. 229). This type of spatial practice detaches itself from the capitalist system in order to construct critiques from a neutral position. It combines architecture and advanced technologies to present an argument or open a line of discussion in regards to social, political or environmental issues.

\section{Design with Variables}

Parametrics in architecture evolved from 3D modeling software. Parametrics can be defined as a design process "that enables the expression of parameters and rules that, together, define, encode and clarify the relationship between design intent and design response" (Jabi, 2013). This design process uses the relationship between the parameters and defined elements to manipulate and guide the design. Rather than providing fixed measurements and forms, parametrics use algorithmic rules to formulate a system that allows for changes in the variables to determine the final result.

Mark Burry was one of the pioneer architects who adopted digital parametrics in his work. In 1991, Burry started to use parametrics to analyze and apply the computational logic behind the geometries of the columns at Sagrada Família (Barcelona, Spain) consulted to help resolve elements of the church which were incompletely resolved in Antonio Gaudi's original design. Through an algorithmic description of geometry, parametrics formed an intertwined relationship between the transforming and splintering contours of the column and its structural behavior. Parametrics help create a system of contiguous associative geometries through the change of input values without recreating the system. This

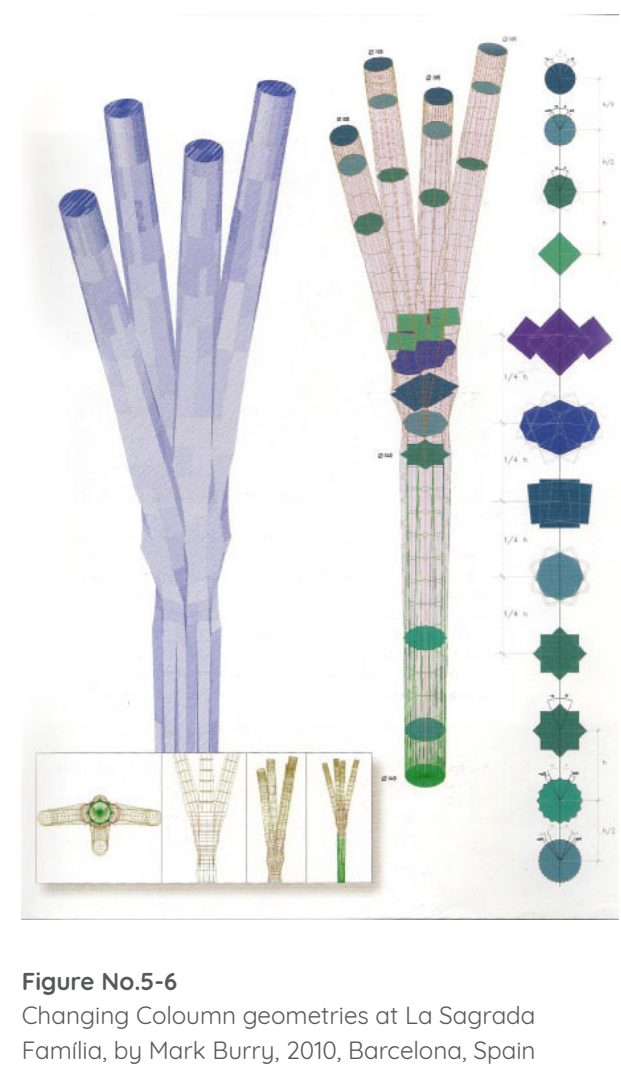


fundamentally shortens the time required to design and explore the complex shapes and structure of the nave.

Many contemporary architects working with parametrics are using the technology for stylistized designs with curvy forms. John Fraser argues that "...the use of parametrics as such does not necessarily lead to any style at all, and is just an efficient way of flexibly describing geometry" (Block \& Bhooshan, 2016, p. 21). Fraser counterargues Patrick Schumacher's Parametricist Manifesto as a new style of architecture that "Avoid repetition, avoid straight lines, avoid right angles, avoid corners, avoid simple repetition of elements" but embraces soft forms and continuity (Schumacher, 2011). Schumacher framed the digital design with variables as a new style, which formulated constraints towards the use of such technology. As critiqued by Michael Meredith, the contemporary use of parametric has "very little instigating complexity other than a mind-numbing image of complexity, falling far short of its rich potentials to correlate multivalent processes, complex functional requirements and collaborative network" (Sakamoto \& Ferré, 2008, p.6). He believes that "architecture requires social engagement; it requires cultural and social relevance," which is absent in much of contemporary parametric practice (Sakamoto \& Ferré, 2008, p. 8-9).

\section{Rule-Based Procedural Algorithm}

Mario Carpo illustrated the advantage of variables within an interrelated and open-ended system by tracing the roots of parametric architecture to classical antiquity, the Middle Ages, and the Renaissance. Carpo's investigation showed that both Renaissance architect Leon Battista Alberti, and Roman architect Vitruvius were using verbal descriptions and modular proportions to describe 
architecture geometry, which is analogous to the "procedural algorithm' in contemporary parametric design. Therefore, the result of such a rule-based description which, per Deleuze, "is not object, but a class of objects" (Block \& Bhooshan, 2016, p.28). For example, the architectural elements in a Gothic building such as the ribs, capitals, or traceries are often similar but not identical. This rulebased design system allows the same architectural element to be produced differently to accommodate different scenarios, therefore making the design a flexible solution.
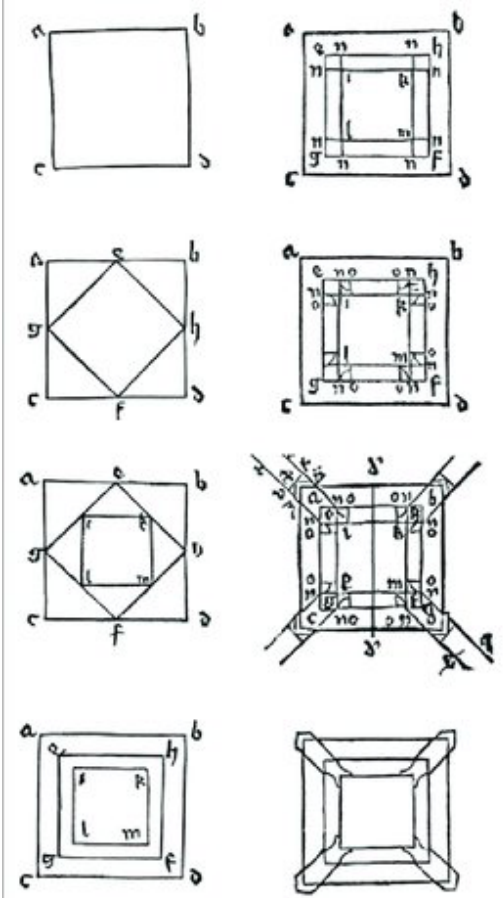
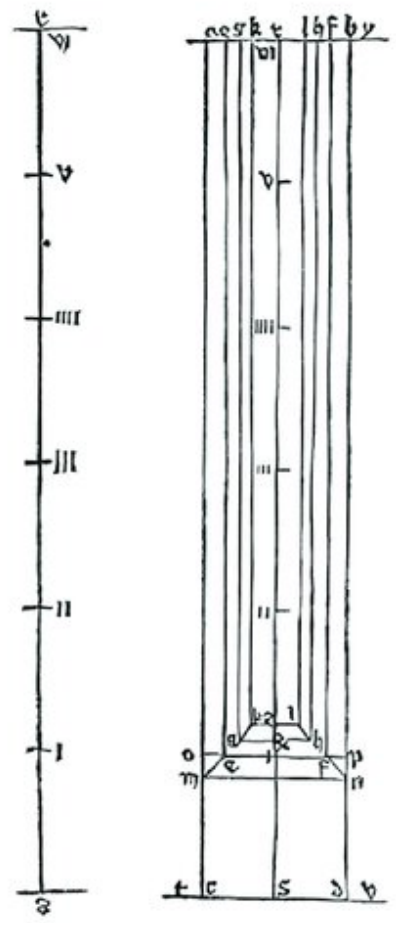

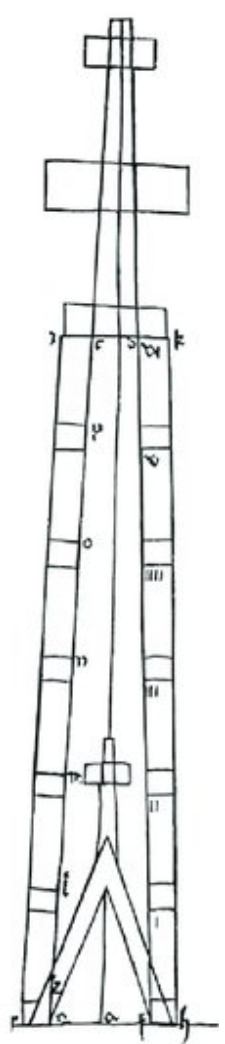

Figure No.5-7

Diagram showing construction details of a spire in medieval period, 1486 There are no numerical values, only description of proportion. 


\section{Rule-Based Design Exploration}

The design exploration shown in Figure No 5.8 and 5.9 is an attempt to use a 'procedural algorithm' as a rule-based design system that permits changes to happen within established constraints. The grid represents a minimum unit of transformation. Defined rules constrain the initial Allocation ofProgram A (red) and Program B (blue) onto the grid, and then the rules provide a guideline for any new additions to the grid space. Therefore, a new cell can be added based on the existing conditions. The system offers users the freedom to operate within the set rules. Instead of designing a fixed form with a fixed relationship, the rules provide a flexible relationship between the two programs. This technique supports the freedom to implement localized future changes in a constrained way that maintains global design intentions. This frames the connection of individual decisions to a broader agenda to avoid the two weaknesses previously identified, chaos or blandness. This design exploration demonstrated that the design of space organization can be related to a set of rules which allow changes to happen without causing disturbance to the entire design.

Rule \#1: Program A must be a group of 4 to 6 cells, that cannot be connected with Program B

Rule \#2: Program B must be a group of 2 to 4 cells, with a maximum one grid space of shared wall between groups.

Rule \#3: Program A and B must be at least one grid space away from each other, separated with a garden. 

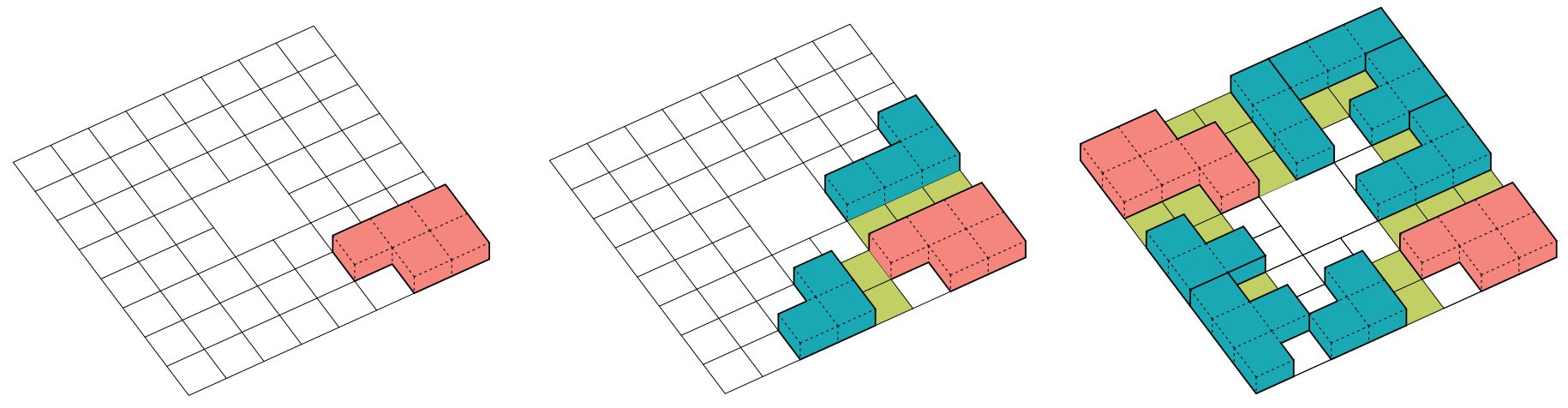

Figure No.5-8

Rule-based design system formation progress

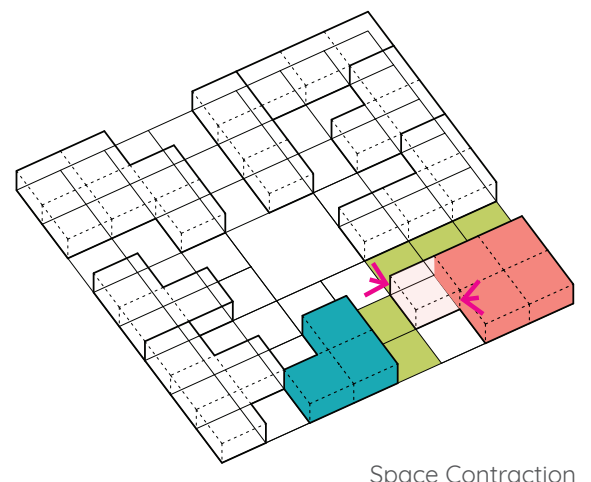

Space Contraction

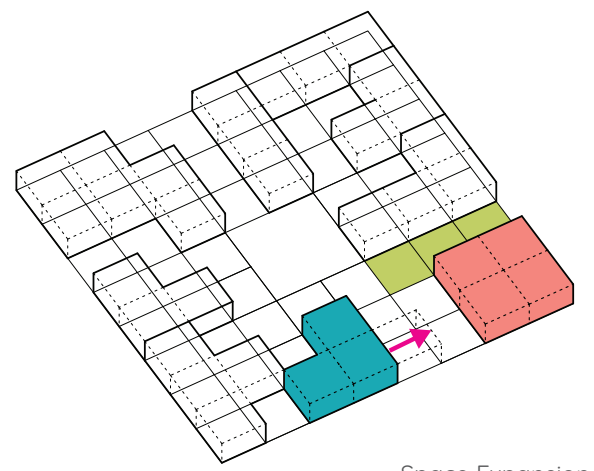

Space Expansion

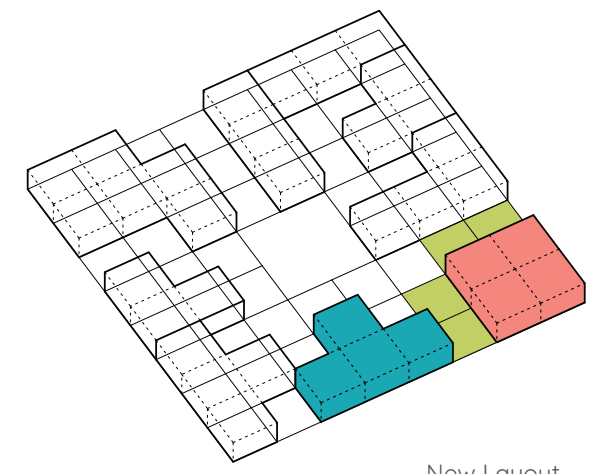

New Layout

Figure No.5-9

Rule-based design system adjustment
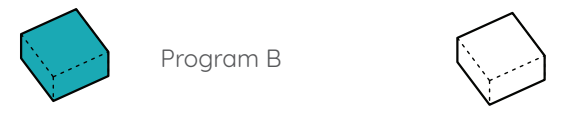

Existing Cells

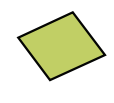

Garden 


\section{Façade Customization Exploration}

The design process of contemporary high-rise residences is predominantly a top-down, centralized decision-making process. Therefore, the design of the façade is usually a standardized expression of an overall formal building mass and does not reflect the individual users' preferences, contributing to an anonymous living experience. This early façade design exploration adopted a systematic approach for user participation. The system offers the users the freedom to customize their individual apartment unit exterior walls within given limits. The concept is to allow the users to determine their balance of choices between lighting condition versus visual privacy, as well as interior space versus exterior balcony. Parametrics also offer an overlay of collective control of the facade deployment, avoiding conflicts and conforming with the basic functioning standards. For example, a minimum and maximum window to wall ratio can be set for different room typologies which provides users global performance range criteria that would limit individual customization capabilities. The system enables the designer to determine a balance of the two separate forces of control between the users and the overall architectural performance. The number of customizable options and the range of values could vary per unit and update when certain units have been configured, thereby using mass customization to achieve personalization for building façades for high-rise residences projects.

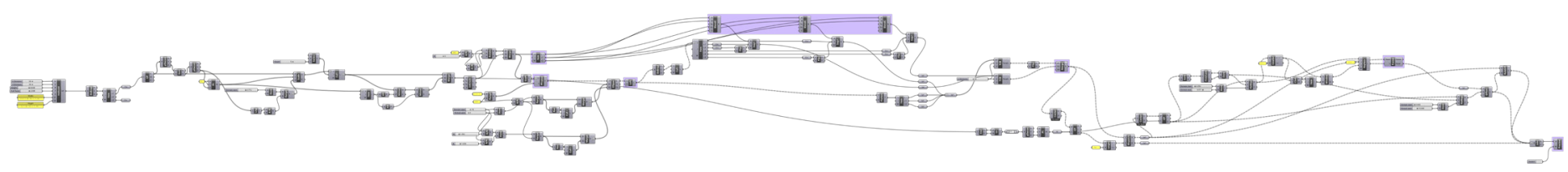




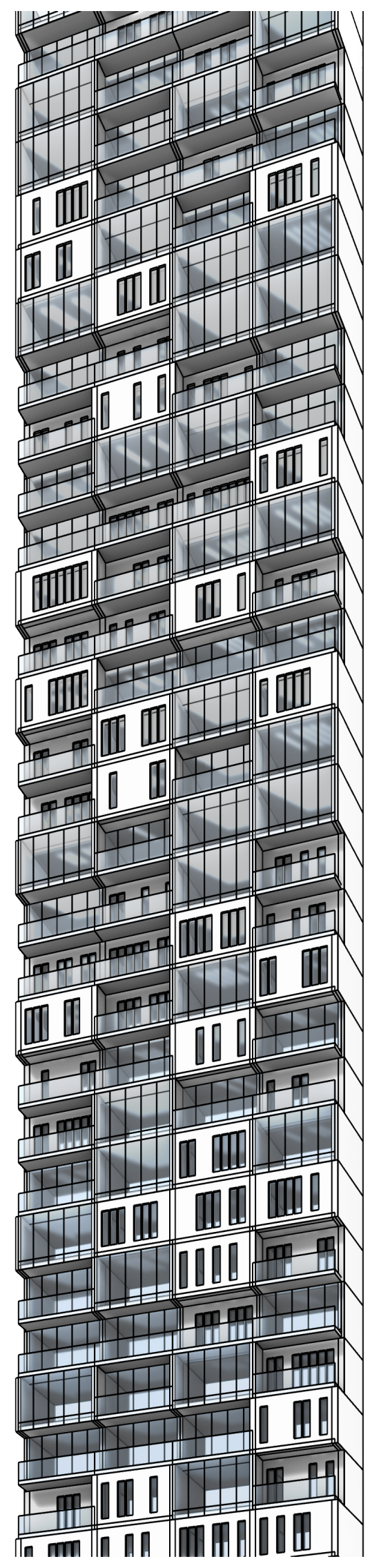

Figure No.5-11

Example of user customizable 


\section{Parametric Control of Allocation}

As architecture struggles to incorporate users' needs as part of design objective, digital technology has already fostered a participatory environment through the network system in software and web design. The Linux operating system is open-source software with which the creator initiates the platform and publishes the source code, then invites other teams and developers to build upon the system. The same concept of participation was used to develop Web2.0 websites such as Facebook, Wikipedia, and Twitter, creating open platforms that give users the freedom to generate content in a collective manner. Carlo Ratti argues that this is an alternative form of collaboration that is not consensus-based, rather, "the autonomy of the individual contributors is guided, moderated and nurtured by editors who can make decisions from the top down," thereby maintaining the innovative forces while offering room for participation (Ratti \& Claudel, 2015, p. 114).

As discussed in Chapter 4, "The Balance of Forces," the lack of resolution for the Allocation Level within an Open Building approach creates conflict between the two forces of control. Failure to promote changes in a high-rise residences environment makes the space incapable of delivering the "natural relation" that John Habraken argued for. Therefore, the goal in this thesis is to incorporate the changing variables of users' space demands over time as part of the design initiative, since a household's need for space evolves through time. A customizable Allocation Level without collective control would create conflict in many aspects, such as management of space expansion, consistency of building performance or maintaining an appropriate living standard. Thus, a parametric system can be used to establish rules for promoting and facilitating (Allocation Level) changes over time, while maintaining established overall design intentions. The design of the system was inspired by 


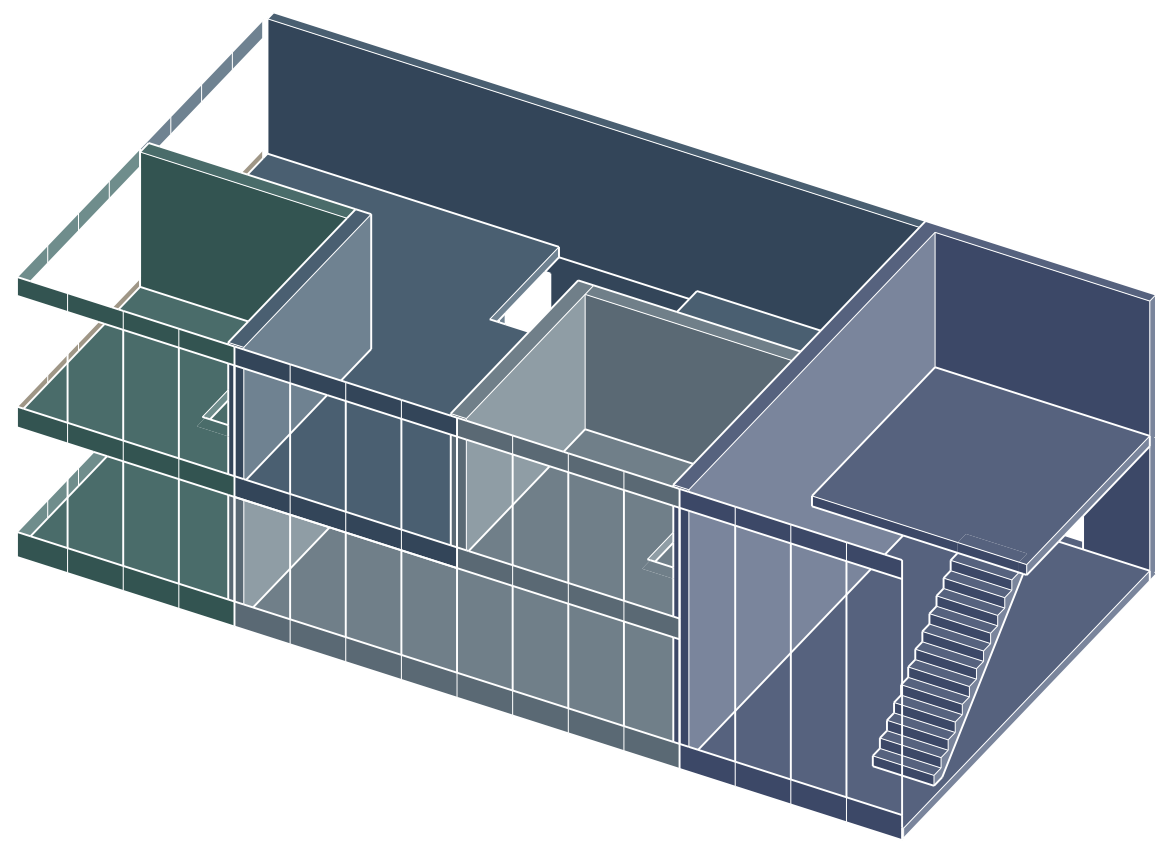

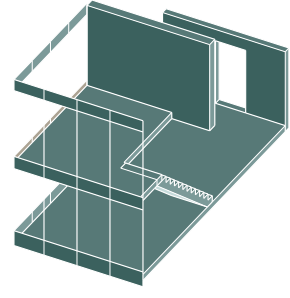

$442 \mathrm{ft}^{2}$

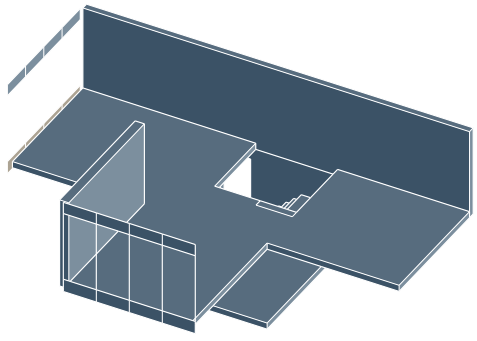

$748 \mathrm{ft}^{2}$

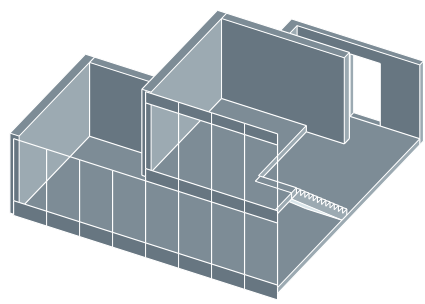

$609 \mathrm{ft}^{2}$

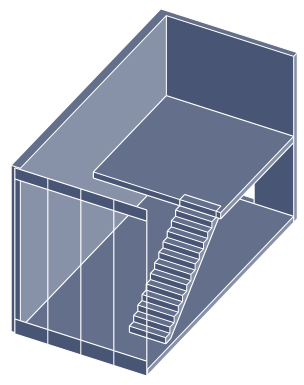

$498 \mathrm{ft}^{2}$ 
the collaboration format of the open-source network, presenting the users an "independent but interconnected" way of operation (Ratti \& Claudel, 2015, p. 112). The parametric system offers a collaborative platform that validates the user's proposed spatial transformation, additionally encouraging social participation among the community members and individual customization of living space.

In order to test the parametric techniques of spatial deployment, the scale and geometry of a range of apartment units were validated, and a typical high-rise residences floor plate layouts were tested (see the following sections and chapter 6). A two-level, two by four cell block of space is designated for this exploration, as validat. ed by the floor plan that will be further discussed in Chapter 7 .

High density residential housing accepts that more than one apartment unit will be integrated into each spatial block; each floor plate will contain 4 spatial blocks; each four metre by four metre cell is a spatial unit but does not define Allocation Level partition locations. When there is a change of space requirement after residency, the parametric model can be used to offer the users different configuration options or validate input change of Allocation, thereby maintaining a satisfactory ratio between the interior and exterior cells, as well as limiting the total number of cells per unit. And most importantly, the system would respond to the changing demands of users' needs over time. 


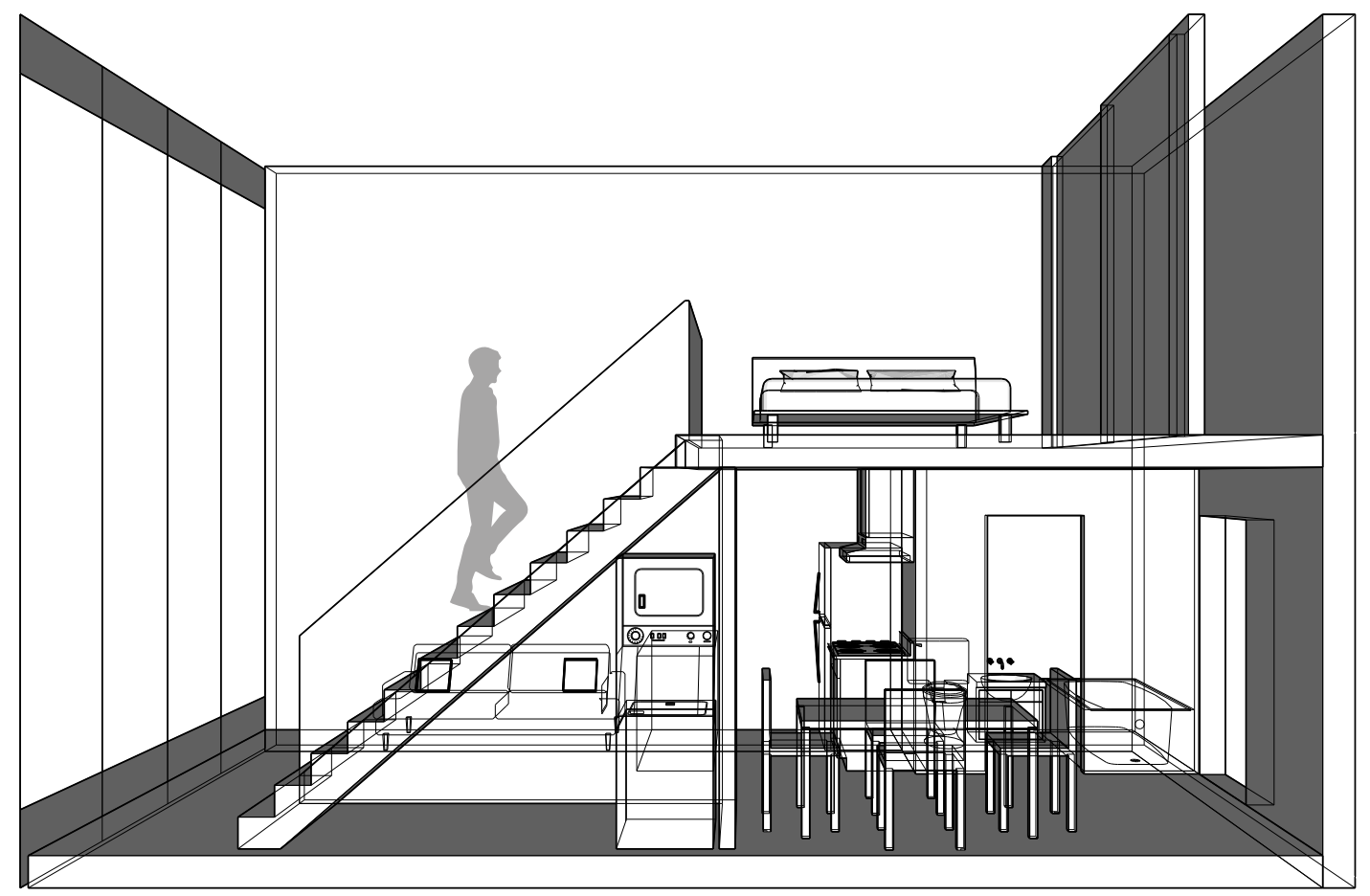




\section{Systematic Participatory Design}

In a Systematic Participatory Design process, the architect can create a parametric framework that provides users the freedom to customize and personalize their individual spaces (Infill Level) within set limits, as well as Allocation Level changes through nego. tiation. It challenges the architect to balance two separate forces of control: the collective and the individual. It is a flexible approach for architectural design that uses rules and relations to guide initial space Allocation and support future changes.

Figure 5.14 illustrates the fundamental logic of the parametric system tested for a two-level generic component within the spatial blocks. The cell components are flanked on 2 sides by a corridor on the lower level. All entrances are on the lower level with a maximum of four units, each colour represents a distinct unit. A minimum of one exterior cell is assigned to each unit. In Figure 5-14B, based on the requested living space per household, the rest of the exterior cells are assigned at a range of proportions that can be connected to the first exterior cells. In Figure 5-14C, the rest of the interior cells are distributed according to the difference between the total requested cells and cells distributed in Figure 5-14B. Lastly, in Figure 5-14D, an algorithm will be used to verify and evaluate the living standards of each unit, providing the statistics of the units such as total area, lighting conditions and circulation. Different combinations of two to four units can be generated with this parametric system.

A two-storey grid was initially proposed to help generate various space combinations for different households, providing various interior layout options and increasing the opportunities and varieties for future changes. However, the configuration was limited to two floors. As shown in Figure 5.15, there was a lack of vertical interrelation among the neighbourhoods, which has also limited the number 
A

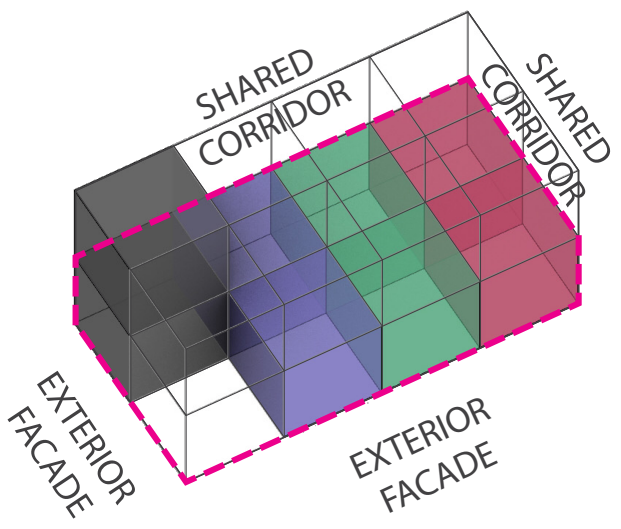

C

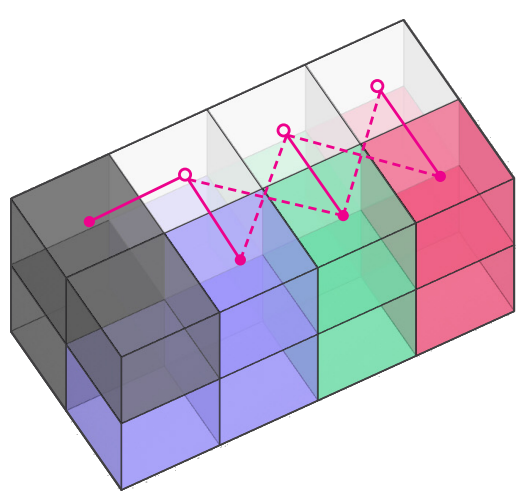

(B)

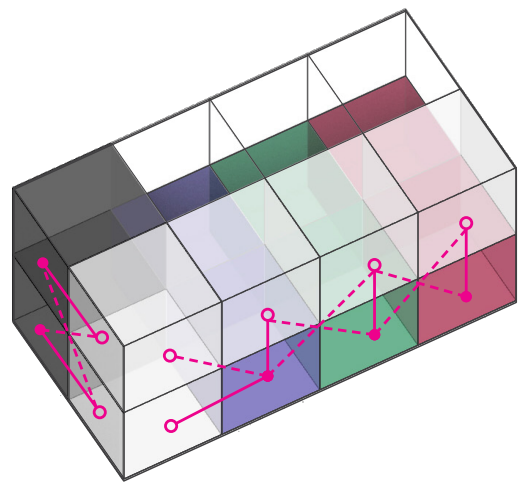

(D)

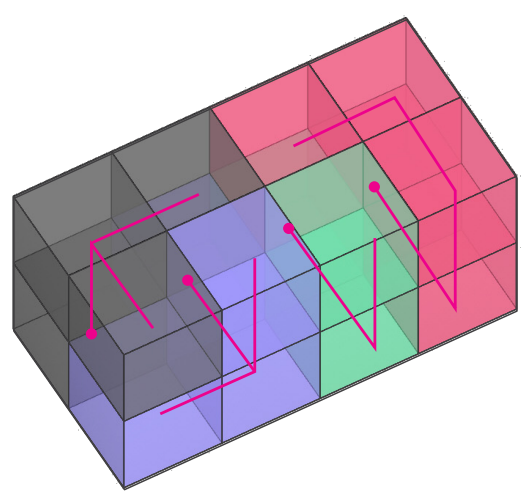

i. Entry Level

Source Cube

Unassigned Cube

— One Step

-.- Two Steps

Parametric System Logic 
of variations and future customization options a unit could have.

Therefore, the parametric model was refined and improved to treat the bulk of the vertically connected blocks as a single entity for unit subdivisions. As shown in Figure 5-16, with different inputs of unit area and a total number of units, the parametric model can as. sign and arrange the units to different households. It ensures the entrance marked by the white dot is skip-stop on every other level, and most entrances are positioned at the center level of the unit. A minimum ratio of exterior cells is also maintained to provide adequate daylighting for each unit. When there is a change of spatial need after initial occupancy, the parametric model can be used to sustain the design decisions made by the architect and help facilitate Allocation Level changes.. It will offer users different configuration options and guide users through Allocation changes in order to maintain satisfactory living conditions for all residences.

This later version of the parametric system can also be operated with a higher complexity of forms. Figure 5-17 demonstrates the functioning of the system with a massing that is vertically shifted. Furthermore, in Diagram 5-18, the source massing is partially carved out, anticipating the insertion of other program uses into the building. Parametrics offers architects the possibility of designing with variables for an interrelated and open-ended system. It helps to create a system of contiguous associative geometries that can be adjusted by changing input values without needing to recreate the entire system. The result of such design is therefore not a single object but, according to Gilles Deleuze, a class of objects that are "all different, as one for each set of parameters, yet all similar as the underlying function is the same for all" (Block \& Bhooshan, 2016, pp.28-29). A class of objects has the capability to accommodate different scenarios with different variations. 
$\otimes \otimes$

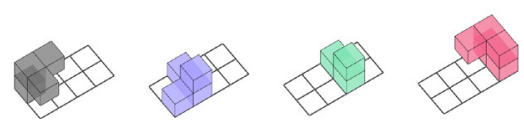

$\otimes \otimes$

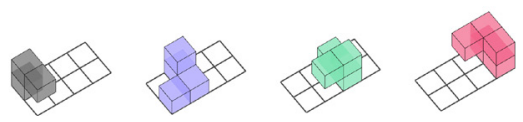

$\otimes \infty$

$\otimes \otimes$

$\otimes \otimes$

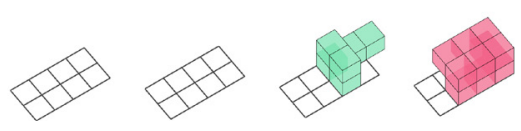

$\otimes \otimes \infty$

$\otimes \otimes \otimes$

$\otimes \otimes$

$\otimes \otimes \&$
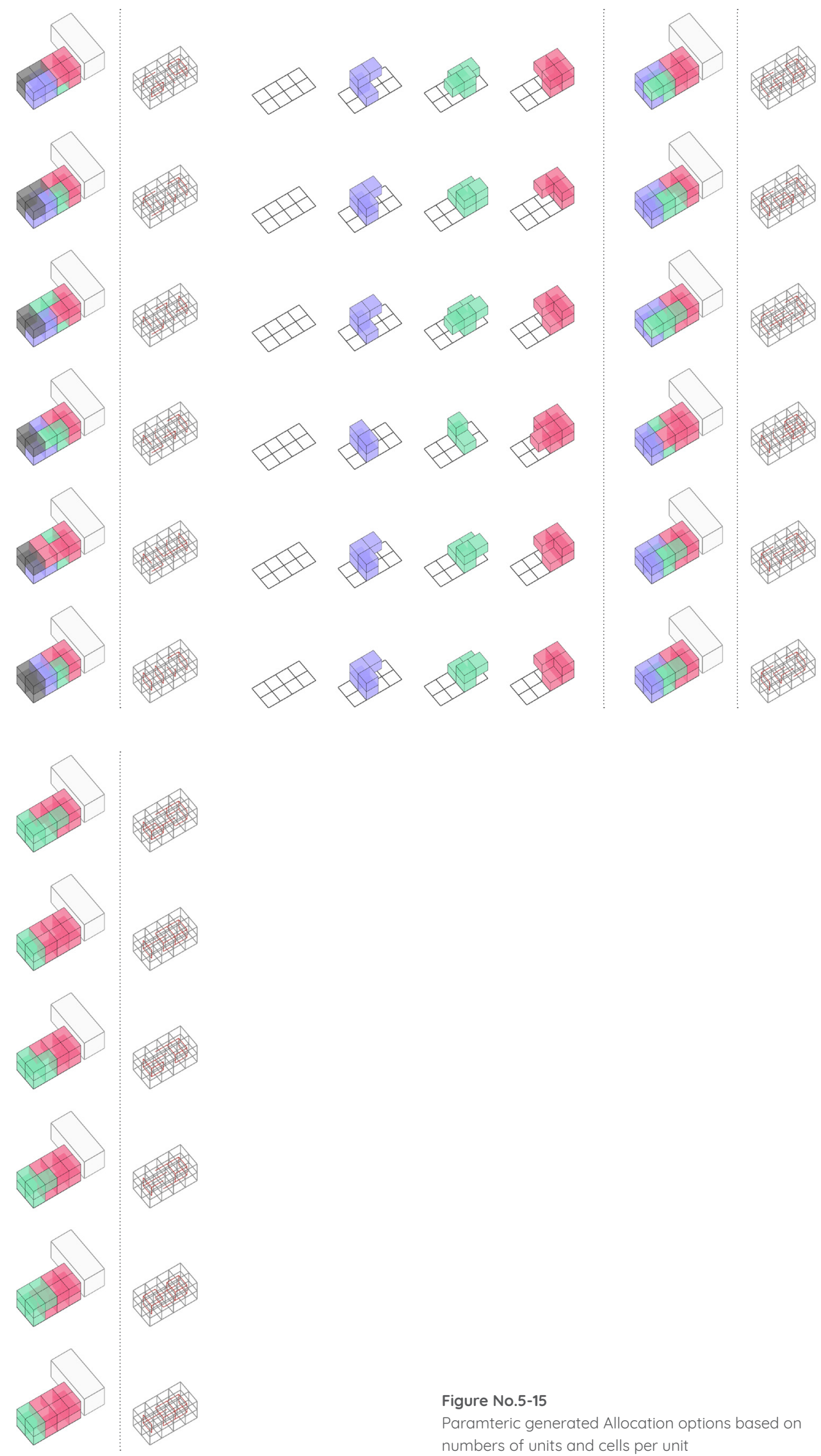

Figure No.5-15

Paramteric generated Allocation options based on numbers of units and cells per unit 


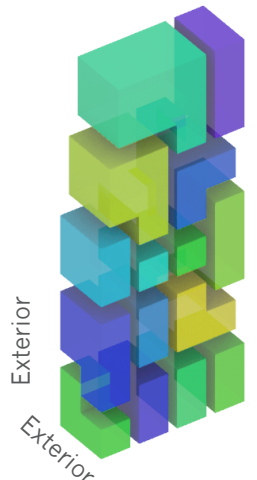

A: Unit area

B: Exterior wall area

C: Ratio of Exterior Wall over unit area

O Unit Entrance

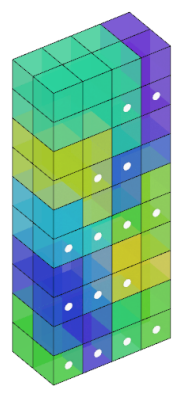

Simple rectangular massing studied for unit subdivisions

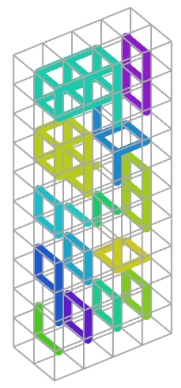

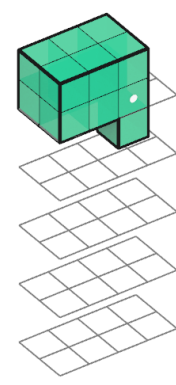

\section{A: $120 \mathrm{~m}^{2}$}

B: $105 \mathrm{~m}^{2}$

C: 0.88
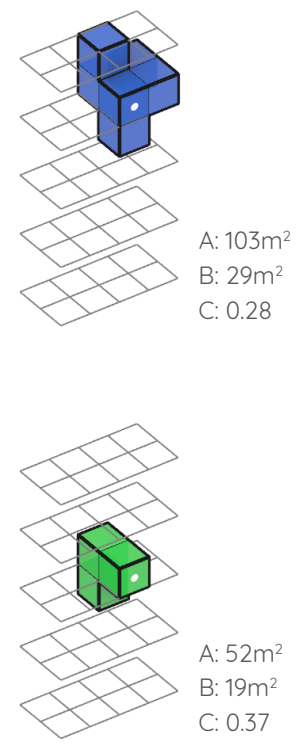

A: $52 m^{2}$

B: $19 \mathrm{~m}^{2}$

C: 0.37
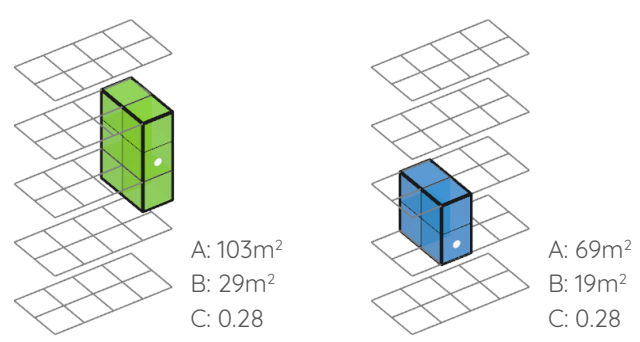
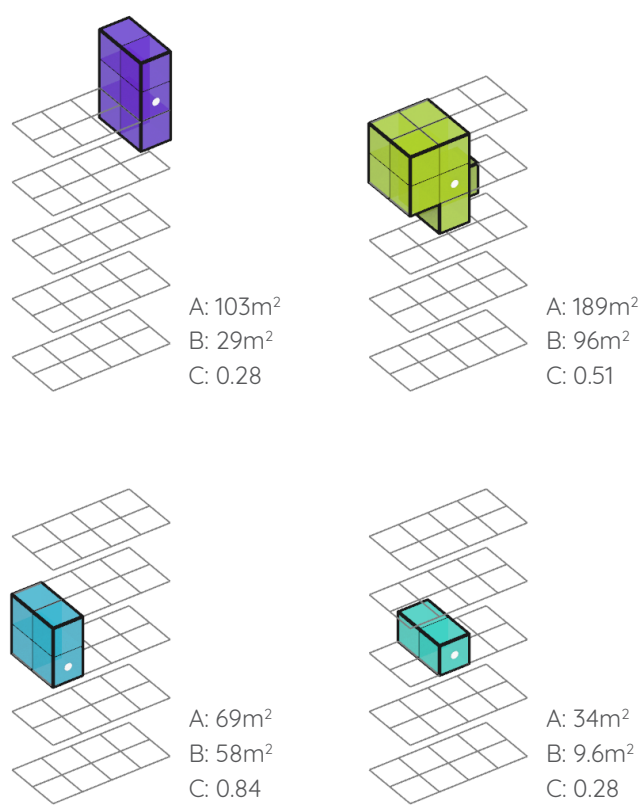

B: $9.6 \mathrm{~m}^{2}$
B: $19 m^{2}$
A: $86 \mathrm{~m}^{2}$

B: $67 \mathrm{~m}^{2}$

C: 0.78

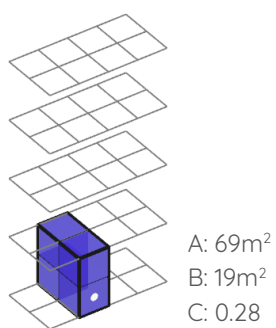

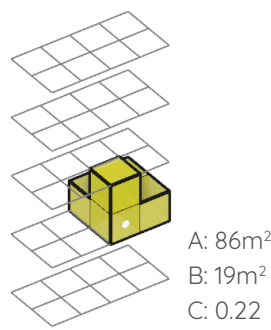
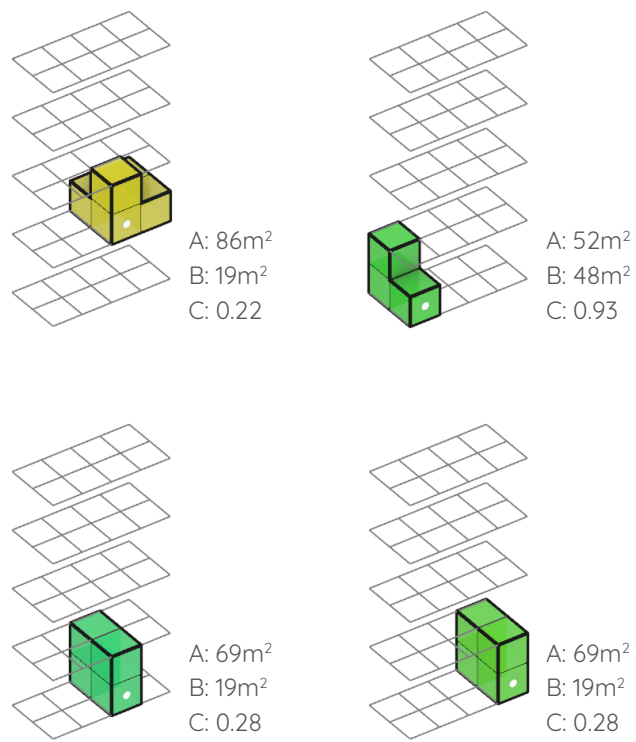

Possibilities of individual unit circulation 

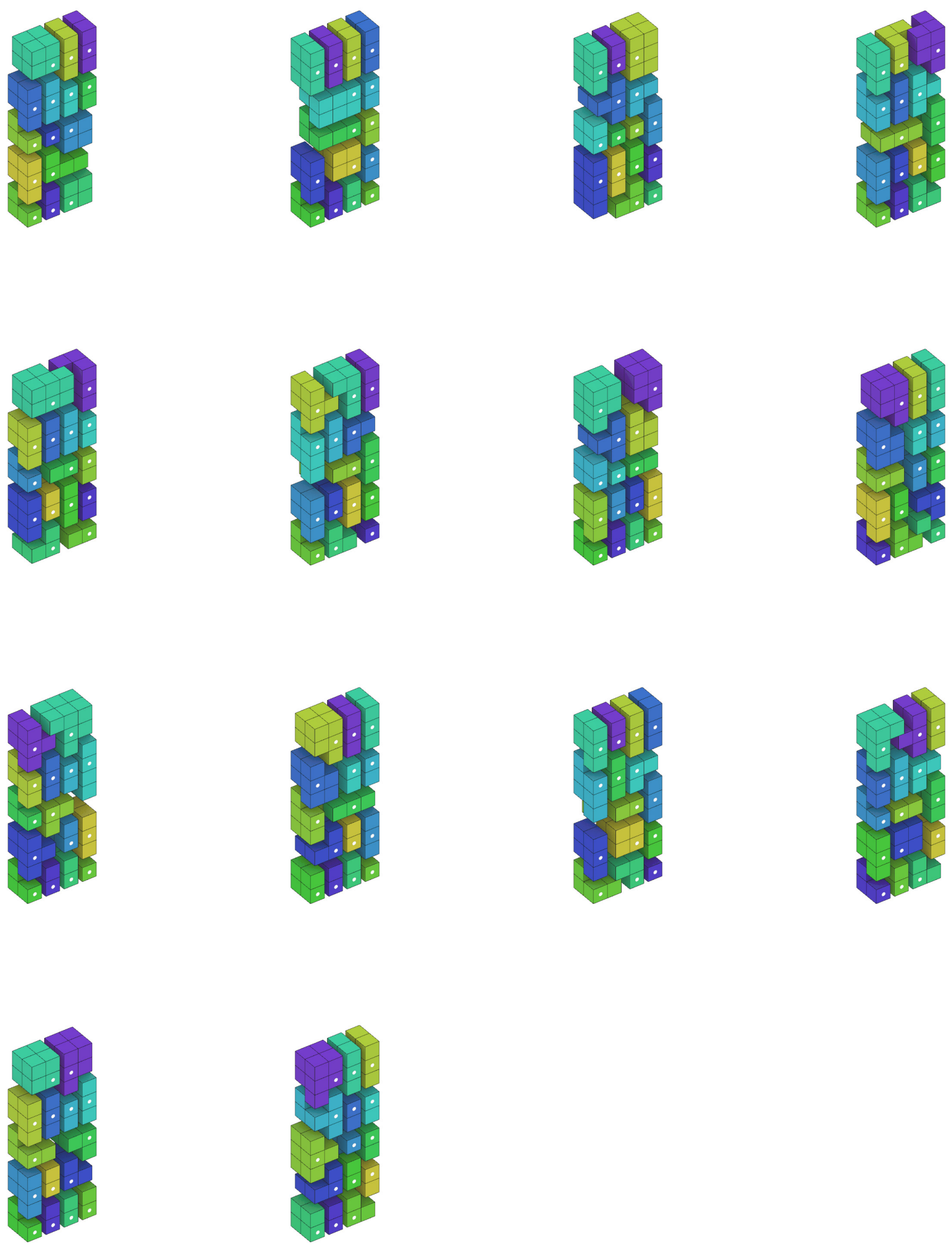

Figure No.5-16

Refined parametric system to treat the bulk of the vertically connected blocks as a single entity 


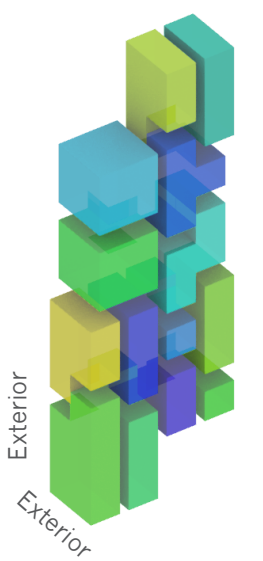

A: Unit area

B: Exterior wall area

C: Ratio of Exterior Wall over unit area

O Unit Entrance

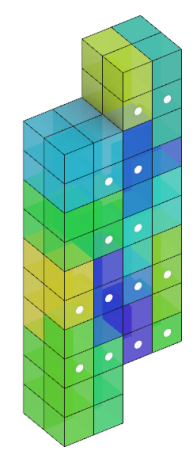

Simple customized massing studied for unit subdivisions

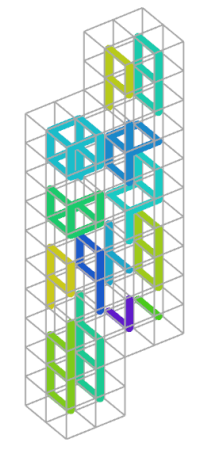

Possibilities of individual unit circulation
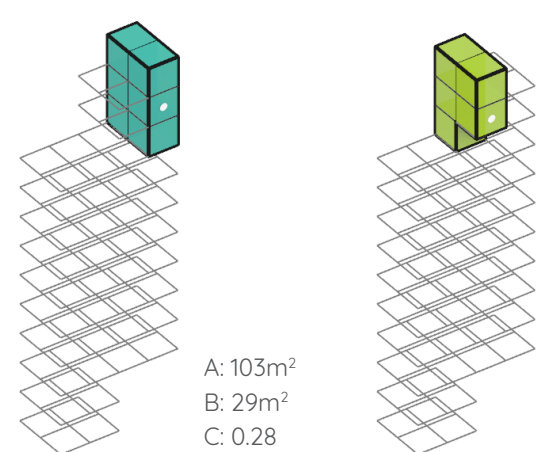

A: $138 \mathrm{~m}^{2}$

B: $77 \mathrm{~m}^{2}$

C: 0.56

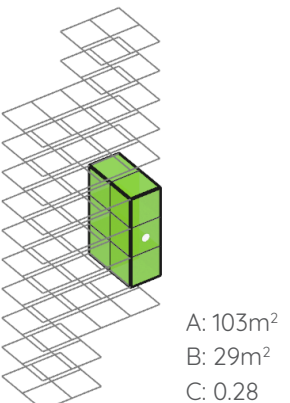

A: $86 \mathrm{~m}^{2}$

B: $77 \mathrm{~m}^{2}$

C: 0.89

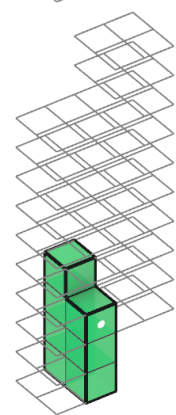

A: $120 \mathrm{~m}^{2}$

B: $38 \mathrm{~m}^{2}$

C: 0.32

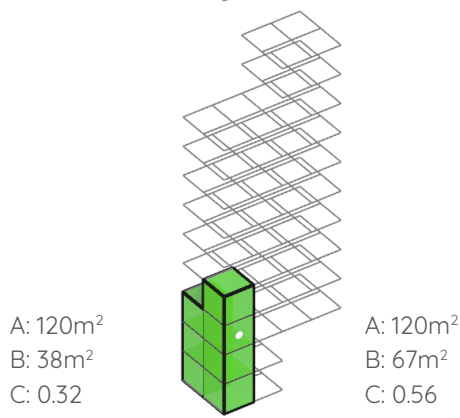

A: $120 \mathrm{~m}^{2}$

B: $29 \mathrm{~m}^{2}$

C: 0.24
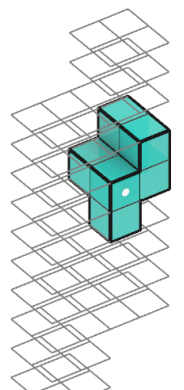

A: $120 \mathrm{~m}^{2}$

B: $29 m^{2}$

C: 0.24
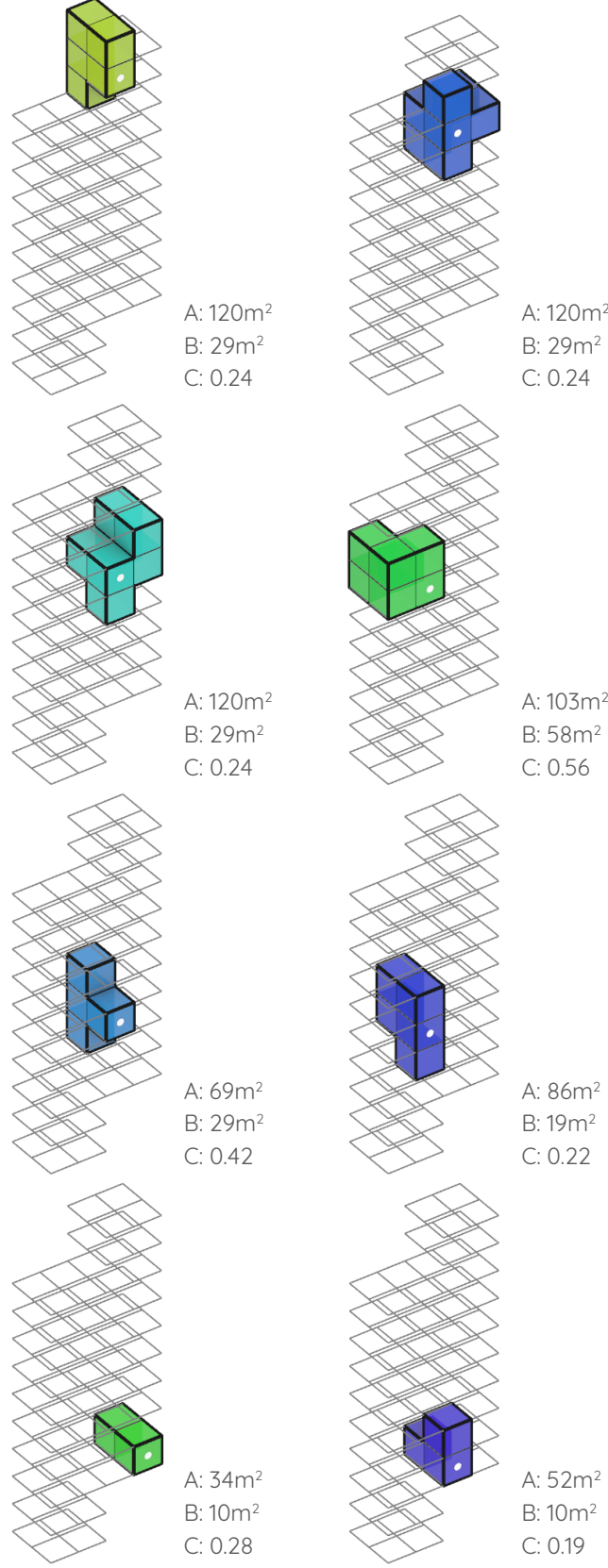

B: $10 \mathrm{~m}^{2}$

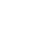



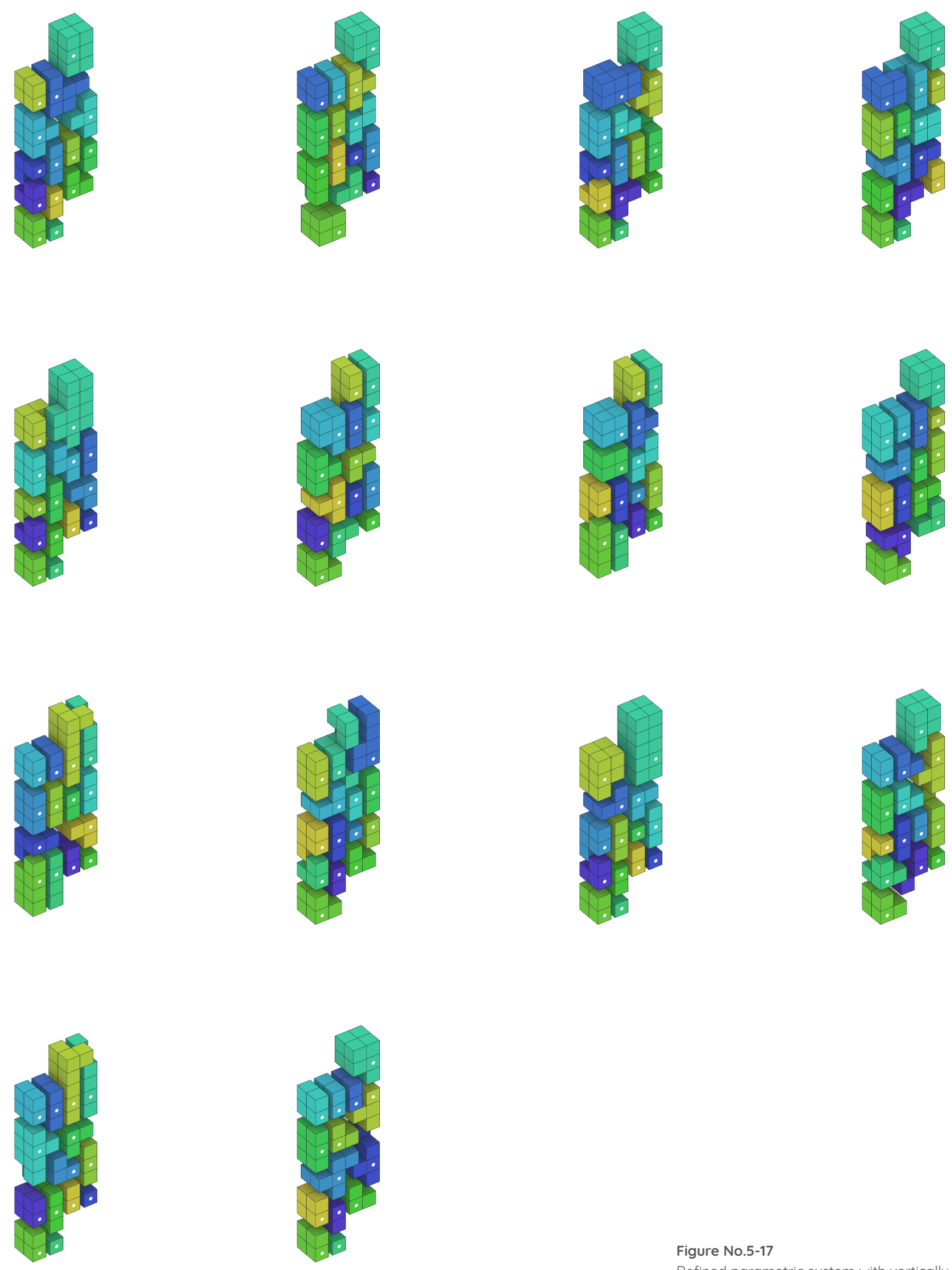

Figure No.5-17

Refined parametric system with vertically shifted massing 


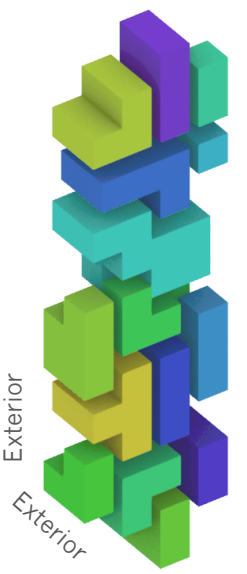

A: Unit area

B: Exterior wall area

C: Ratio of Exterior Wall over unit area

O Unit Entrance

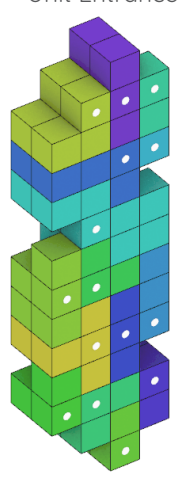

Higher complexity massing studied for unit subdivisions

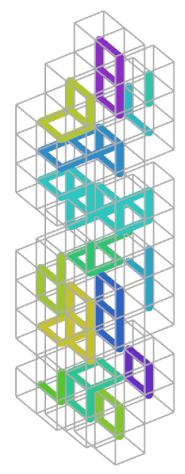

Possibilities of individual unit circulation

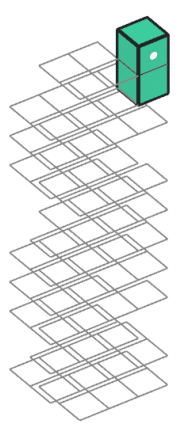

A: $34 m^{2}$

B: $19 m^{2}$

C: 0.56
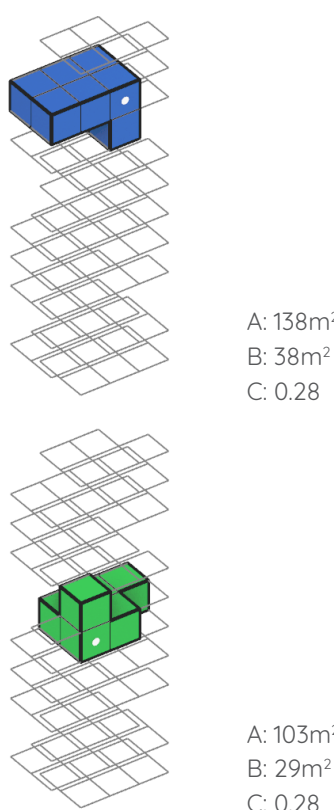

c: 0.28

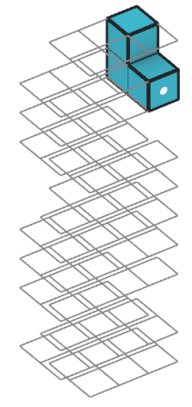

A: $103 m^{2}$

B: $29 m^{2}$

C: 0.28

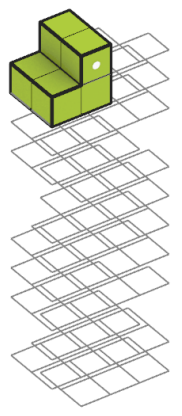

A: $103 m^{2}$

B: $48 m^{2}$

C: 0.47

A: $52 m^{2}$

B: $19 m^{2}$

C: 0.37

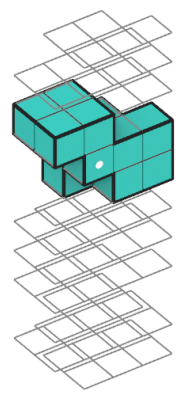

A: $241 \mathrm{~m}^{2}$

B: $67 \mathrm{~m}^{2}$

C: 0.28
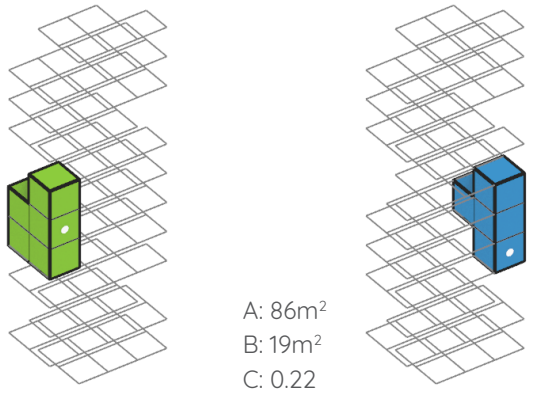

A: $69 m^{2}$

A: $86 \mathrm{~m}^{2}$

B: $19 m^{2}$

C: 0.22
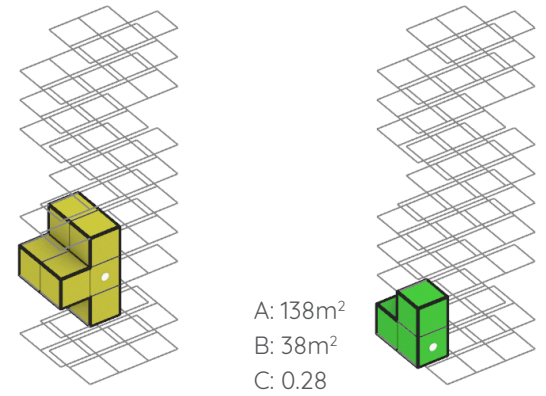

B: $19 \mathrm{~m}^{2}$
C: 0.28

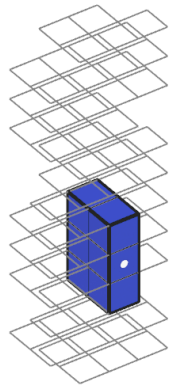

A: $103 m^{2}$

C: 0.28
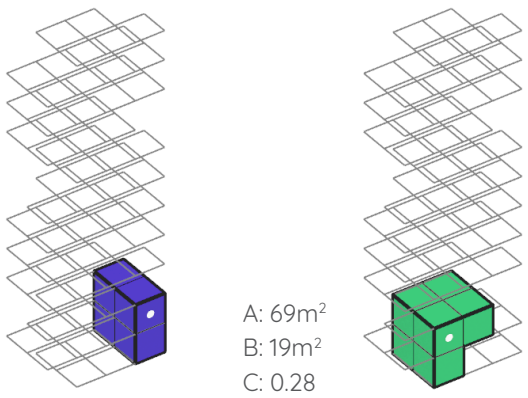

B: $19 \mathrm{~m}^{2}$

C: 0.28

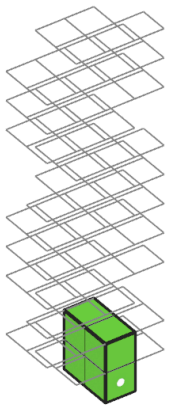

A: $69 \mathrm{~m}^{2}$

B: $19 \mathrm{~m}^{2}$

C: 0.28
A: $52 \mathrm{~m}^{2}$

B: $10 \mathrm{~m}^{2}$

C: 0.19 

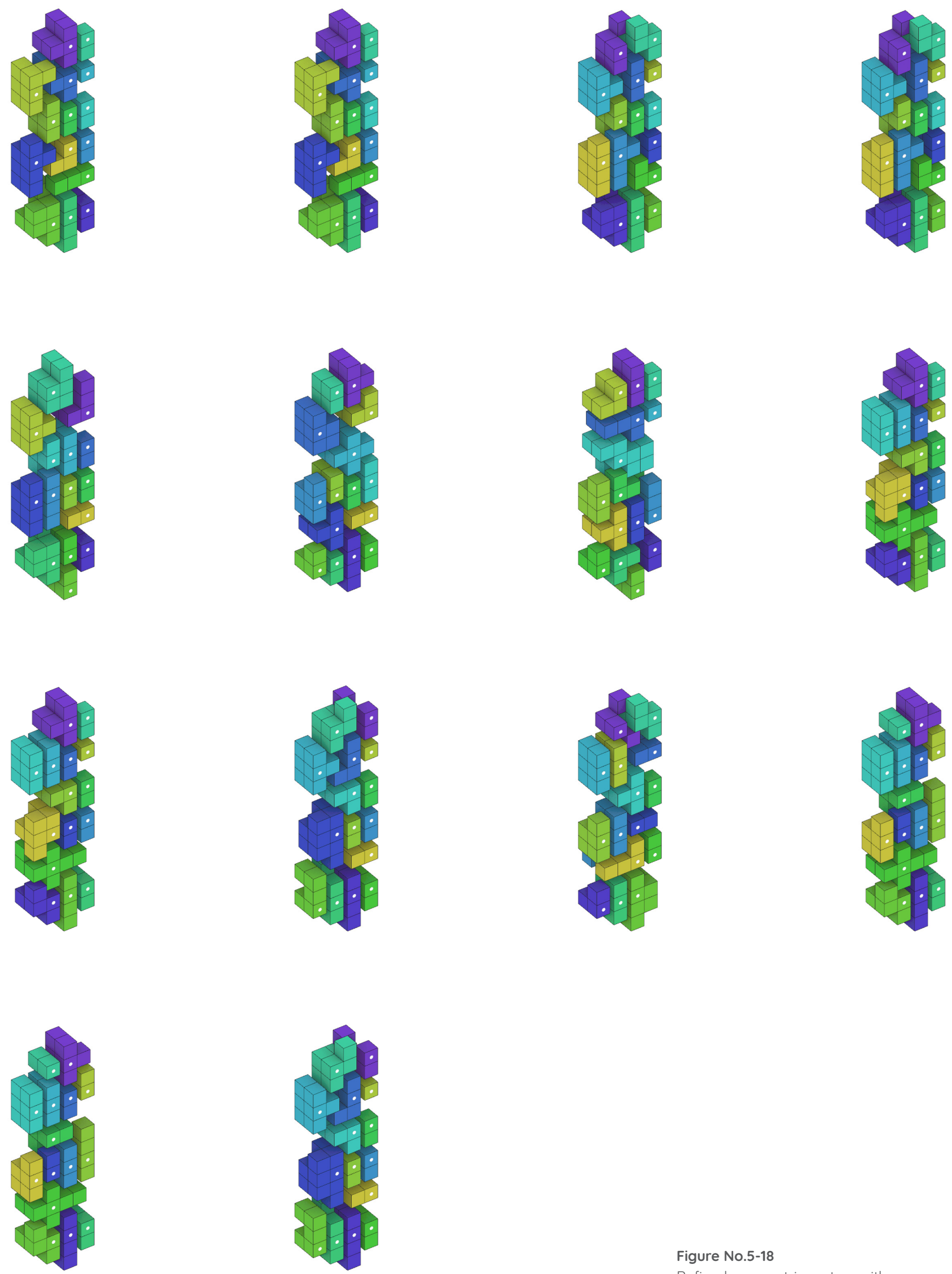

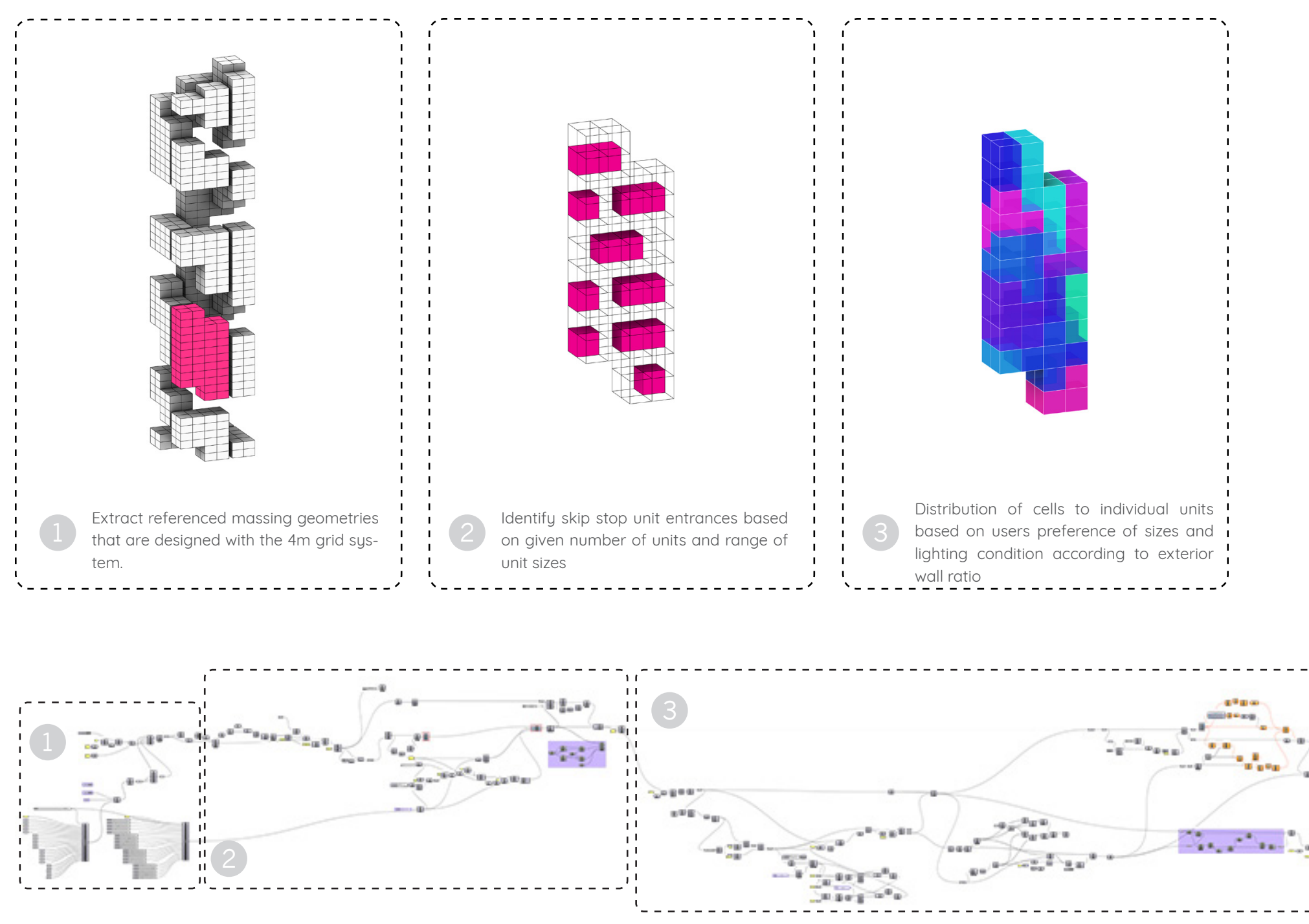

Figure No.5-19

Grasshopper script

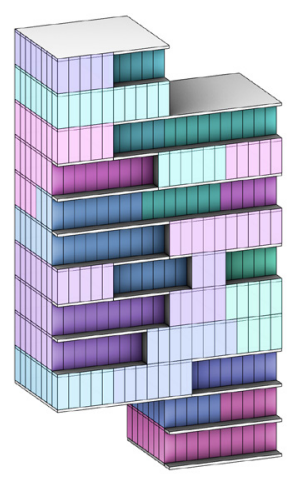

Using the mullion grid as a guideline for the Infill customization of balconies 


\section{Role of Algorithm}

The role of parametrics in this thesis is to provide a connection or platform that could help link the different project stakeholders together. Consequently, different project agendas would be supported and a broad knowledge base would be drawn upon to realize a successful high density residential project. Therefore, the algorithms are not neutral or autonomous artificial intelligence; the criteria are set by pre-defined data and decisions made by the architect. Even in the initial design phases, the algorithm is simply the execution of pre-established rules in a hierarchical order. The choices of having entrances at the mid-levels, ensuring a minimum ratio of 0.19 of the exterior wall over the total floor area (shown in Figure 5.16 to Figure 5-18), or keeping the cells of the apartment units closer together, are all pre-defined architectural decisions that ensure the fundamental living performance is sustained within the design. Therefore, the decisions and limits to customization are not made solely by the machines, but are guided by the architects' knowledge. It is critical for architects to discover ways for technology support, and even enhance our professional knowledge or thinking, and not vice versa. Although the technology is not yet advanced enough for the realization of a project of this complexity, this thesis does offer a potential direction for future use of parametrics technology that can be further investigated.

Prior to occupancy, the role of the algorithm is to help the residents to establish an Allocation Level space within the Support Level based on their requirements for volume, position, or natural light. Architects can also create prototypes for a range of unit types that can be customized per user scenarios, offering apartment design suggestions to the users of the Infill Level based on their individual needs. After occupancy, the role of the algorithm is to oversee the ongoing changes of Allocation and Infill Level, setting 
limits for each proposed change to happen without disturbance to the overall design and sustaining the living quality. For example, units would not be allowed to exceed a maximum area, and a minimum window-to-wall ratio is set for different room types. Therefore, a range of parameters can be used to sustain the design intention while deploying spatial changes in the Allocation Level. In addition, architects can offer individual customization of Infill Level after residency for those struggling to achieve a design solution based on the existing condition. As a result, the design variation is achieved through a combination of the architect's predefined algorithm and the architect's design or suggestions that are all driven by users' individual needs.

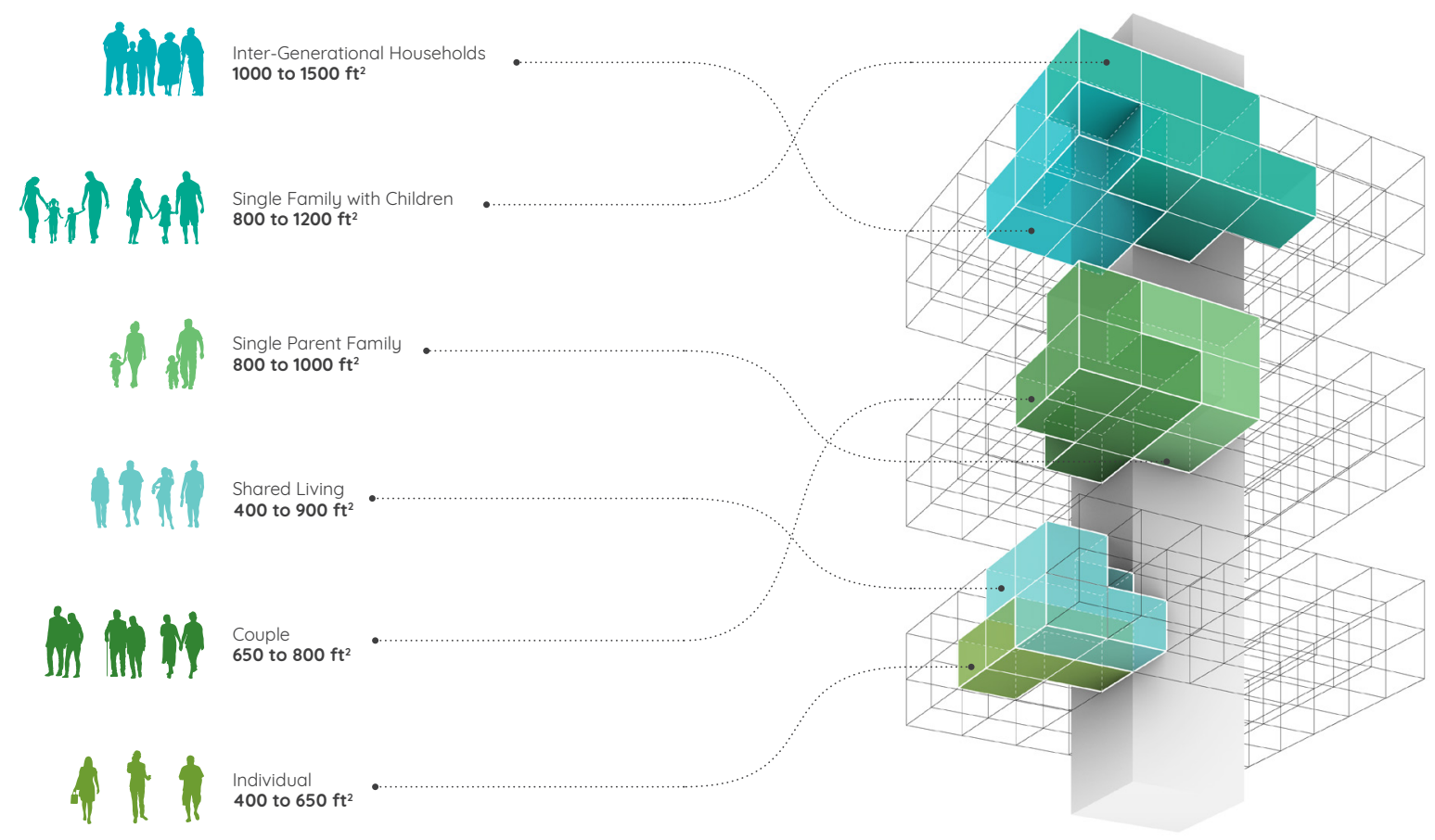




\section{6 | Unit Customization}

\section{Customization Through Neighbourhood Negotiation}

Contemporary high-density residential projects have compacted the living space of society and shortened the distance among residences. However, this denser living environment does not promote a healthier community - it tends to isolate individual households into their own personal spaces. This untouchable space boundary has created a strict physical separation between apartment units, reducing the chance for social cross-connection, causing segregation and isolation among households. Therefore, having a flexible Allocation Level enables residents to resolve the changes in their spatial needs over time and makes the community space an outcome of neighbourhood negotiation. Adopting a personalization culture in the design of high-rise residences not only provides convenience for individual users but can also facilitate interaction among the residents. In order to make changes that reflect changing individual needs, the users are required to communicate with their adjacent neighbours. This form of communication is essential to promote long-lasting relationships among the residents. Therefore, the community space is formed through neighbourhood negotiation. Healthier neighbourhood relations along with personalized individual spaces can promote a longer residency period for each individual household as well an enduring lifespan for a building. 

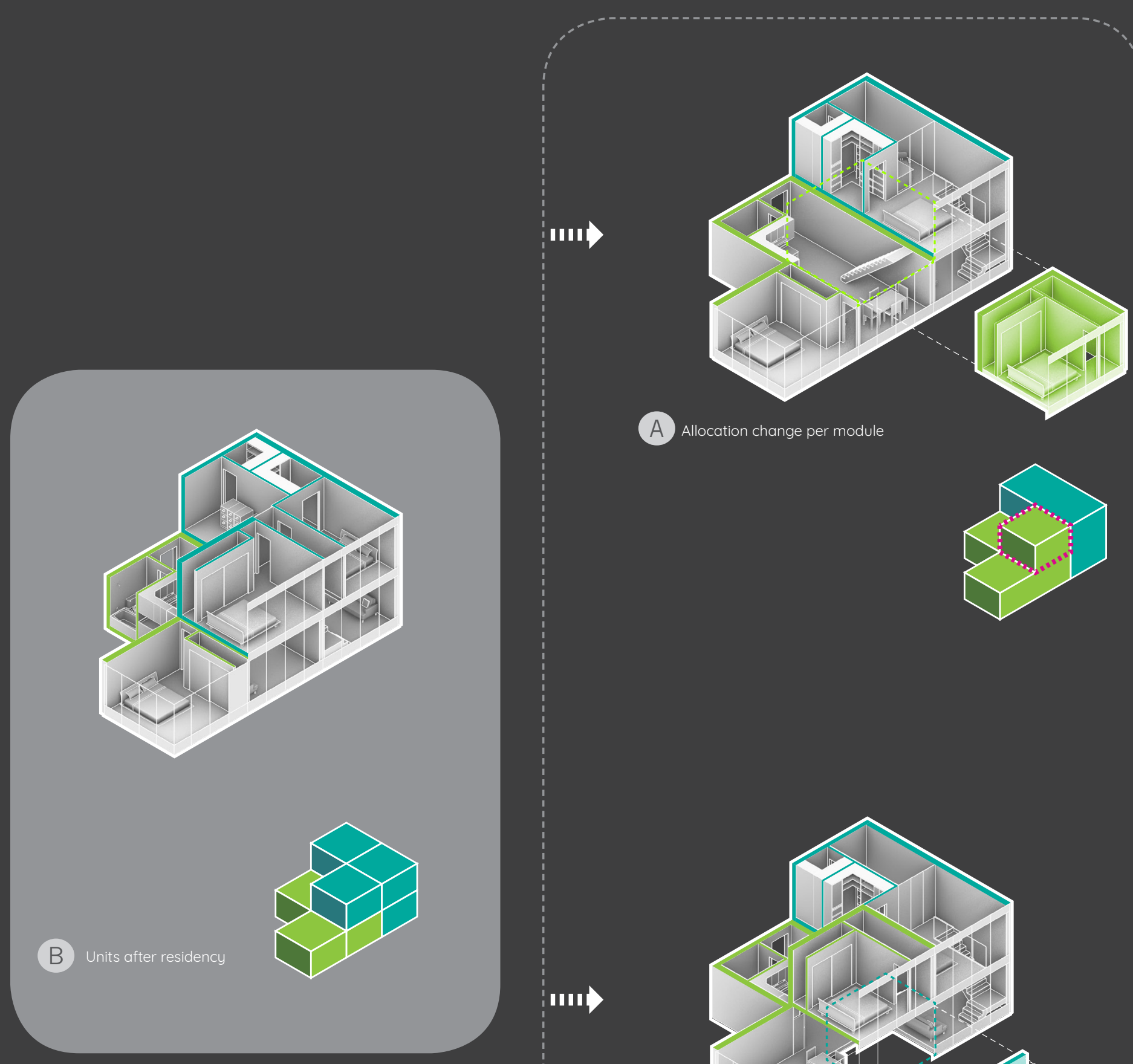

A Allocation change per module

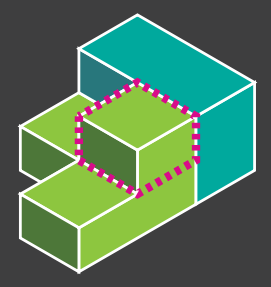


Three types of Allocation transformation are designed to respond to different scenarios shown in Figure 6-1. Unit boundaries are parametically assigned (Allocation Level) on the modular grid prior to initial occupation (Figure 6-1A). However, after residency, the unit boundary can be shifted by transferring an entire spatial module for large space arrangements, such as an additional bedroom with a closet or a den as office space, as shown in Figure 6-1B. For the case of smaller space transformation shown in Figure 6.1C, the neighbouring residents can negotiate to shift the demising wall increments of as little as a mullion space $(860 \mathrm{~mm})$. These changes can be used to increase the size of an existing room or the addition of a smaller size room, such as a storage closet or washroom.

Figure 6.2 is a typical real-life scenario that demonstrates the shifting of the unit boundaries through neighbourhood negotiation. The owner of the $32 \mathrm{~m}^{2}$ studio unit is a single young professional. The space was sufficient for him until he got married and his wife moved in. With a higher income support, the conventional choice is to search for a new home and relocate. However, Allocation Level unit customization allows him to look for possible Allocation changes within the block. He needs an additional bedroom and some office space. He took a look at the Allocation model and in-put his extra 

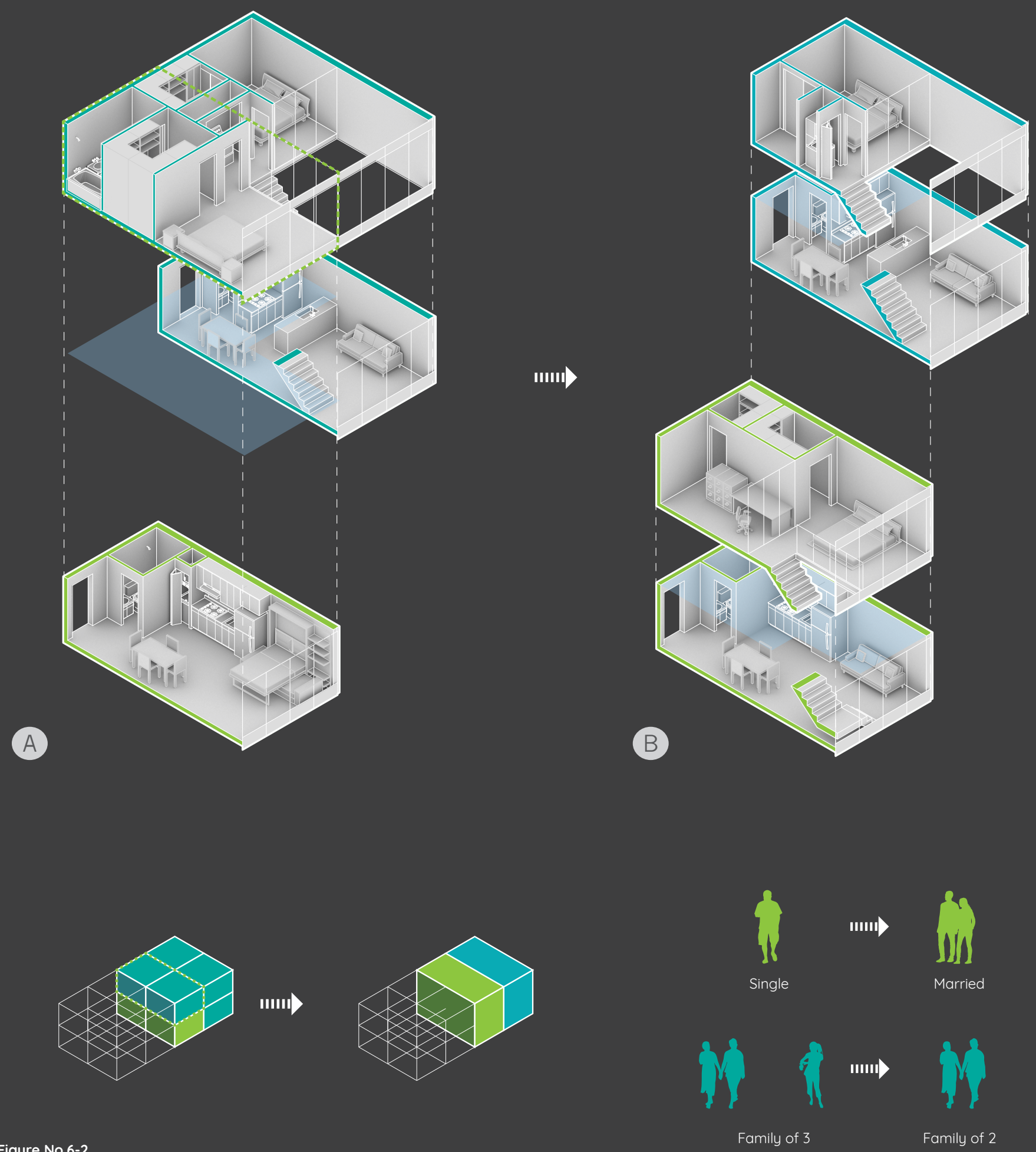

Figure No.6-2

Simulation for shifting of shifting of Allocation Level boundaries 
space needs. The model shows that some of his neighbours a have excessive space per their demographic profile; based on the spatial opportunities and program criteria, several apartment unit configurations were designed. This information forms the basis for neighbour-to-neighbour facilitated negotiation for space purchase or exchange. The newly-weds identified the most desirable Allocation Level change would be with their upstairs neighbour (Figure 6-2A) . After some negotiation, empty-nester couple (their daughter moved away for university) sold the two-cube space (Figure 6-2B). The newly-weds then transformed the one-bedroom and one-bathroom space into a bedroom plus den to fulfill their needs for living and working. The empty-nesters invested the income from the sale in their retirement fund, allowing them to remain in the neighbourhood they love and saving operating cost downsizing their apartment into a two-people living space. This example demonstrates how parametric techniques and reconceptualizing the high-rise residential model though Allocation Level flexibility to support changing space needs that occur with an increase or decrease in family size. This example demonstrates that the change of space demand can be resolved through negotiation with adjacent neighbours. In addition, this solution allows the resident to have a prolonged period of residency within the community.

Figure 6-3 is an example of unit transformation that creates shared space among units. A shared space can reduce the redundancy of sharable rooms between two or more units. For example, students, single residents or inter-generational families can share a kitchen, dining or living room by combining part of their individual space into a common space shared between two, formerly separate, apartment units. The shared space allows friends or family to live closer together without sacrificing too much individual privacy. 

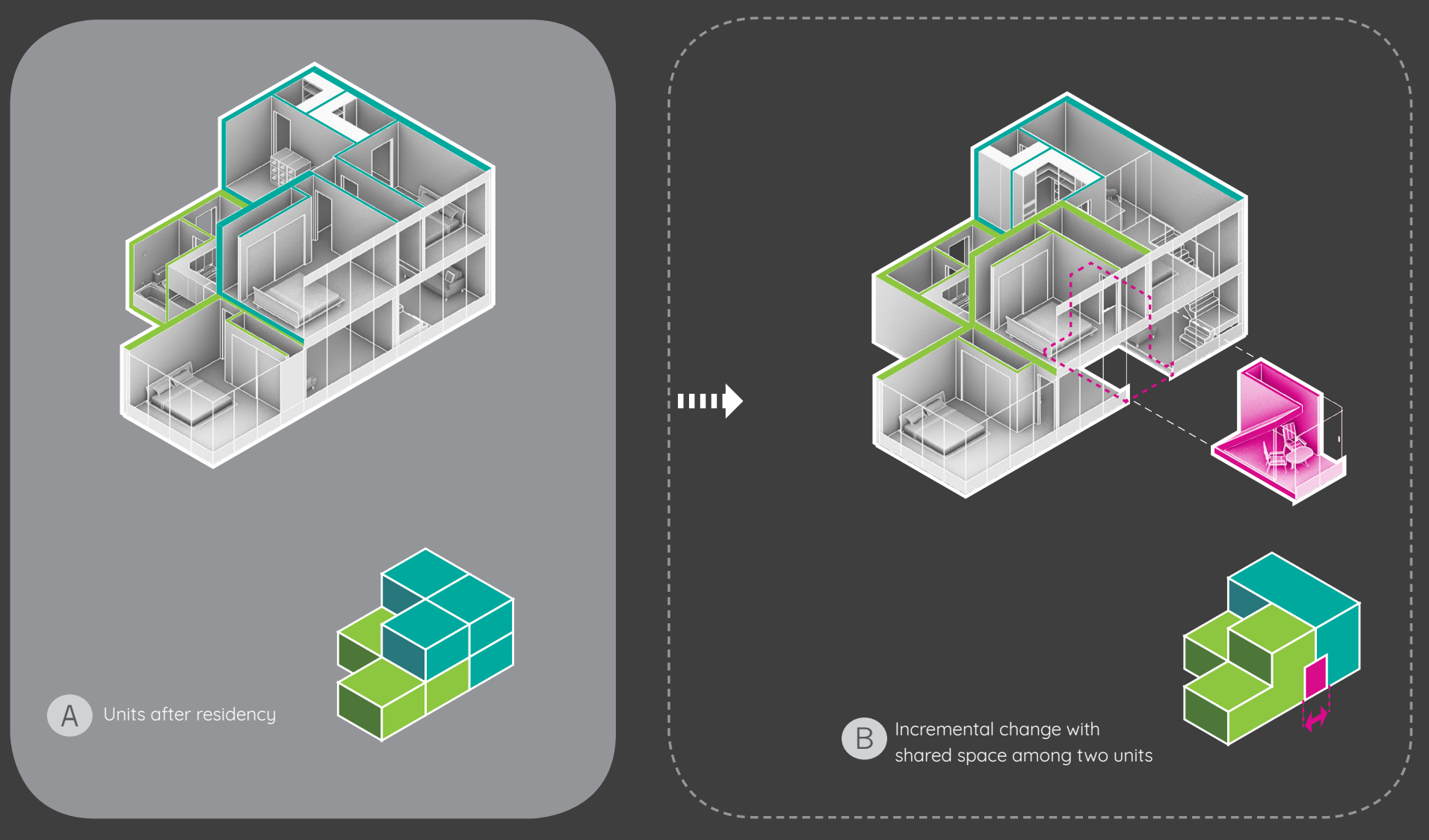

Figure No.6-3

Unit customization through sharing of space 
Figure 6.4 demonstrates the possibility of space sharing among student residents. This example shows that two students living in two small units have a reduced quality of life because of the necessary duplication of underutilized facilities such as kitchen, dining, and utility spaces (Figure 6.4A). Through negotiation, the two units can have a shared kitchen and transfer part of the kitchen and living room of one unit for an additional bedroom to accommodate a third student (Figure 6-4B). Space can also be shared among a single, extended family. Figure 6.5 shows the benefit that shared space can provide for multi-generational families. Contemporary high density residential design is typically limited to generic features and apartment unit sizes, from a studio to a three-bedroom. Therefore, a multi-generational family can only live separately in two nearby apartment units. However, shared space allows the two units to combine their kitchen and living room for common activities between the family members. This shared space can promote intimacy within the larger family but also offers an appropriate degree of privacy for each of the family's sub-groups through differentiation of private public use zoning within the apartment unit. 

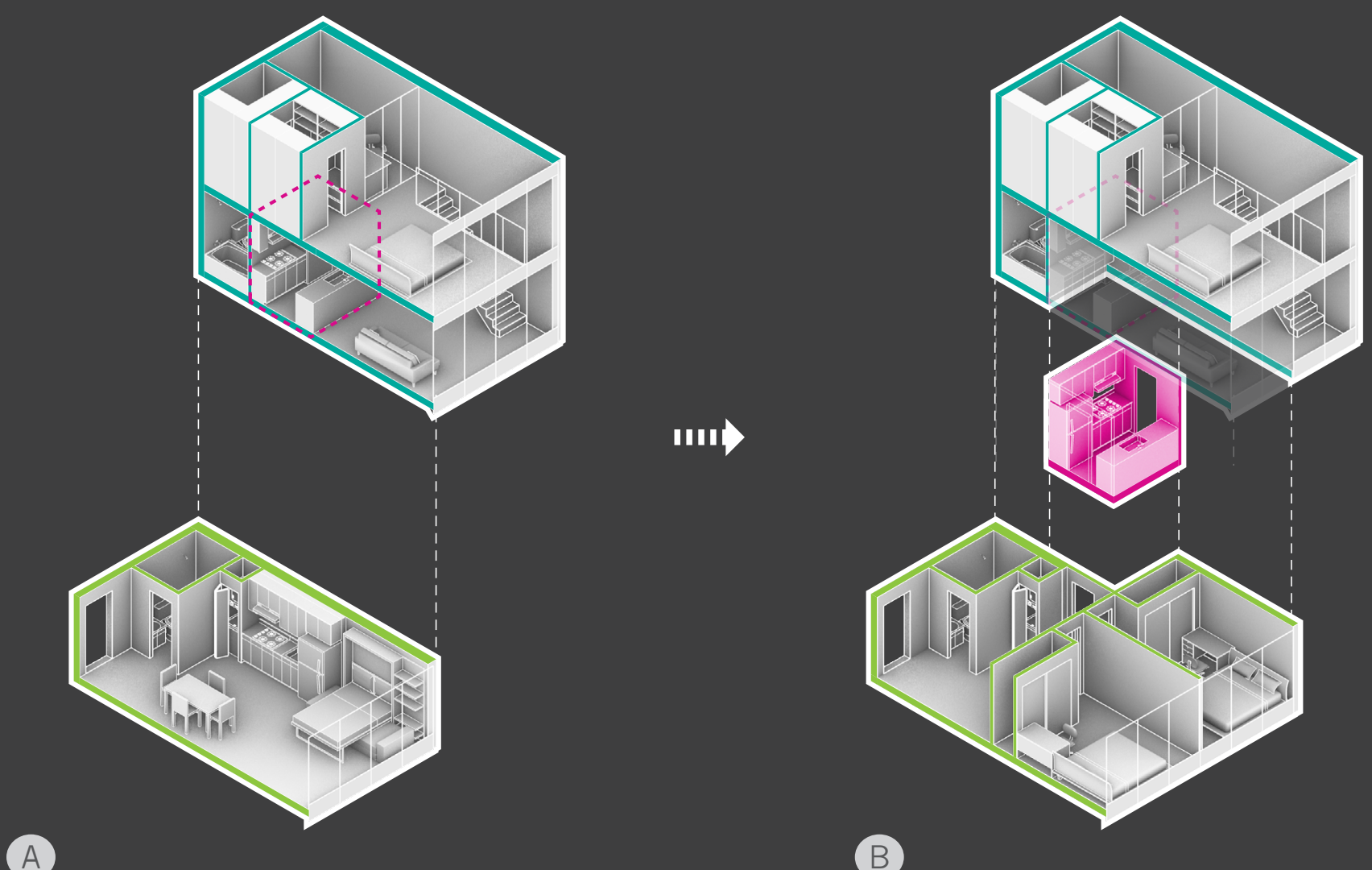

A
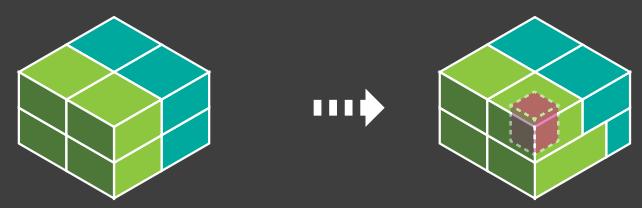

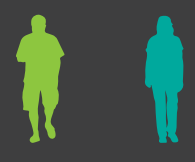

2 Students

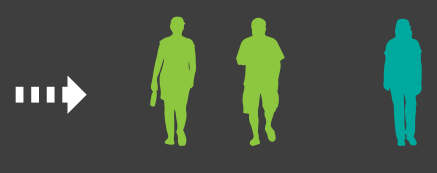

3 Students 
The mass production mindset has treated residential units in high-density residential projects as mass-produced commodities, with no interest or ability to respond to residents' individual needs or desires. The units are not designed to withstand users' change of needs, offer options for customization, and fail to support the development of long-lasting relationships among the residents for a stable and healthy community. The apartment unit is seen as a commodity which is only defined by measurable features (GFA, number of bedrooms and bathrooms) but is otherwise anonymous and fixed. With no flexibility in the mode of occupancy, the high-density residential typology is seen by many as transient and many units are resold within a short time period as individual life situations change. Allocation Level changes may not be able to offer all scenarios of spatial demand; however, it does offer a bigger range of possibilities when changes happen. It allows the community members to act as a collective group to resolve their issues. Consequently, a dense living environment could transform from a device that isolates and anonymizes individuals into a catalyst for a community. 

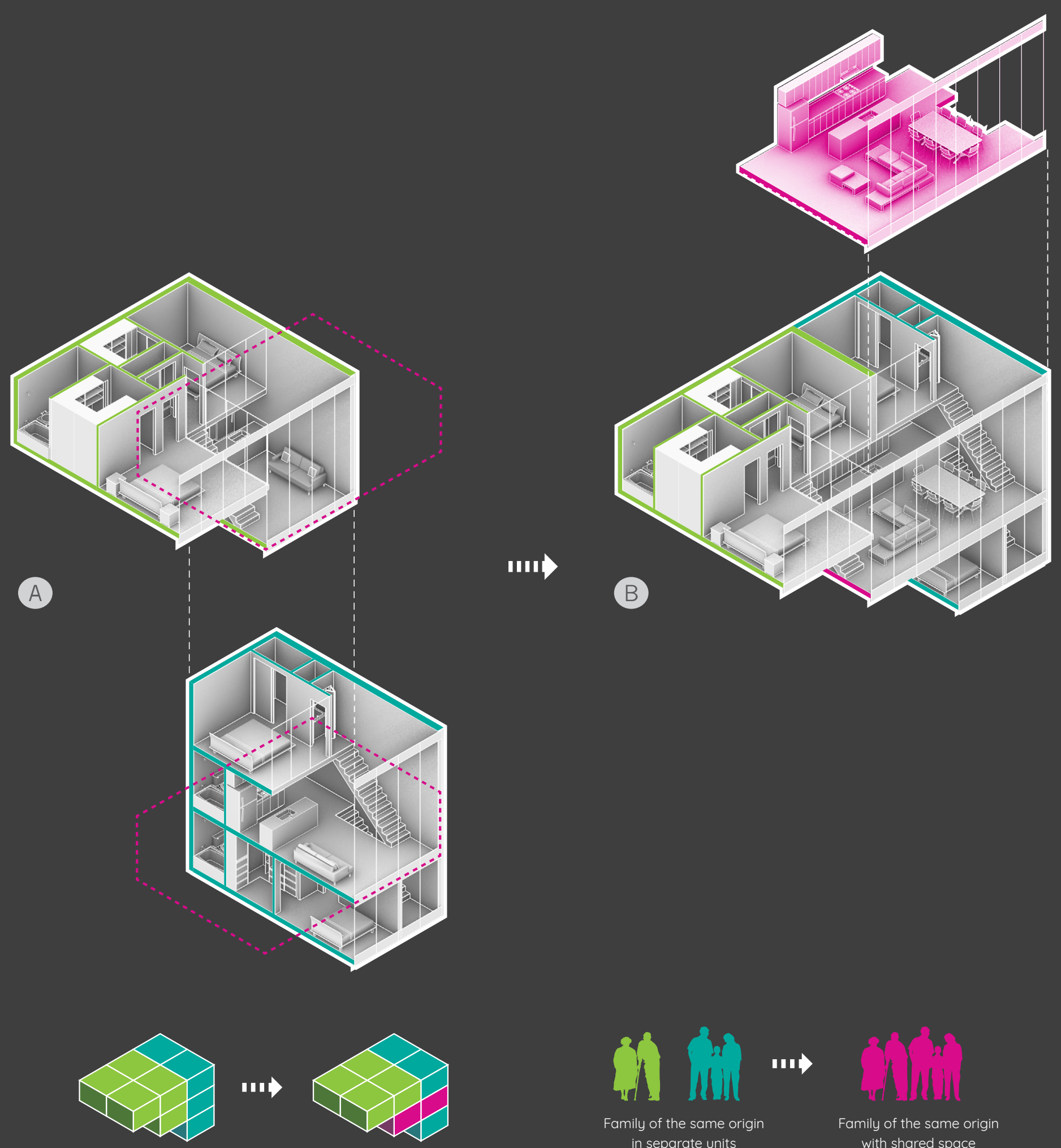

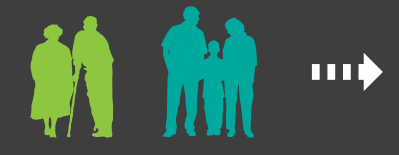

Family of the same origin in separate units

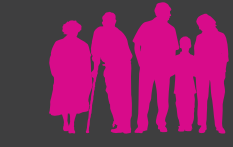

Family of the same origin with shared space 


\section{Infill Customization}

The Infill customization of residential units is not architectural fiction but has been an ongoing development of the Open Building initiatives over several decades. Different Open Building projects are built with various degrees of customization limits. Twenty-six case studies were discussed in the book Residential Open Building by Stephen Kendall, which span from 1966 to 1998 (Kendall \& Teicher, 2000). These case studies show the possibility of deploying flexible Infill and Allocation Levels in residential design that can be supported by the existing housing market. In comparison to traditional residential high-density residential buildings, most Open Building projects are built with a higher initial cost for additional capacity of Infill customization. However, this higher initial cost can be offset by its long-term social benefit and higher adaptivity for future renovation. Freehold Open Building projects are often bought with a base building cost from developers at a unit cost per square footage. Then the owners would pay an additional cost for the Infill construction (Kendall \& Teicher, 2000).

The same approach can be used for the shifting Allocation Level by transferring part of the units to the adjacent neighbour at a per unit area market cost. The additional value of shared space can also be calculated using a ratio of the contributed space over the total shared area. New systems have been developed to support leasehold tenancy of Open Building units. Buyrent was initiated in the Netherlands for renters to lease the base building space and have complete control of the Infill through a subscription to an organization (Kendall \& Teicher, 2000, p.230). These programs often have a higher initial cost, but the price can be compensated through a lower tenant turnover rate (Kendall \& Teicher, 2000, p.231). Renters can have an enduring relationship with their rented space through a personalized Infill Level. Consequently, flexible Infill and Allocation can 
be implemented into the current market of high-density residential development with new regulations and financial programs that can benefit both property owners and leasehold occupants.
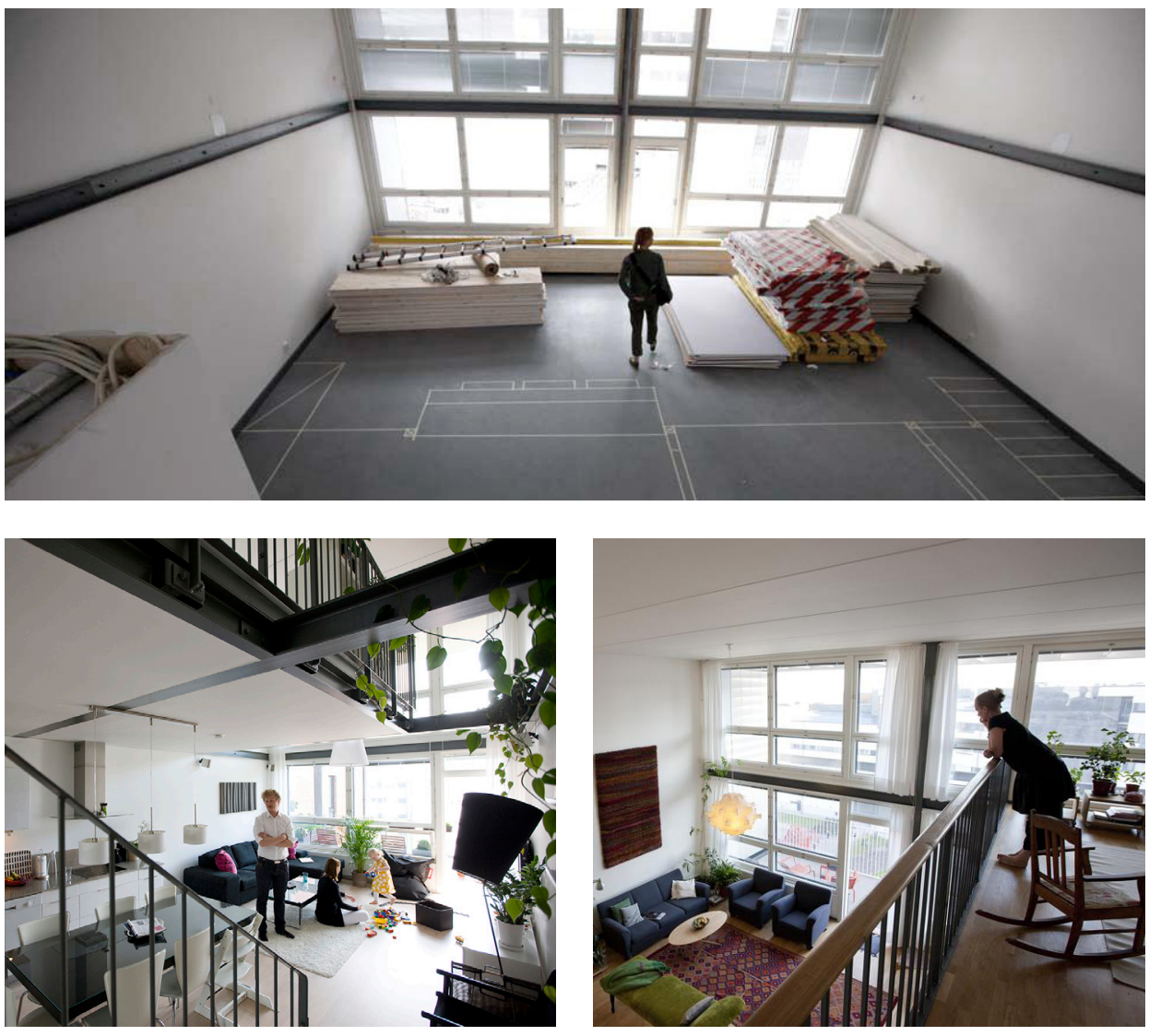

Figure No.6-6

Tila Housing Project by Talli Architecture, 2010, Helsinki, Example of Open Building project. Image showing in progress construction of Infill Level

Figure No.6-7

Tila Housing Project by Talli Architecture, 2010, Helsinki, Two images of different design options for the Infill Level 


\section{Facade Customization}

The facade customization system is designed as a extension of the parametric Façade Exploration (see p.51-52). Parametrics can be deployed to create a systematic participatory design platform that could include users performance variability (changing spatial needs) as one of the driving factors of design. Performance variables is often achieved through significant customization of parts and would require additional work to install. The goal for the design of this facade system is to offer users customization without compromising constructibility.

Therefore, a window wall system is adopted to allow installation from the inside. A mullion grid of $860 \mathrm{~mm}$ is adopted for the overall design. Two half sized $430 \mathrm{~mm}$ panels can also be combined for finetuning of window size. Consequently, the façade system is designed to maintain visual coherence and deliver customization options for the users to swap and change.

The three different panel systems provide the users flexibility

of choices between lighting conditions, visual privacy and furniture layouts. Spaces like bedrooms and offices do not require a fully glazed curtain wall, which could be partially enclosed for better thermal performance.

There is also the flexibility of choices between the interior space versus the exterior balcony. Various lengths and locations of balconies can be chosen based on user preferences. 

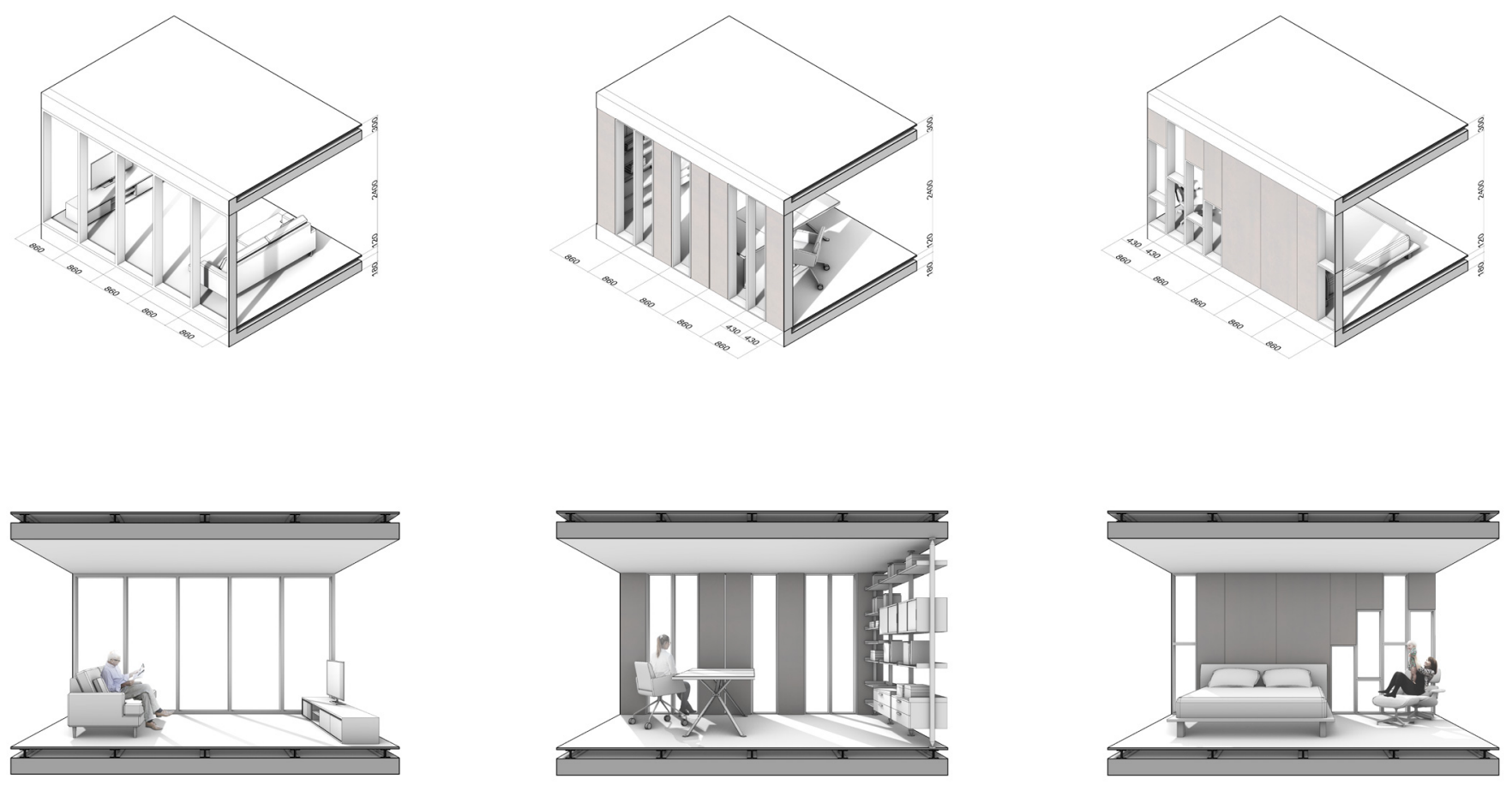

Figure No.6-8

Three types of facade panel systems
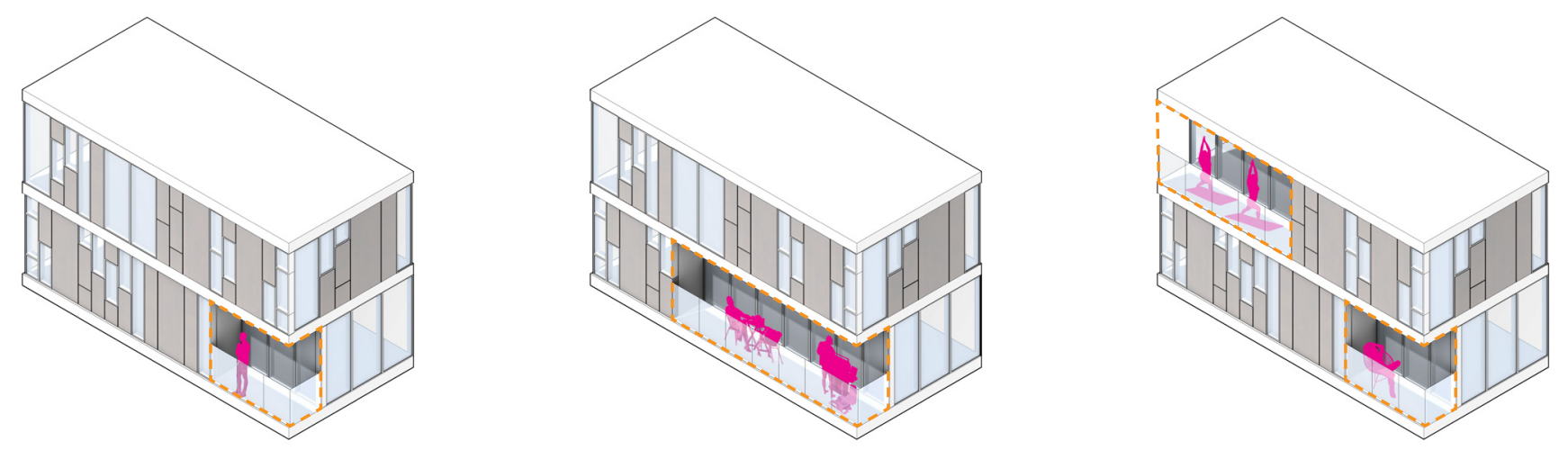

Figure No.6-9

Balcony customization based on user preferences 


\section{7 | Design Study of Support Level}

The Support Level is defined as "the permanent, shared part of a building which provides serviced space for occupancy" in the Residential Open Building initiative (Kendall \& Teicher, 2000, p.32). This definition reveals a relatively permanent characteristic of the Support Level, which is mostly designed or planned by the architect. However, in addition to the building service elements such as structure, mechanical and electrical services, as well as corridors, elevators, and emergency exit systems, the Support Level determines the overall quality of the living environment. Therefore, the role of the support should not be limited to merely engineering components of service spaces but should be driven by architectural design intentions for an active neighbourhood relation, as well as the community's function to incentivize public interaction. With this objective in mind, the design study of the Support Level includes mixed-use planning that intertwines residential space and public space. This concept has then developed into the Vertical Community for the following chapter (see Chapter 8).

\section{Core and Floor Plate Study}

Two typologies of residential core and corridor were studied for the design of the Vertical Community. The first type shown in Figure 7.1 is a centre core design that condenses all the vertical circulation, means of egress, and services in the middle of the building and apartment units are distributed around the core in a radial format. This centre core design is typical of point tower highdensity residential buildings to achieve highly efficient space layouts (Bielefeld 2016, p.198-199). The second type shown in Figure 7.2 is a long corridor design with dispersed exit stairs, elevators, and mechanical services along the corridor. This type of design can mostly be found in mid-rise residential buildings with a linear, spine- 

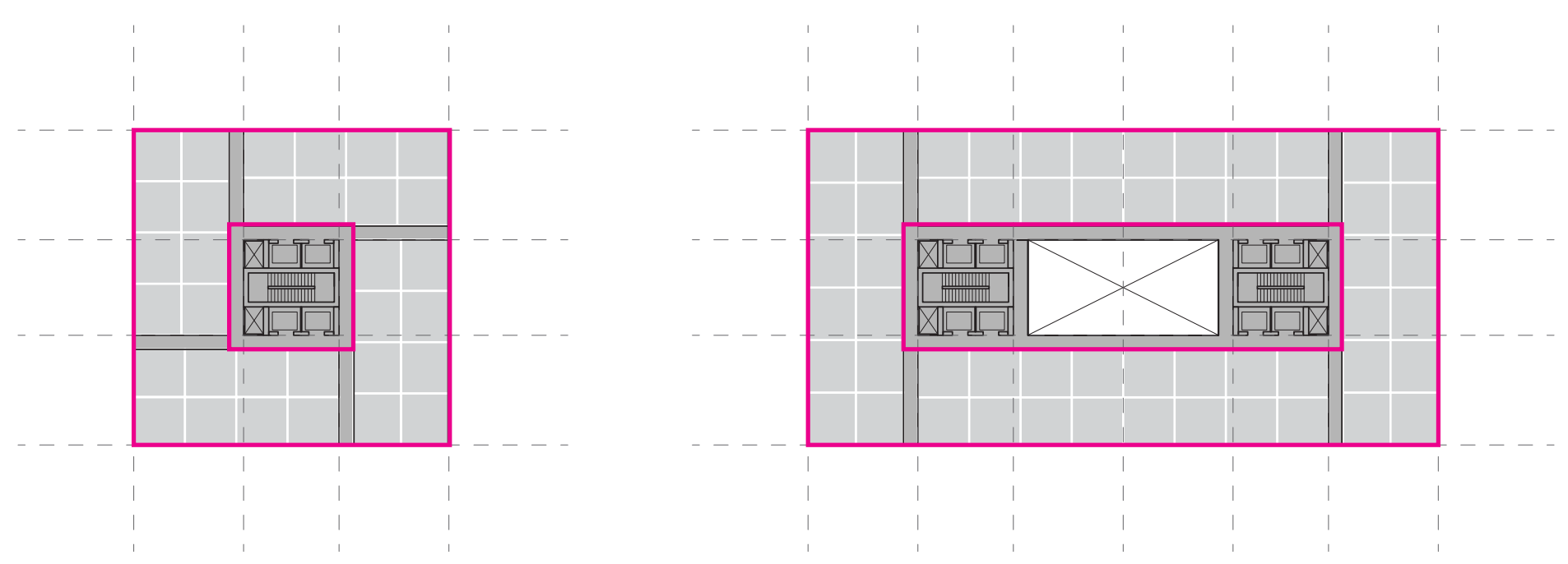

Figure No.7-1

Single and double centre core design with block massing. Detail information of the floor-plate is elaborated in the Figure No.7-9. 
and-fingers, or courtyard massing (Bielefeld, 2016, p.199.201). The goal for the design of the Vertical Community is to establish an interconnected community with various sizes of residential units, small to large commercial spaces, and large public spaces. Therefore, one of the key requirements for the choice of core and corridor is to provide flexibility and continuity in space arrangement. The long corridor design with scattered vertical circulation and means of egress would lead to a discontinuity of programmable space caused by the separation of elevator and exit stairs. As shown in Figure 7.2, three programmable spaces are being chopped off by the two main elevator shafts and the centre corridor; therefore, larger social programs can only be added in three of the six regions for a continuous uninterrupted space. Since both core and corridor typologies are based on the layout of residential units, the depth of the units would determine the maximum width of the larger social space; hence the maximum size social space would be highly similar in both typologies. In contrast, the centre core design provides an unrestricted programmable space around the periphery of the core, which offers a higher degree of flexibility for both the commercial space as well as the larger social space. 


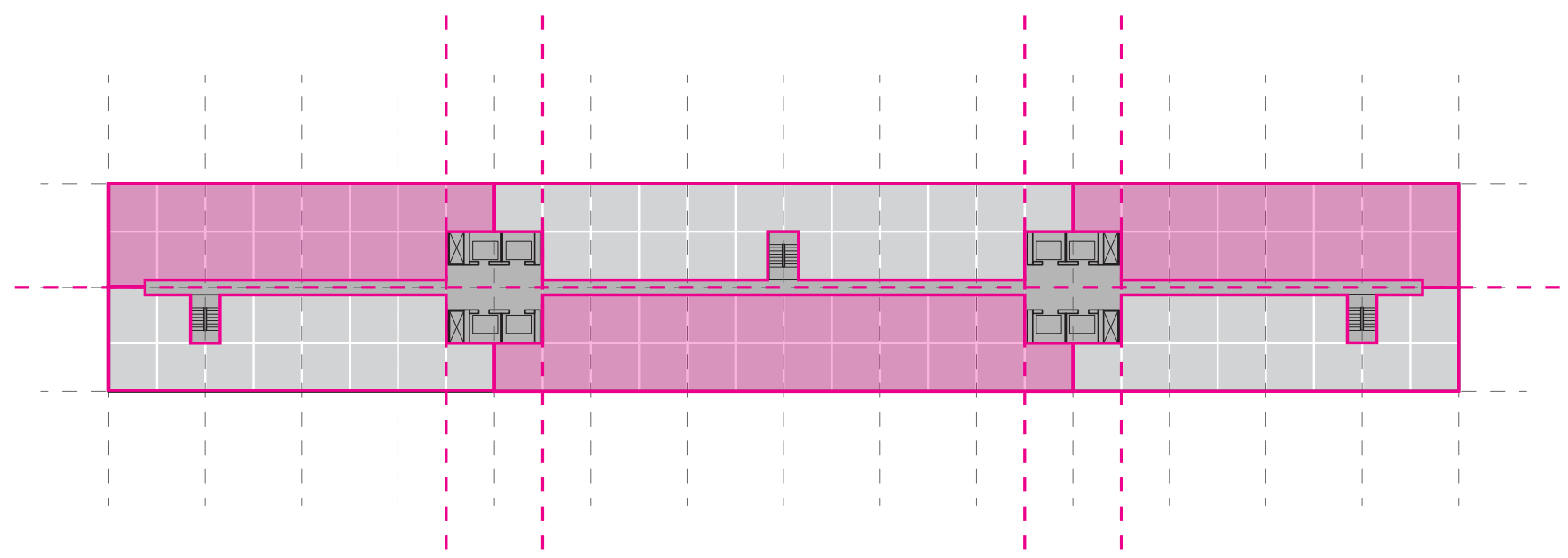

Figure No.7-2

Linear corridor design with scattered vertical

circulation and means of egress 

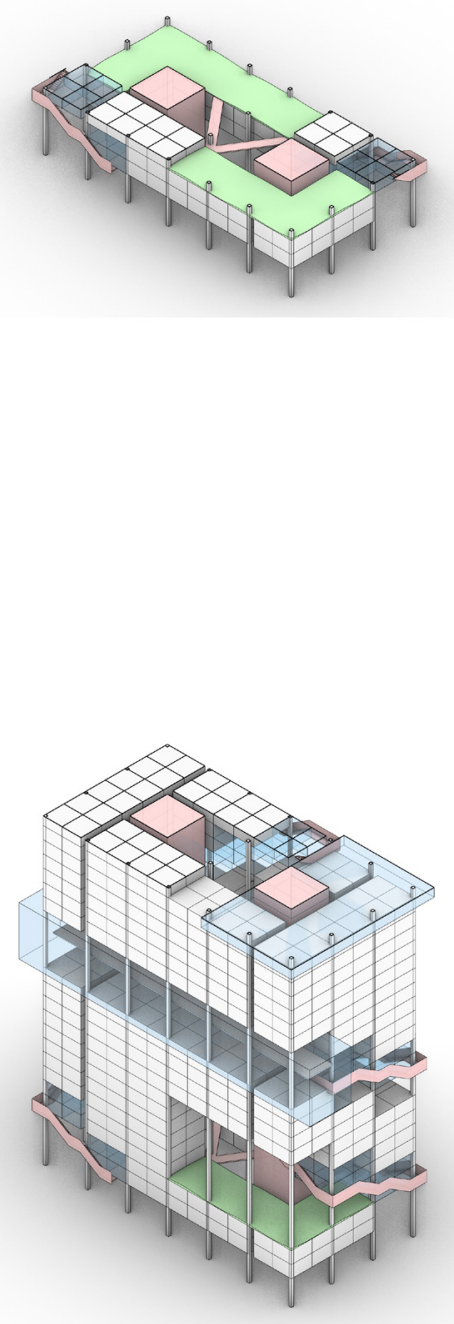

Circulation

Residential
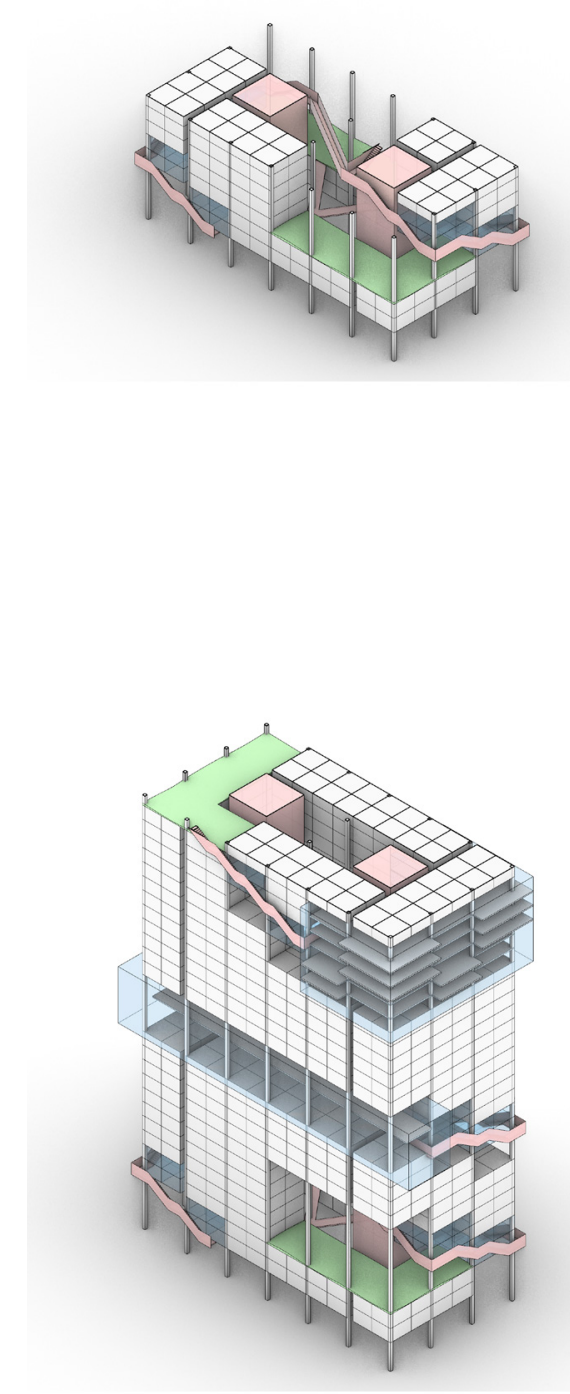

Commercial or Social Space

Urban Park

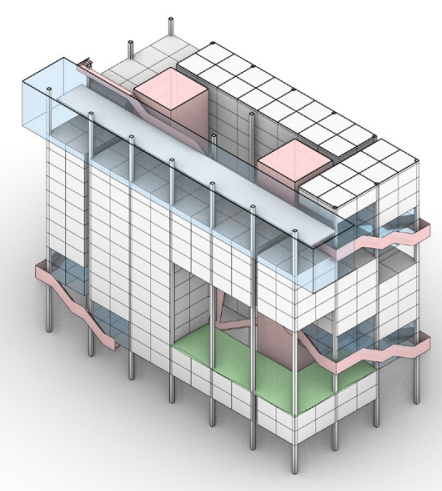

Figure No.7-3

Axonometric sectional plan showing relation of programs and circulation 


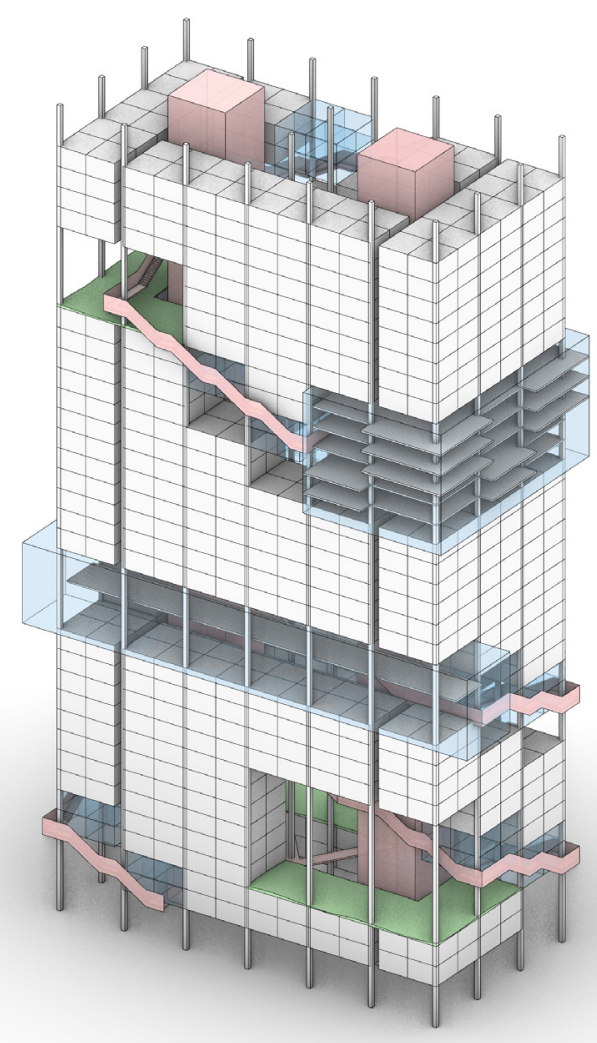

Figure No.7-4

Vertical Community design option of with double centre core

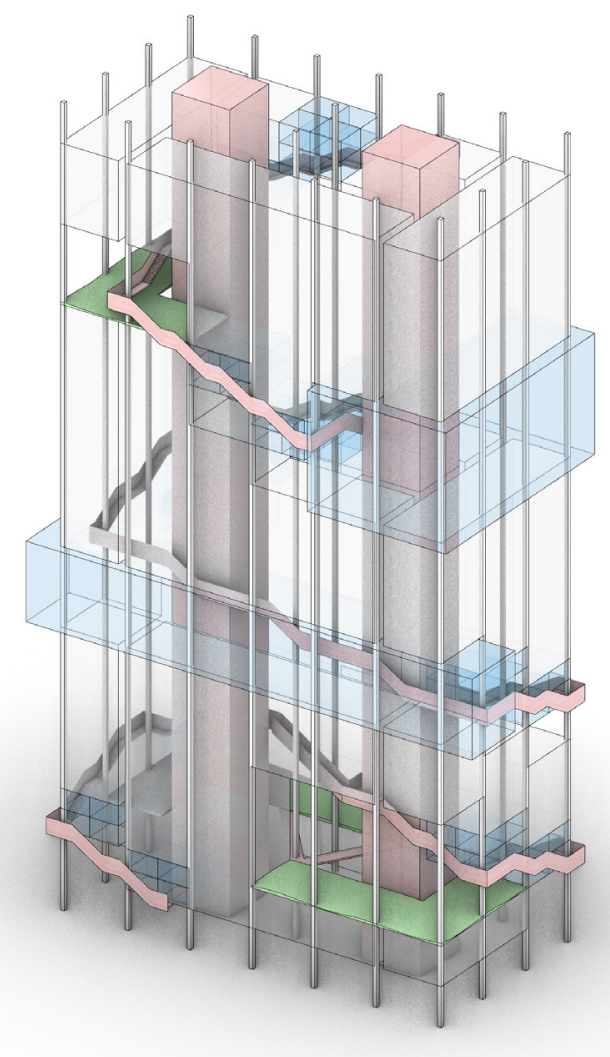

Figure No.7-5

Vertical circulation of double core design with twin helix exterior stairways at the lower levels 

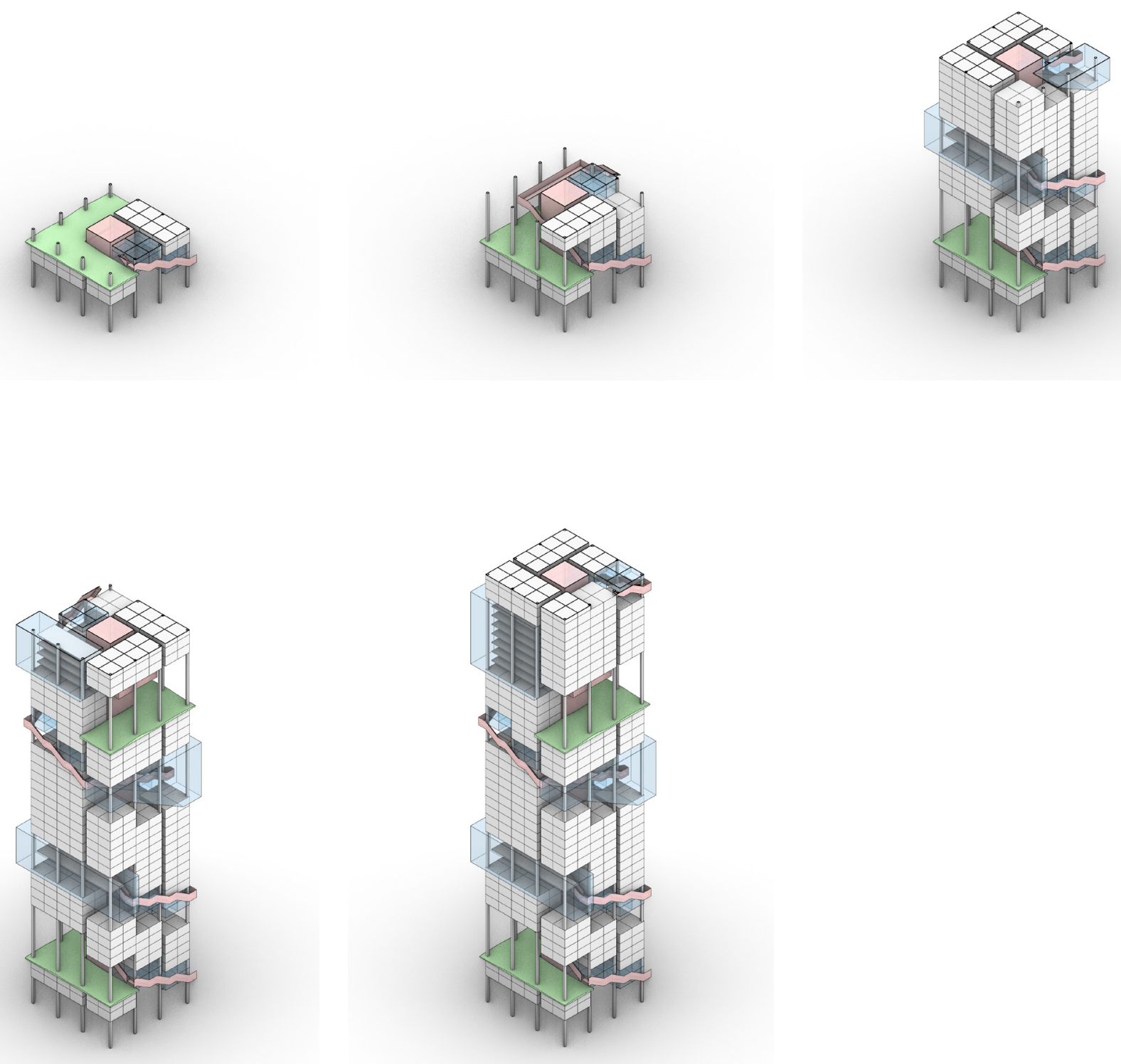

Circulation

Residential
Commercial or Social Space

Urban Park
Figure No.7-6

Axonometric sectional plan showing relation of programs and circulation 


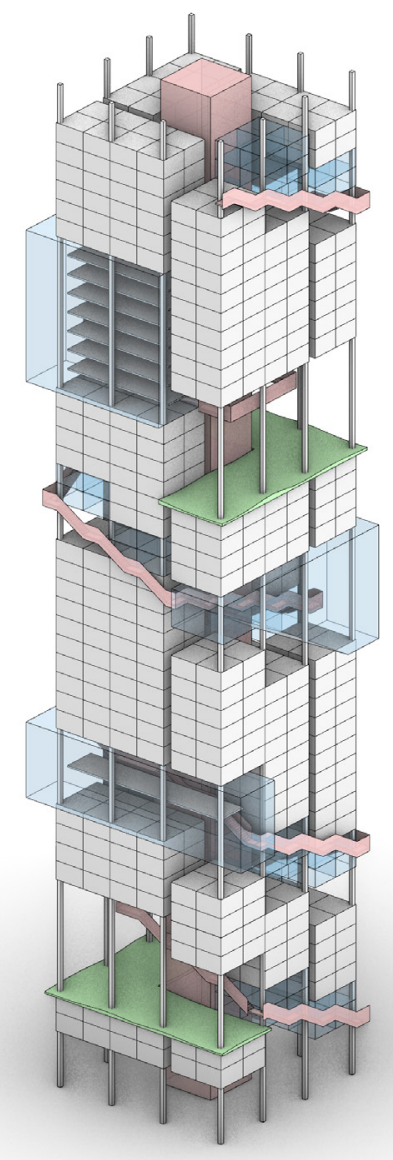

Figure No.7-7

Vertical Community design option of with single centre core

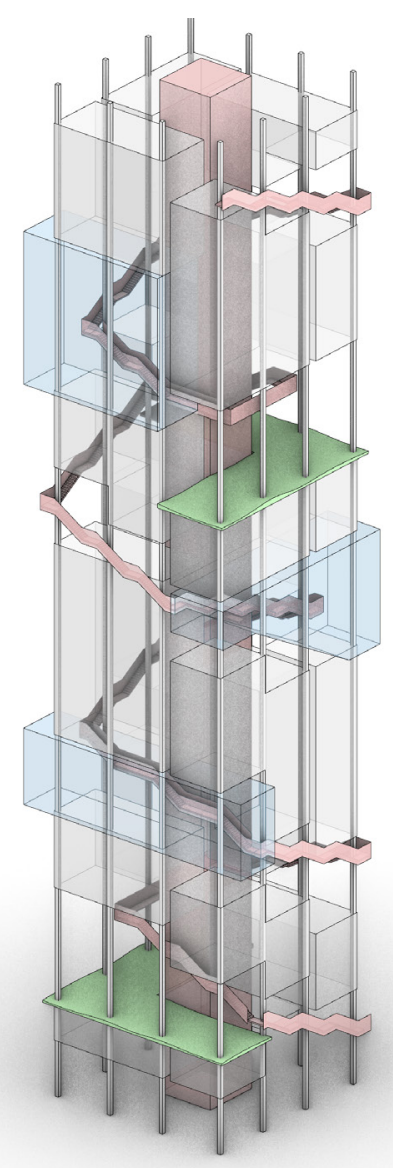

Figure No.7-8

Vertical circulation of single core design with single helix stairway 


\section{Support Level Design}

A logical design of the Support Level can offer a higher degree of flexibility in customization of Allocation and Infill Levels. The choice of the centre core design allows the majority of the structure and services to be located either close to the core or near the edges of the floor plates, thereby creating an unconstrained space between the corridor and the building façade and allowing the Infill Level partition walls or the Allocation Level demising walls to shift without interference. Service shafts are positioned between every two grid cells along the corridor wall for apartment unit access to domestic water and sanitary services. This position of service shafts also pushes rooms that do not require access to daylight, such as a washroom or kitchen further away from the building façade, which ensures that the bedroom, living room and dining room have access to daylight.

The single centre core design was further developed for the final design of this thesis, as it is one of the most commonly used typologies for high-density residential designs. The integration of residential and public space has raised many issues related to privacy and separating access to circulation routes and exit stairs between the two groups of users, the residents and the public. A skip-stop residential entrance design was adopted in Chapter 5 for the parametrics system exploration to support a larger range of space allocation and to offer more options for interior layout, as most residential units could have additional levels. The skip-stop residential entrance has 'freed' the corridor space for the intermediate levels, can provide access to the commercial and public spaces. As shown in Figure 7-9, the lower skip-stop level is exclusively used for the residences of the building. The corridor on that level provides access to each residential unit, as well as the shared residential community space. The commercial space only has access to this corridor during 


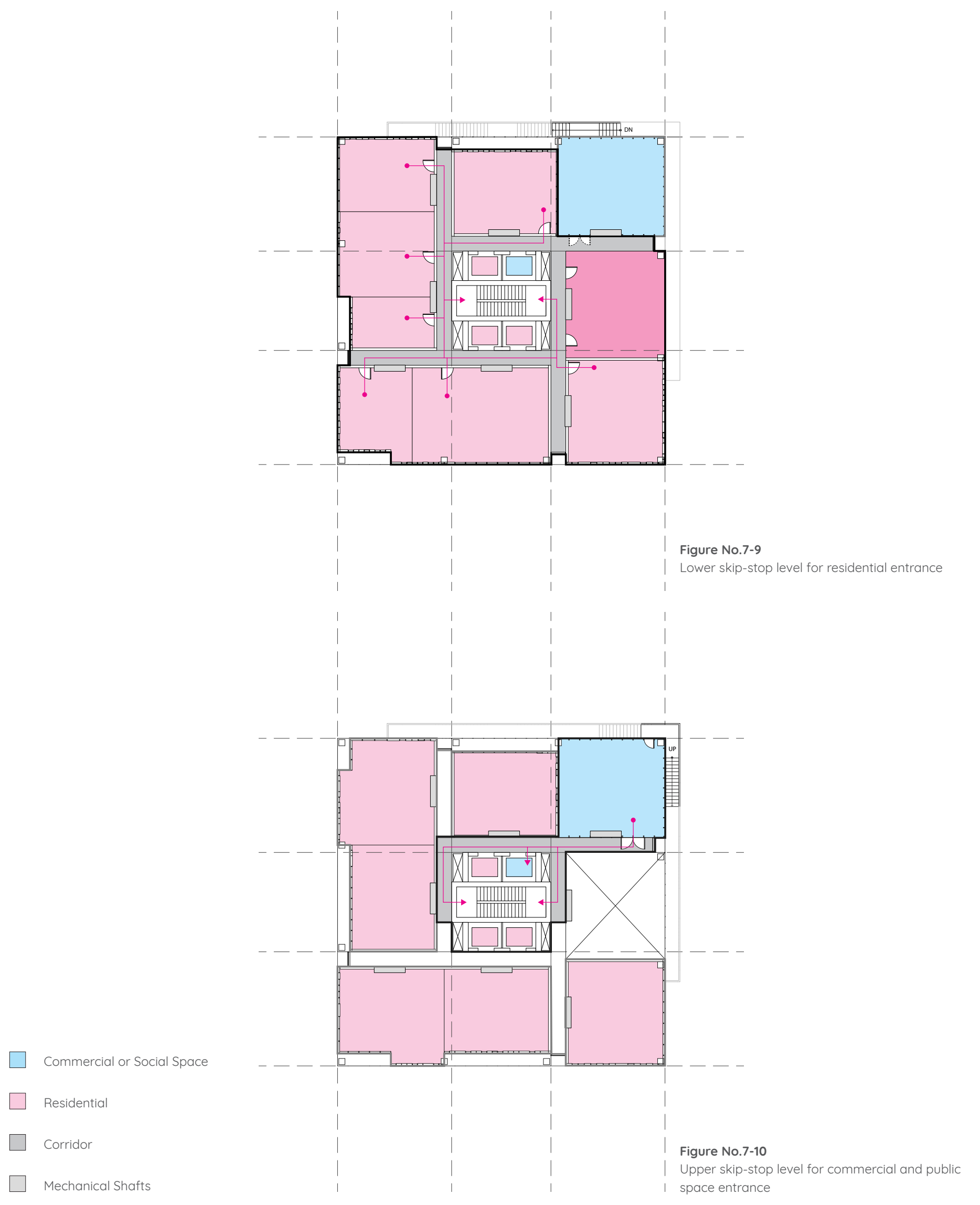




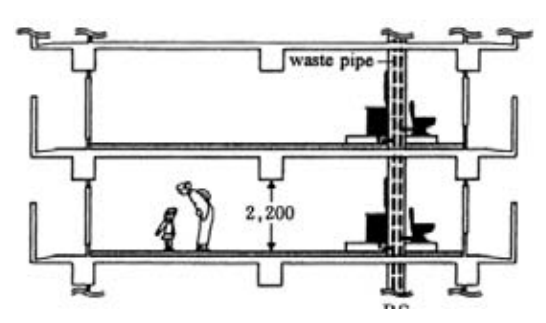

Figure No.7-11

Conventional Japanese residential structure system

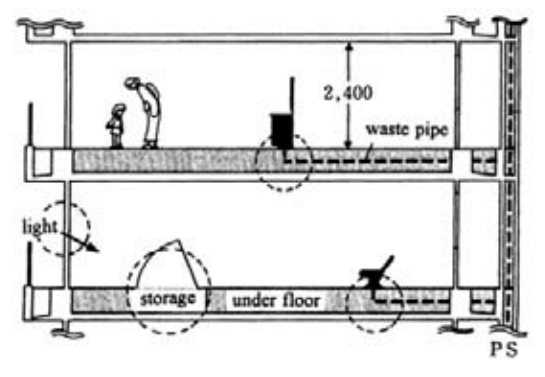

Figure No.7-12

Inverted Slab/Beam Support structure designed for Japanese Open Building projects a fire emergency. The upper skip-stop level (fig. 7-10) provides access to commercial and public spaces through dedicated elevators and corridors, exit systems, and a continuous external stairway access for public use.

The Support Level incorporates the fixed and service support components of the building. Part of its duty is to provide service space for the Infill and Allocation Levels. Therefore, the service shafts are distributed between every two unit cells. These additional service shafts allow all units to have access to vertical plumbing and electrical wiring without horizontally spanning the pipes or cables across other units. Horizontal service space is also included in the design through adaptable raised flooring systems that are commonly used in other Open Building residential projects and office spaces.

Multiple raised floor systems and products are being studied and refined by manufacturers to achieve better ease of installation, and higher flexibility for pipe layout. Japanese Open Building designs have even investigated an inverted slab and beam support system that could better integrate the raised floor space within the structural system, which reduces the floor-to-floor building height (Kendall \& Teicher, 2000, p.185).

The facade mullion grid is also part of the Support Level, as it provides the underlying module for establishing and changing Allocation Level alignments. With additional horizontal and vertical service space, unit and room boundaries are relatively freed from the mechanical and electrical services. As a result, the design of the Support Level allows spatial deployment to be changed without overcomplicating the construction and renovation process. 


\begin{tabular}{|l|l|l|l|l|l|l|}
\hline \multicolumn{2}{|l|}{} & \multicolumn{1}{|l|}{} & & \\
\hline
\end{tabular}
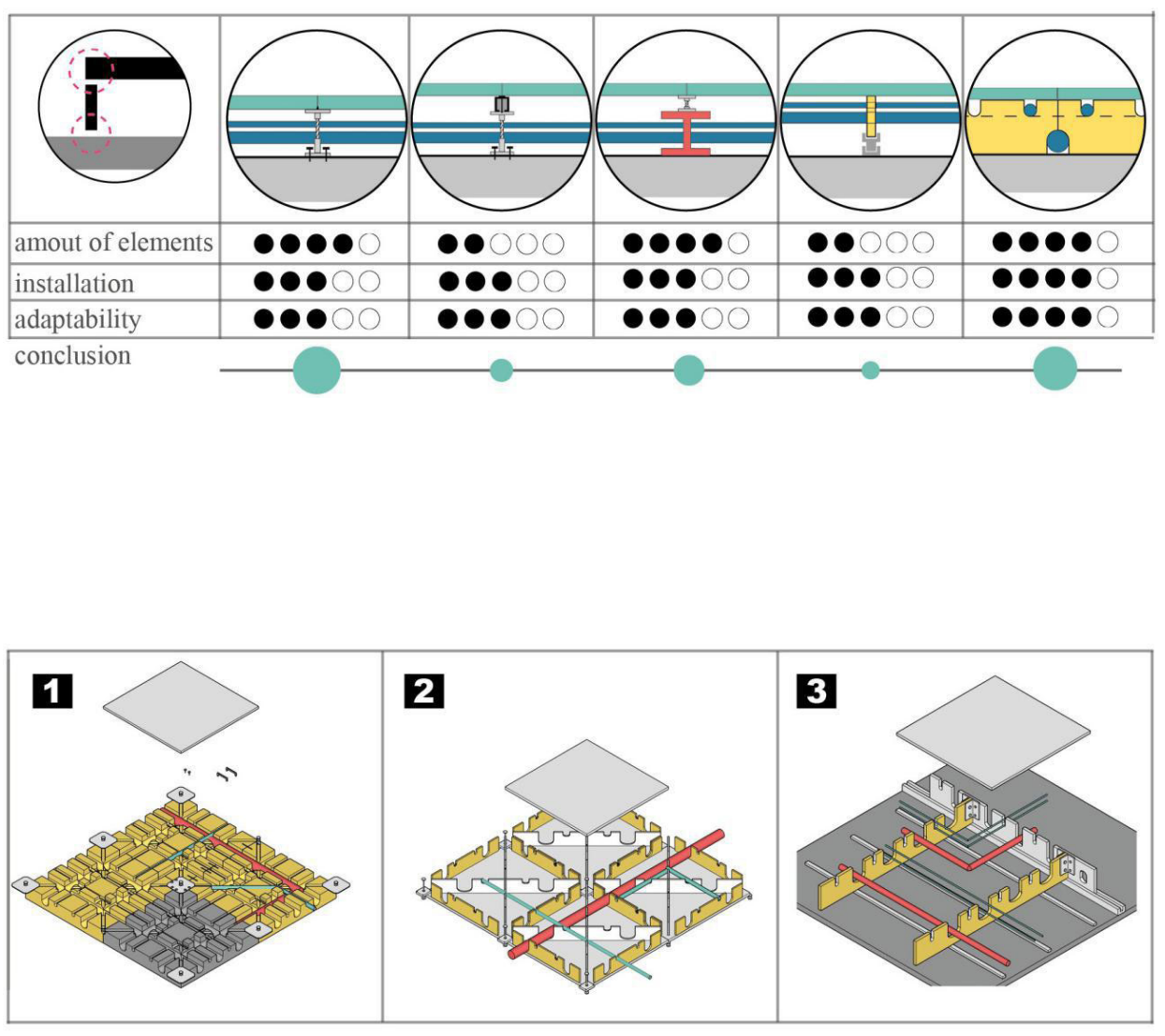

Figure No.7-13

Plumbing solutions for Open Building projects

Figure No.7-14

Raised floor systems and products

Figure No.7-15

3D illustration for the plumbing distribution of different raised floor systems 


\section{8 | Vertical Community Design Investigation}

The accelerating global population shift from rural towards urban areas is one of the major factors that is transforming cities. Presently, over fifty-five percent of the world's population lives in cities; the number is expected to exceed sixty-eight percent by 2050 (UN DESA, 2018). Megacities, with a population of more than ten million inhabitants, are not only increasing in number but continuously growing in scale and density, imposing new challenges to urban living conditions (UN DESA, 2018). The traditionally desirable single family suburban home (particularly in North America) produces urban sprawl and inefficient use of resources, contributing significantly to environmental degradation. While the increasing density in megacities is addressed through vertical growth, skyscrapers are built taller with a greater density without consideration of the social wellbeing of the residents. The mass-production model of high-rise residences produce social isolation and segregation of occupants; society becomes further segregated due to minimal opportunities for social interaction and the absence of any sense of community.

\section{Social Context of High-density Residential Towers}

Within a high-density megacity, the scale of the population becomes disproportionate with the conventional classification of urban territories. The increase in population and density has shifted the conventional classification of territories down by one level. The population of the contemporary urban district is often equal to a typical conventional city while the contemporary urban block contains a population equal to the conventional district and the contemporary high-rise building has the same population as the conventional block or neighbourhood. Therefore, a residential tower with a single-purpose design that only meets the living standards of individual households is no longer applicable. The design of high-rise buildings needs to 


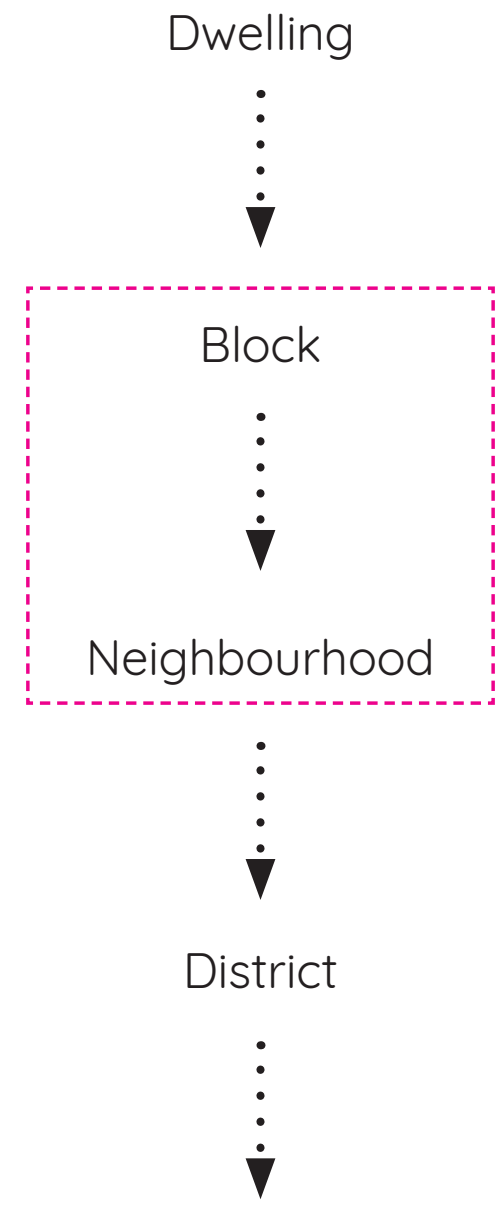

City 


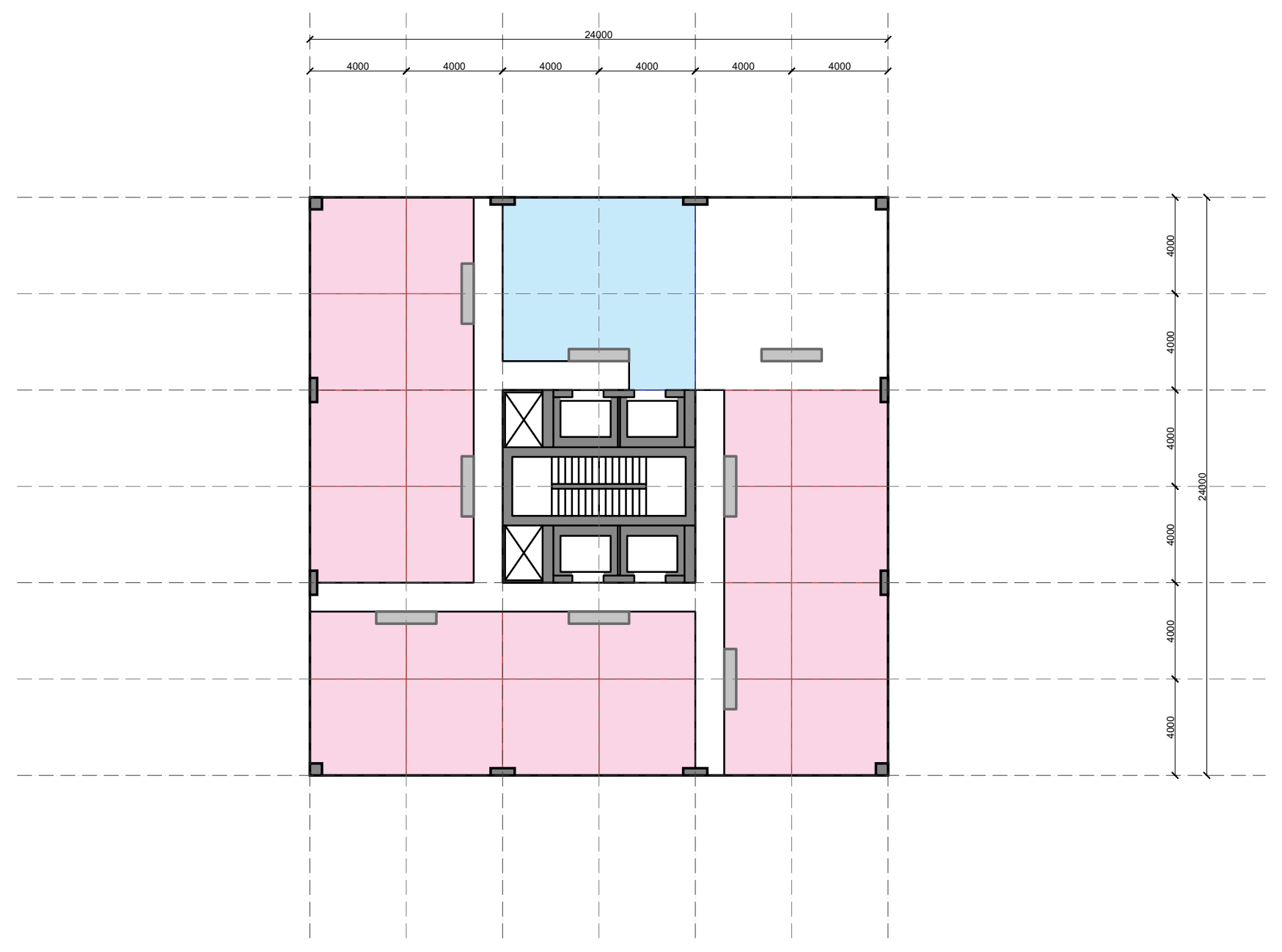

Figure No.8-2

Plan showing division of blocks and standard high-

rise building core 


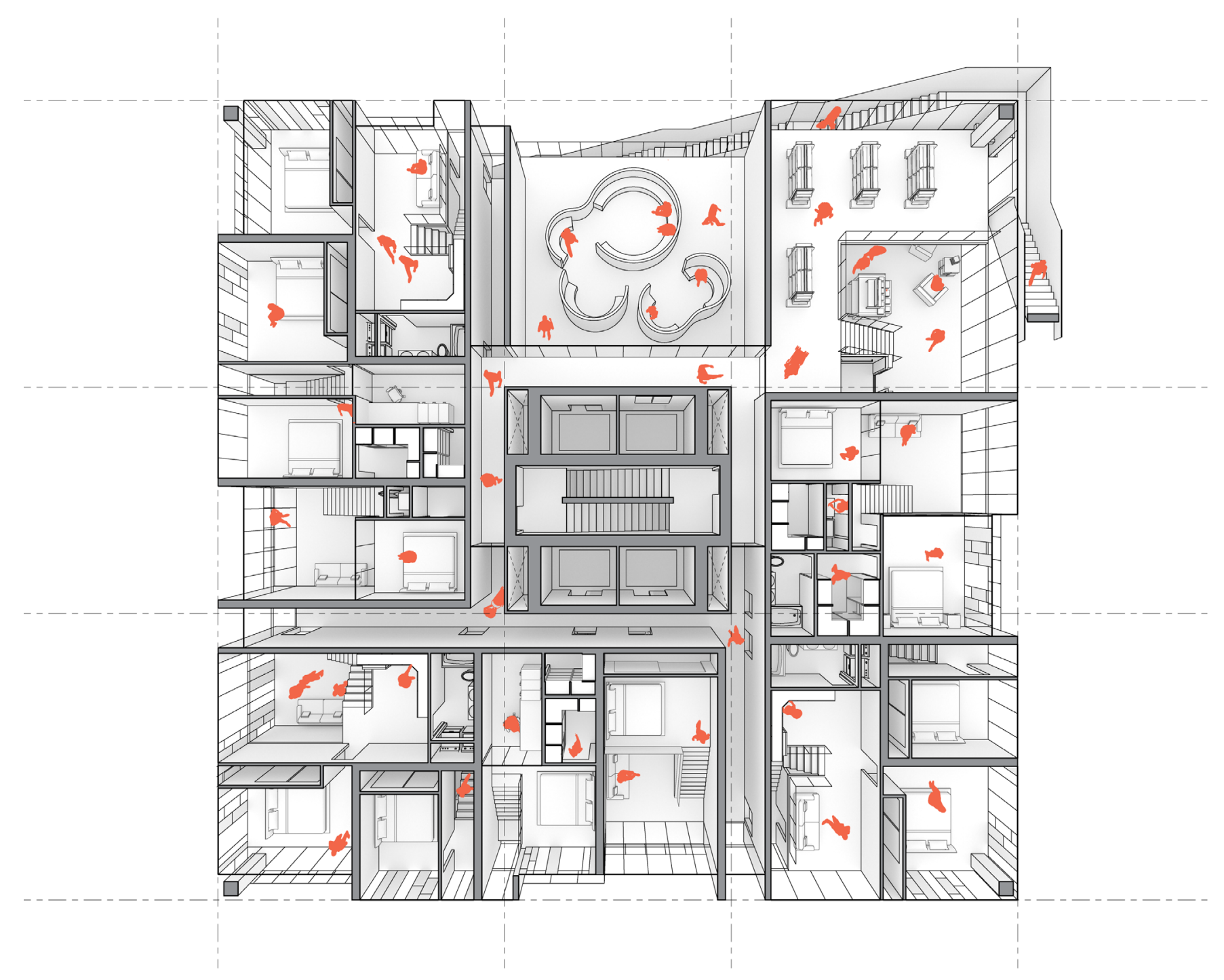

Figure No.8-3

Perspectival plan showing customized residential

units and activities within a vertical neighbourhood 
address the original functions of conventional neighbourhoods. Jane Jacobs describes conventional neighbourhoods as "mundane organs of self-government... a self-management of society" (Jacobs, 1961, p. 114). This description of neighbourhoods suggests a collective control of the space that they inhabit, which could be addressed through user participation and customization in design. Jacobs identified the importance of a smaller-scale neighbourhood for having an "innate degree of natural cross-connections within itself" (Jacobs, 1961, p. 115). People become more familiar with those that they often see; therefore, a smaller community can promote intimacy, which supports social and individual health. Contemporary high-rise buildings often contain thousands of households that are all individually segregated without opportunities for interaction. The density did not offer intimacy among the community members, only a dense isolation of individual households. Jacobs also described the benefit to cities achieved by grouping people together with similar interests and through the communication of knowledge (Jacobs, 1961, p. 118-119). Lastly, Jacobs believes that neighbourhoods should embrace diversity in many aspects, such as amenities and functionality, as well as cultural identity and ethnicity (Jacobs, 1961, p. 139). A diverse environment would not be vulnerable to changes, therefore creating a long-lasting relationship between the residents and facilitated by the built environment.

The goal of this design research is to investigate the possibilities of incorporating the elements of the conventional neighbourhood, as highlighted by Jane Jacobs, into a high-density residential design, thus transforming monotonous and anonymous high-density residential towards a vertical community. As shown in Figure 8.2, a standard design of the centre core and corridor, with perimeter structure providing an open floor plate, was adopted to maintain 


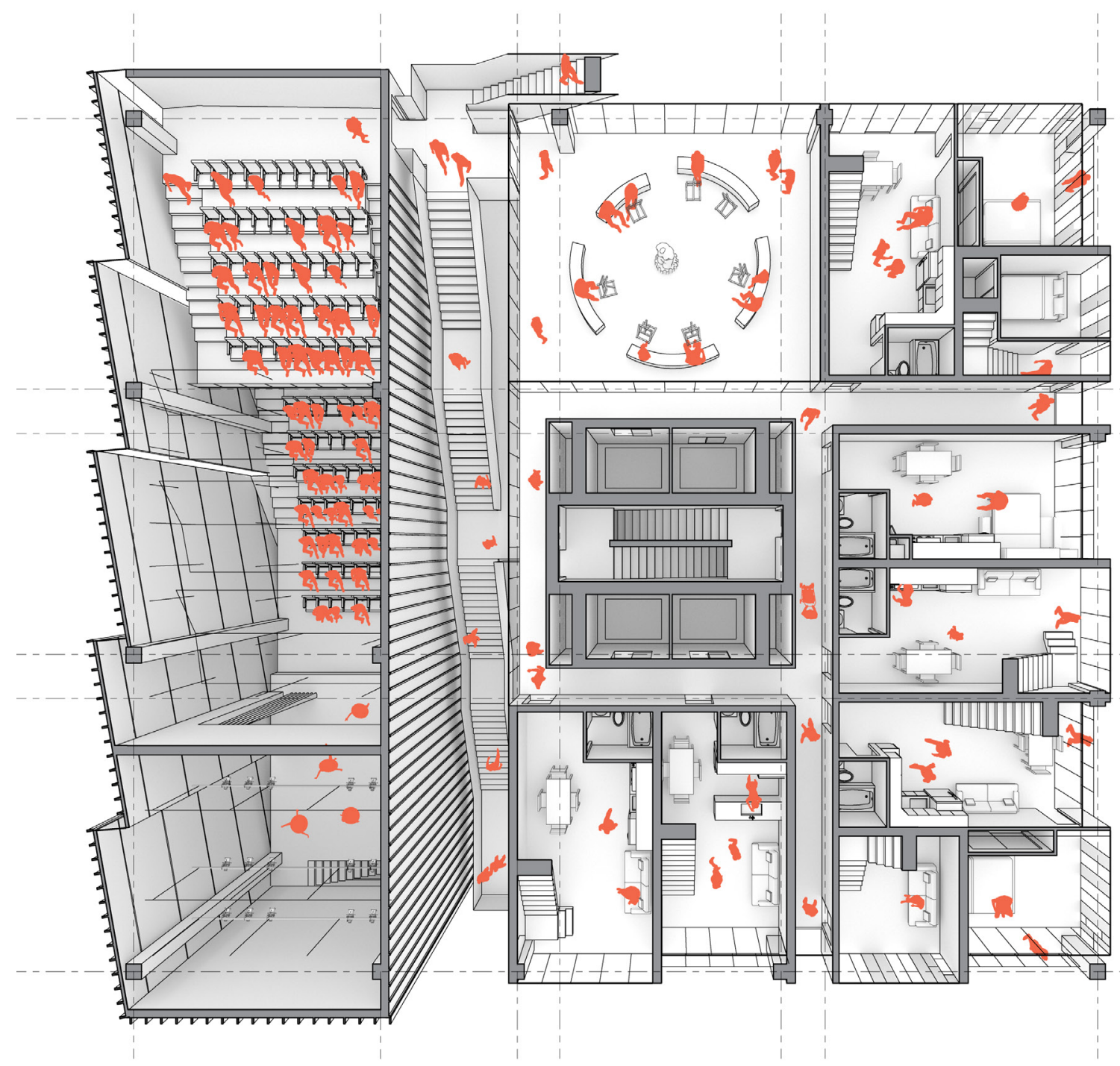

Figure No.8-4

Perspectival plan showing multipurpose theater as large public space that interrelate with its adjacent residential block. 
the maintain typical efficiencies of a high-rise building design while supporting maximum Allocation and Infill Level flexibility over time.

\section{Vertical Podium: Commercial and Public Neighbourhood Activities}

Current urban zoning in many cities has adopted an approach were very tall point towers with significant space between building forms rise from street-related massing of commercial uses. Commercial space, shops and restaurants are often restricted to the first or second level of the podium of a tower. By keeping public or commercial space closer to the ground level, the conventional podium design strategy has created a limit cap for the total amount of public space with confined activity variations that an urban zone could have. This restriction of space worsens as public spaces are redeveloped into monotonous high-density residential projects. As the height of residential buildings continues to increase, the population density also rises - producing a disproportionate commercial-to-amenity space ratio. Unacceptably insufficient space for social gathering, and poor access to very few other amenities (food, daycare, etc.) demands a rethinking of this typology. Therefore, public and commercial space must no longer be constrained to the ground plane (lot area), but should grow in response to the population of a given space, and in addition, its variety should be determined by the neighborhood's social and cultural atmosphere.

The Kowloon Walled City developed a sense of intimacy within a high-density community through a scattering of spontaneous businesses and restaurants within the community, as well as having a close interrelation of commercial, residential and public space. Therefore, in this design study, the podium functions are vertically distributed through the height of the tower and accessed with skip. 


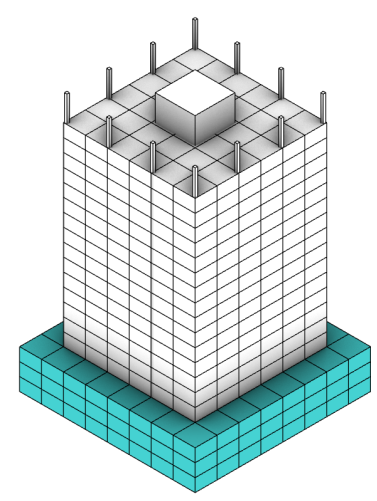

Conventional high-rise residences with separate programing between the tower and podium

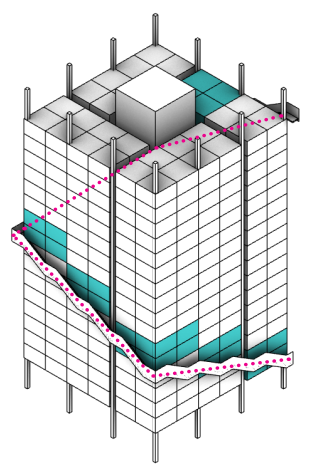

Vertical distribution of the small public space along the helix stairs circulation

Shared activity space distributed under the public program

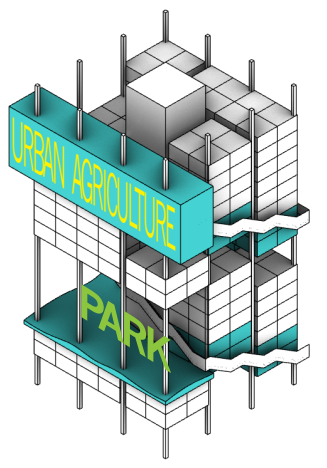

Larger anchored public programs inserted into the vertical neighbourhood

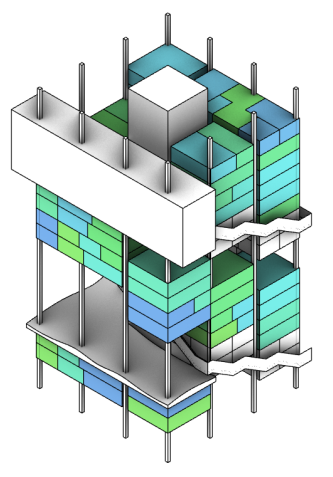

Shifted boundary and changing Allocation Level after residency through neighbourhood negotiation

based on space demand and common interest
Customizable and interchangeable residential building facade that reflect the living habit of individual user
Figure No.8-5

Design process diagram showing and intertwined relation between the public/ commercial space with residential units that together forms a vertical community 
stop elevators and a helical stairway. Attaching the commercial and public spaces onto the residential building can help develop a new social dynamics within the residential community, as most public spaces are available within walking distance. Residents can be socially engaged by simply walking out of their apartment unit into a public space such as a park or community space within the building. This vertical distribution of conventional podium space activities can provide a better balance of public / commercial versus residential activities, thereby promoting social intimacy through interconnection of public and residential space.

\section{Block Scale Residential Community}

The block-level in the Vertical Community is planned to occupy fifteen to twenty households, people are grouped with similar interest, on every two to four floors (Figure 8-7). They manage the space they inhabit collectively. Therefore, both public and private shared community spaces are inserted within the block. These social activity hotspots could help stimulate intimacy within the neighbourhood. The neighbourhood is the tower itself, composed of multiple residential blocks with a helix stairway that interconnects all public amenities and commercial spaces (Figure 8-5). The primary public anchor amenities, including urban parks, multipurpose theatre, urban agriculture, fitness centre, and shared office space, are carved out from the residential block. The helix stairway was rerouted to reduce the travel distance, as well as to offer different views of scenery along the stairway. The public anchor programs allow residents within the community to cross connect and also interact with the public. Urban park spaces shown in Figure 8-11 were designed with a high ceiling for better exposure of sunlight. Natural contours of landscaping and seating are combined for people to gather and relax. In between 


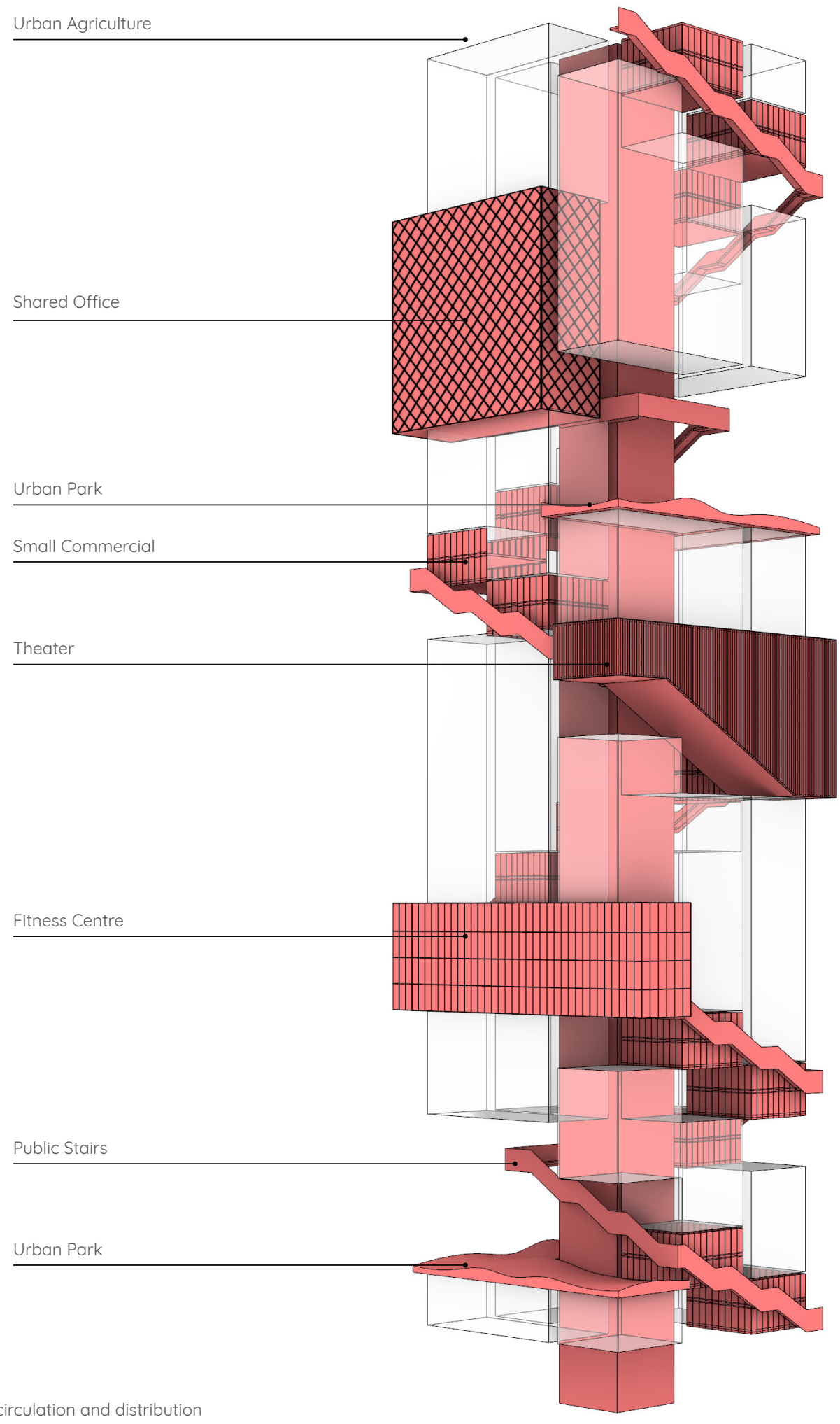

Diagram showing vertical circulation and distribution

of public space along the circulation 
the major anchors are the smaller commercial spaces. The shared activity spaces for the residences are also distributed with the helix stairway under the smaller commercial spaces (Figure 8-9). This design strategy resolves potential privacy issues as the public uses the stairway, removing direct line of sight from public spaces to residential units. As a result, the Vertical Community transforms the high density, multi-story residential tower into its appropriate classification as a neighbourhood rather than the anonymous monoculture of a typical high-density residential building.

\section{Social Dynamics Within The Vertical Community}

Personalization culture is achieved through the combination of the individual action of customizing the Infill Level and the neighbourhood negotiation at the Allocation Level. Residents with similar interests would be drawn together by the social characteristic of different blocks, which is related to the block's adjacent public amenities, similar to the formation of conventional neighbourhoods. For example, the residents of the area of Emily Carr University of Art + Design, on Granville Island, in Vancouver, includes many students and other individuals who are interested in art and design, and that has influenced the social character of that neighbourhood (Hussen, 2017). If an art university were an anchor of the vertical community, it would stimulate the adjacent residential blocks within the tower to become art-oriented. The block's community spaces could also become art or performance-related. The public-owned community space could be managed by one of the residents within that block through election. Activities such as art classes, discussions, or social gathering, can then be scheduled routinely within their community space. Furniture and room layouts would support the particular community activities. Residents living within those blocks can also 


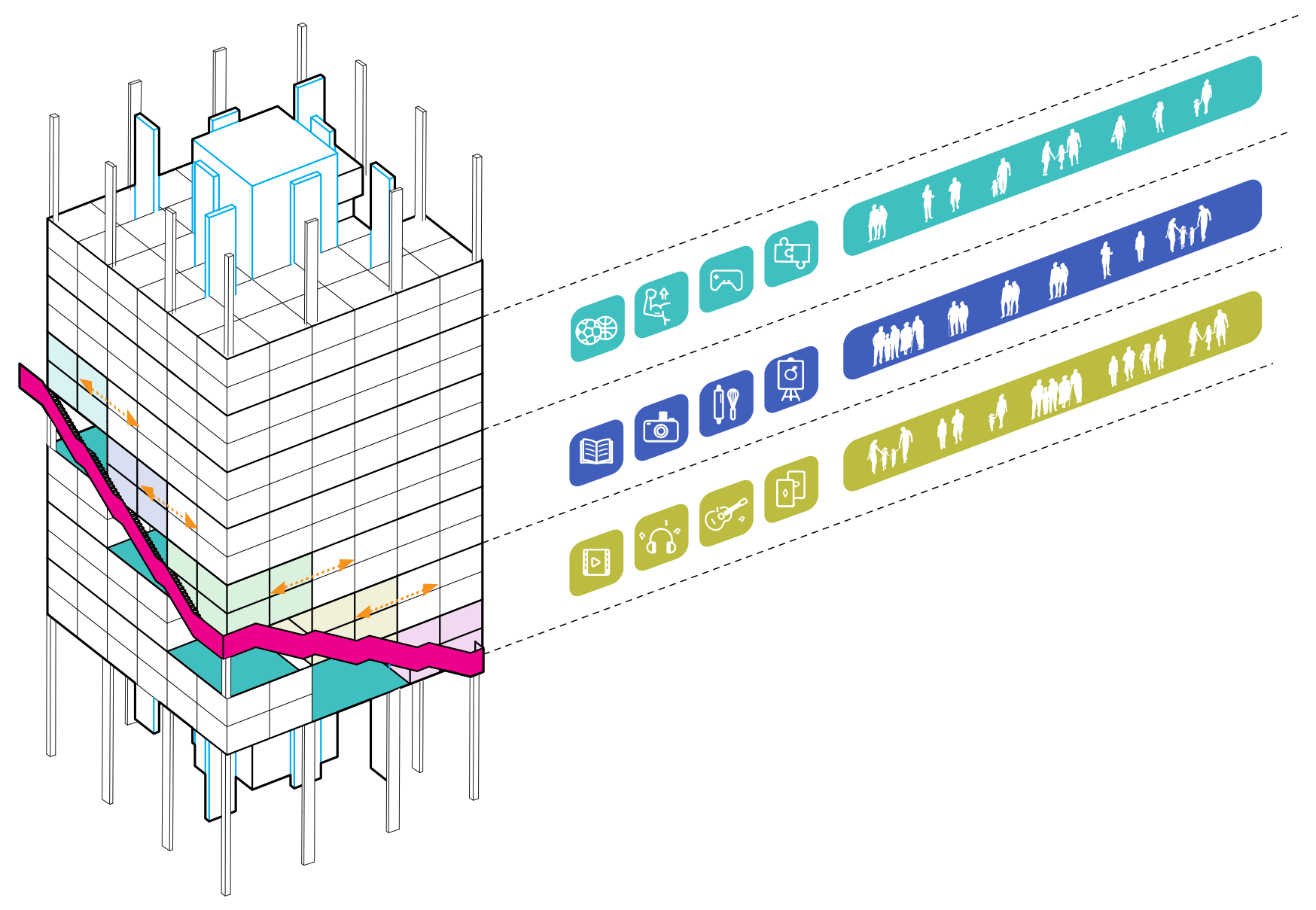

Figure No.8-7

Grouping residents with similar interest within a block 
Figure No.8-8

Corner aerial view of the vertical neighbourhood. Showing the Vertical Community within a high density urban context resulted from urbanization.

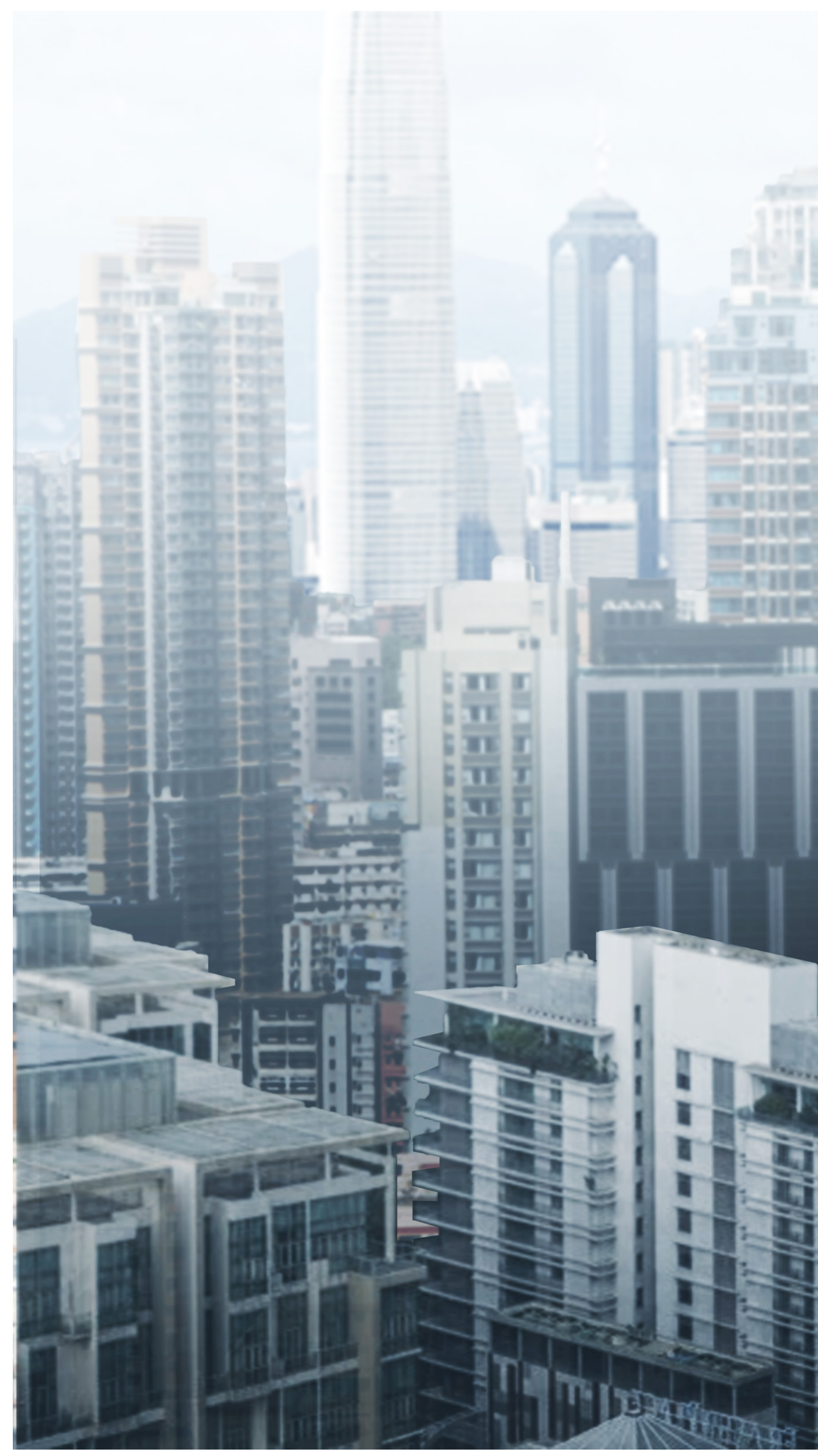




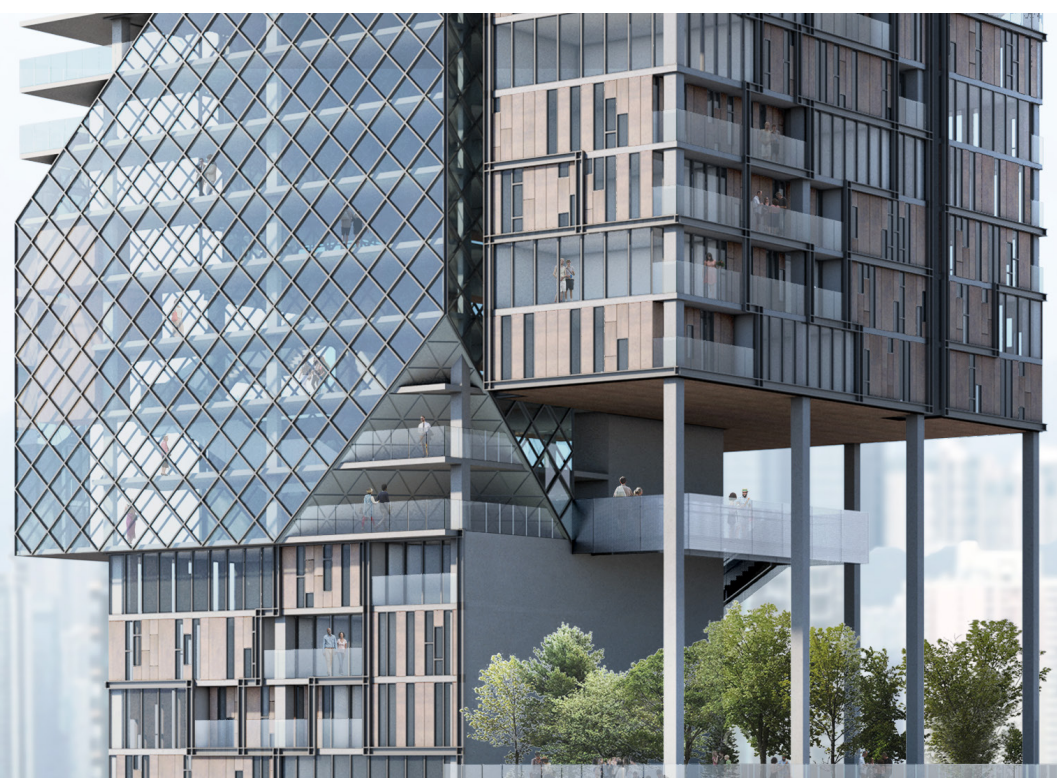

FI Fin 
easily have access to its adjacent public art galleries and interact with the rest of the neighbourhood or public who visit the building.

\section{Feasibility}

The contemporary development of high-density residential projects in Toronto is dominated by developer companies constructing for the condominium market. As a result, the primary drivers for any project are profitability and risk mitigation. After the project is built, ownership of apartment units is transferred to individual owners who will either occupy the unit or rent to a tenant, and the retail areas are often bundled and sold to a real estate management company (REIT) who operates that portion of the building much like a shopping mall. This design proposal would not conflict with much of the current development model, but with the added participation of public sector tenants in the mix. Therefore, additional city planning is required for the vertical space of the city. Moreover, there are important roles and responsibilities for many other AEC related participants to collaborate and further investigate the concept from their industry standpoint. For example, the current construction delivery system would require some refinement to allow the base building contract to supply the Support and Allocation Level elements and a large number of smaller contractor teams would construct the Infill Levels for both residential and public/commercial users. Commercial office building construction easily accommodates similar complexity issues, with separate building permits and construction contracts for base building and tenant improvements. Developer profitability would not necessarily be impacted; as scope is reduced, investment timeframes would shorten and risk is shared.

Some of these problems can be resolved through the new 


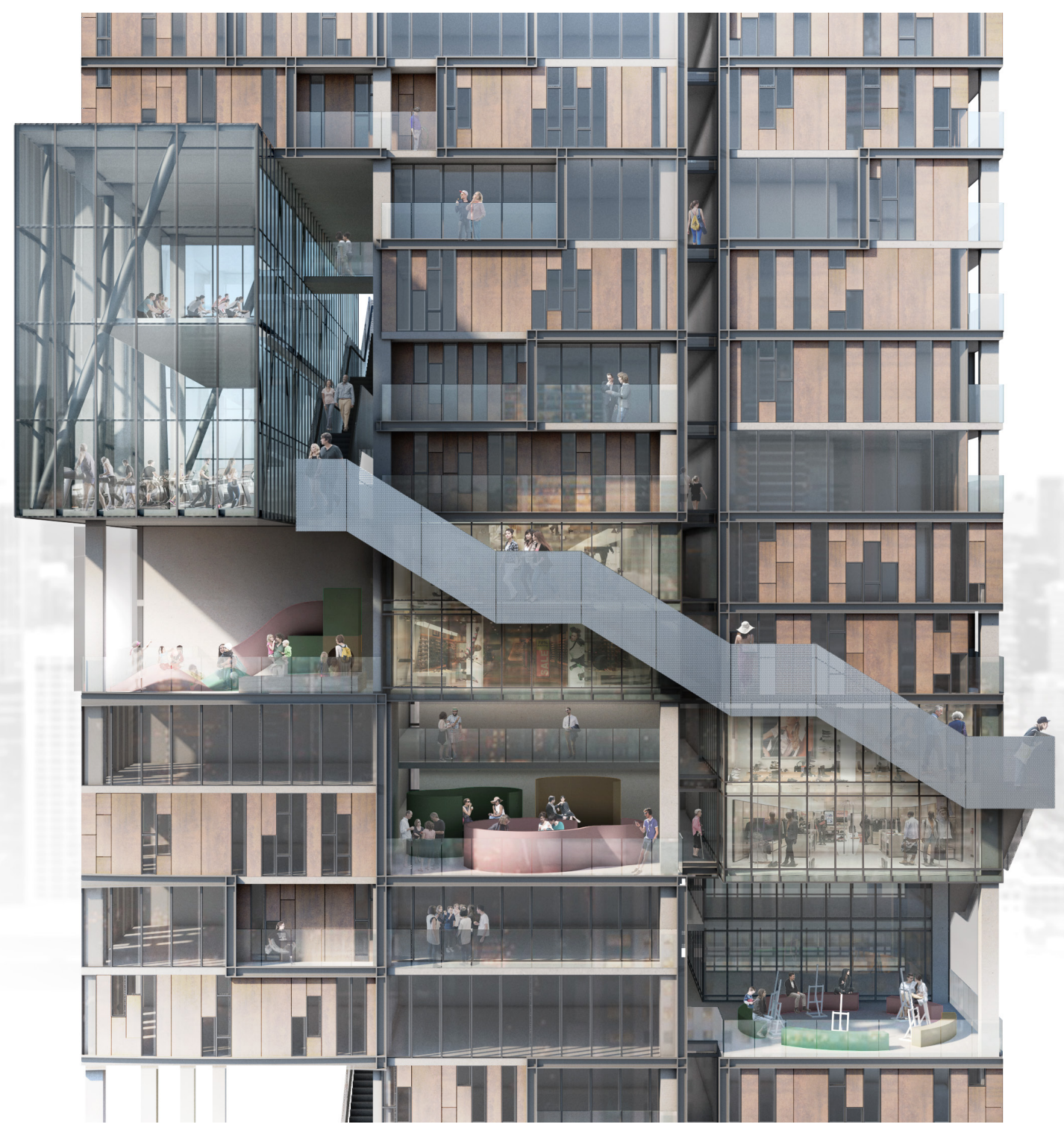

Figure No.8-9

Perspective elevation showing exterior access for the fitness centre and community spaces 
development of technologies. For example, a combination of UpCodes (a searchable building code platform adopted by several North American jurisdictions), that uses Al technology to evaluate virtual 3D models for violation of building codes, and 3D scanning technology could together be deployed to reduce the complexity of building permit application and inspection (Sisson, 2019). Others require industries adaptation: for instance, developers need to work with an urban planning department for construction and management of public spaces within their project. Municipalities need to provide guidance to achieve a certain ratio of public spaces for the future development of high-rise buildings. Therefore, technology and industry adaptation is key to the success of this design. Many examples of elements of required processes currently exist, demonstrating the feasibility of this concept in the very near future. 


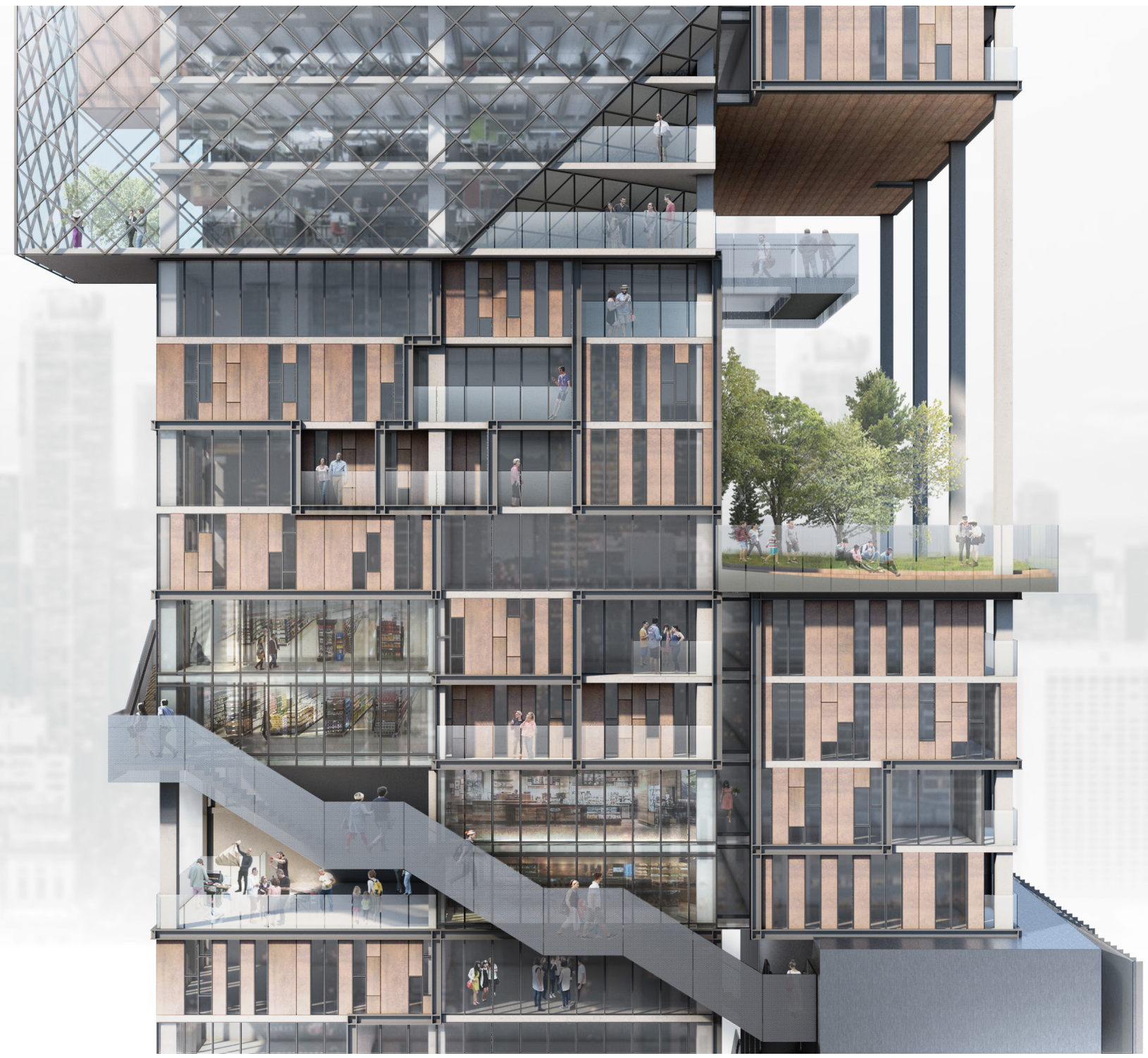

Figure No.8-10

Perspective elevation showing park and shared office space connected through the helix stairs 


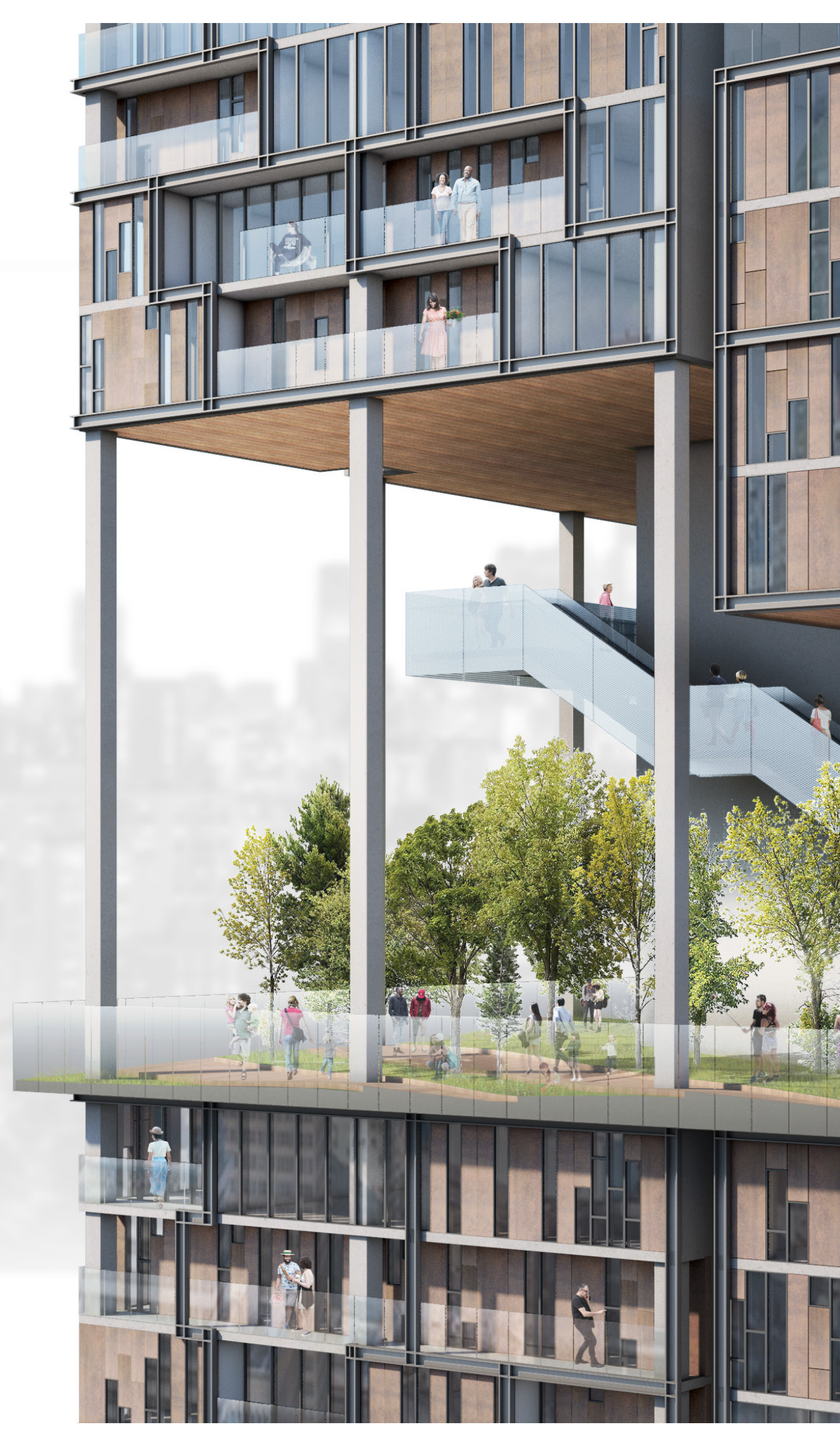




\section{9 | Conclusion}

Technologies and tools are invented based on active force of curiosity and passive force for survival, which are the fundamental motivations for the development of humanity (Wernick, 2017). Architecture, as a representation of human civilization, evolves through the discovery of new technology, techniques and knowledge. From Alberti's mathematical approach for graphic representation to Le Corbusier's Domino House based on the tools of mass production, architecture has never been isolated from technological development. Therefore, architecture should not escape from reality by ignoring the presence of new technologies but should continuously search for opportunities to integrate technology that could support and enhance the design process or achieve unprecedented results that could benefit society as well as the development of the profession of architecture and the construction industry.

The contemporary design of high-density housing is heavily influenced by modernist architecture's visionary planning notion of top-down design. This approach in design has resulted in a standardized and replicated built environment that is mass produced, without any relation to the actual needs of its inhabitants. Since a highly controlled design process produces uniformity, and the lack of control results in chaos, the design of high-density housing requires strategic changes in the design process that will allow the architect to balance the two separate forces of control between the collective and the individual. Parametrics technology can be deployed in this case for a systematic participatory strategy that allows the architect to design with users' performance variability and search for design solutions that could reflect the changing needs of users.

The development of the digital machine has enabled a technological transformation from mass production to mass 
customization. This technological change created new opportunities for architects to design with digital tools such as parametrics. However, the use of parametrics in architecture has remained within the conceptual frame of the past - that of conventional machines, which is limited to the stylistic design of building forms. By integrating parametrics technology with John Habraken and Steven Kendall's flexible residential design concept of Support, Allocation, and Infill building levels, a systematic participatory design is developed to incorporate user preferences and address the ongoing changes within the built environment. This deployment of mass customization technology in architecture has correlated parametrics' strength to create an open-ended and iterative system with user's spatial and performance needs. This design strategy can nurture a personalization culture in architecture that supports social diversity and ongoing changes through user customization. Most importantly, this initiative can promote architects to investigate design strategies that are not based on preconceived ideas, but search for design solutions that could be customized to incentivize people's emotional connection with the physical environment.

The role of the Support Level is expanded in this thesis from the basic structure and mechanical services proposed by John Habraken into the design and planning for an active neighbourhood relation, as well as the functioning of a community for public collaboration and promoting intimacy among the various users. A Vertical Community is proposed based on the trend of urbanization and increasing demand of high-density residential buildings. This mixed-used complex is designed to address the original function of conventional neighbourhoods. Through the dispersing of public space, grouping residents with similar interests, and flexible Allocation design strategy, a community-oriented social dynamic is formed within the mixed- 
used complex. This social intimacy makes the community space an outcome of neighbourhood negotiation, making architecture more sustainable by establishing an enduring relationship with the users.

With the support of technology and innovative construction methods, the design of high density residential can transition and evolve from a product of mass fabrication into a customized home tailored for the user and supported by the neighbourhood. As Mario Carpo states, "All that is digital is variable, and all that is digitally variable is potentially open to interaction, communality and participation" (Lorenzo-Eiroa, 2013, p.48). This systematic participatory design approach shifts the design of high-density residential complexes from stacked plan layouts with a monumental façade and anonymous occupation, into a dynamic system that always maintains overall coherence. In this case, the parameter is no longer in service for a particular style from a single hand but rather helps the community members and architect to collaborate and design through many hands. 


\section{Bibliography}

Abramson, D. M. (2017). Obsolescence: An architectural history. University of Chicago Press.

Block, P., \& Bhooshan, S. (2016). Parametricism 2.0: Rethinking achitecture's agenda for the 21 st century (P. Schumacher, Ed.). John Wiley \& Sons.

Blundell-Jones, P. (Ed.). (2009). Architecture and participation. Taylor \& Francis.

Carpo, M. (2011). The alphabet and the algorithm. MIT Press.

Deutsch, R. (2019). Superusers: Design technology specialists and the future of practice. Routledge.

Fok, W. W., \& Picon, A. (Eds.). (2016). Digital property: Open-source architecture. John Wiley \& Sons.

Girard, G., \& Lambot, I. (1993). City of darkness: Life in Kowloon Walled City. Watermark.

Habraken, N. J., \& Teicher, J. (1972). Supports: An alternative to mass housing.

Habraken, N. J., \& Teicher, J. (2000). The structure of the ordinary: Form and control in the built environment. MIT Press.

Jacobs, J. (1961). The death and life of great American cities (Vintage Books ed). Vintage Books.

Kendall, S., \& Teicher, J. (2000). Residential Open Building. E\&FNSpon.

Kolarevic, B., \& Duarte, J. P. (2019). Mass customization and design democratization.

Le Corbusier. (2014). Towards a new architecture. Brewer, Warren \& Putnam.

Lorenzo-Eiroa, P. (2013). Architecture in Formation: On the Nature of Information in Digital Architecture. Routledge. 
Marcus, C. C. (1995). House as a mirror of self: Exploring the deeper meaning of home. Conari Press.

Miessen, M. (2010). The Nightmare of Participation: Crossbench Praxis as a Mode of Criticality. Sternberg Press.

Ratti, C., \& Claudel, M. (2015). Open source architecture. Thames \& Hudson.

Sakamoto, T., \& Ferré, A. (Eds.). (2008). From control to design: Parametric/ algorithmic architecture. Actar-D.Alexander, C., \& Alexander, C. (2005). A vision of a living world: An essay on the art of building and the nature of the universe. Center for Environmental Structure.

Alexander, C., Ishikawa, S., \& Silverstein, M. (1977). A pattern language: Towns, buildings, construction. Oxford University Press.

Bielefeld, B. (Ed.). (2016). Planning architecture: Dimensions and typologies. Birkhäuser.

Deutsch, R. (2019). Superusers: Design technology specialists and the future of practice. Routledge.

Hussen, A. (2017, June 1). Arts \& Culture. Granville Island. https:// granvilleisland.com/about-us

Hounshell, D. A. (1984). From the American system to mass production, 1800-1932: The development of manufacturing technology in the United States. Johns Hopkins University Press.

Kohlstedt, K. (2018, February 23). Ville Radieuse: Le Corbusier's Functionalist Plan for a Utopian "Radiant City." https://99percentinvisible.org/article/ville-radieuse-le-corbusiers. functionalist-plan-utopian-radiant-city/

Koolhaas, R. (2002). Junkspace. The MIT Press, 100, 175-190.

Koolhaas, R., Mau, B., Sigler, J., Werlemann, H., \& Office for Metropolitan 


\section{Bibliography}

Architecture (Eds.). (1995). Small, medium, large, extra-large: Office for Metropolitan Architecture, Rem Koolhaas, and Bruce Mau. Monacelli Press.

Koolhaas, R., Obrist, H. U., Ota, K., \& Westcott, J. (2011). Project Japan: Metabolism talks. TASCHEN GmbH.

Kunstler, J. H. (1993). The geography of nowhere: The rise and decline of America's man-made landscape. Simon \& Schuster.

Lam, S. (2016, December 2). Here's What Western Accounts of the Kowloon Walled City Don't Tell You. ArchDaily. http://www.archdaily. com/800698/heres-what-western-accounts-of-the-kowloon-walledcity-dont-tell-you

Ledoux, C.-N. (1804). L'Architecture consideree sous le rapport de l'art, des moeurs et de la legislation. HACHETTE LIVRE BNF.

Luke, F. (2017, May 15). AD Classics: Pruitt-lgoe Housing Project / Minoru Yamasaki. ArchDaily. http://www.archdaily.com/870685/ad. classics-pruitt-igoe-housing-project-minoru-yamasaki-st-louis-usamodernism

Pallasmaa, J. (2000). Hapticity and time. Architectural Review, 207.1, $78-84$.

Ratti, C., \& Claudel, M. (2016). The city of tomorrow: Sensors, networks, hackers, and the future of urban life. Yale University Press.

RIBA. (2019, November 22). What is Modern architecture? https://www. architecture.com/explore-architecture/modernism

Rudofsky, B. (1987). Architecture without architects: A short introduction to non-pedigreed architecture. University of New Mexico Press.

Sisson, P. (2019, April 17). A startup's 'spellcheck for buildings' program is innovative. https://www.curbed.com/2019/4/17/18412217/aistartup-building-codes-upcodes-lawsuit-icc 
Schumacher, P. (2011). The autopoiesis of architecture. Vol. 1: A new framework for architecture. Wiley.

Sennott, R. S. (2004). Encyclopedia of 20th century architecture.

Fitzroy Dearborn. http://catalog.hathitrust.org/api/volumes/ oclc/52688206.html

Spencer, D. (2016). The architecture of neoliberalism: How contemporary architecture became an instrument of control and compliance. Bloomsbury Academic.

Statista. (2020, February 12). Best-selling plug-in electric vehicle models worldwide in 2019. https://www.statista.com/statistics/960121/ sales-of-all-electric-vehicles-worldwide-by-model/

Sudjic, D. (2005). The edifice complex: How the rich and powerful shape the world. Allen Lane.

Sveiven, S. (2011, February 9). AD Classics: Nakagin Capsule Tower I Kisho Kurokawa. ArchDaily. http://www.archdaily.com/110745/adclassics-nakagin-capsule-tower-kisho-kurokawa/

UN DESA. (2018, May 16). 2018 Revision of World Urbanization Prospects. https://www.un.org/development/desa/publications/2018. revision-of-world-urbanization-prospects.html

Vanstiphout, W. (2011, August). Historian of the Present: Wouter Vanstiphout [Australian Design Review].

Wernick, A. (2017). Why are humans so curious? The World from PRX. https://www.pri.org/stories/2017-08-27/why-are-humans-socurious

Zucchi, B., \& De Carlo, G. (1992). Giancarlo De Carlo. Butterworth Architecture. 


\section{Appendix A}

Elevations

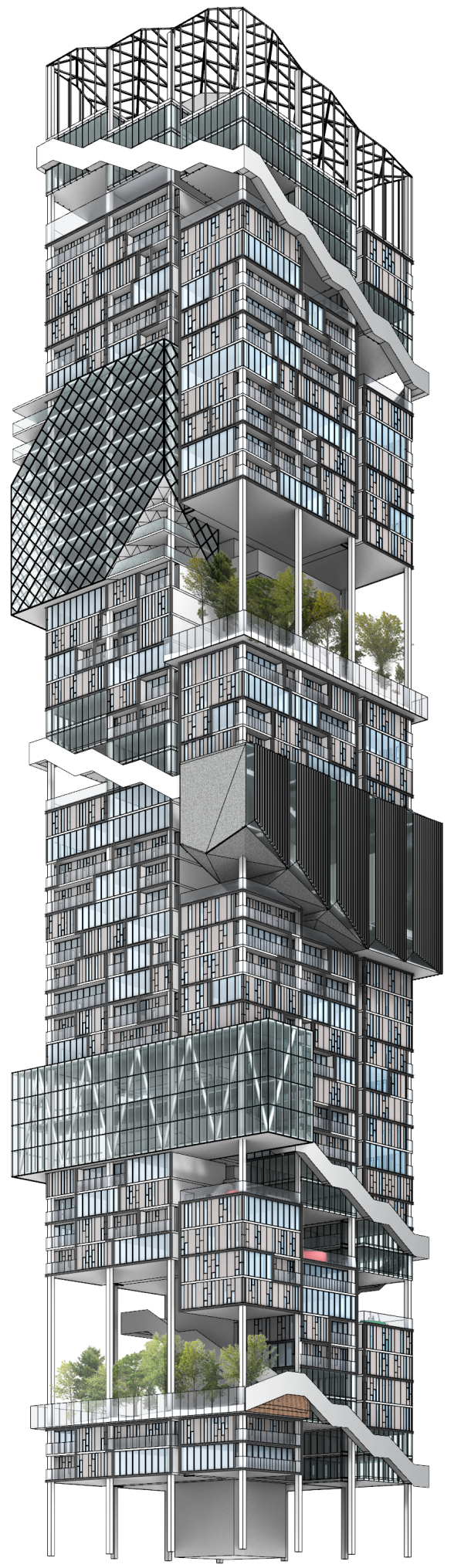



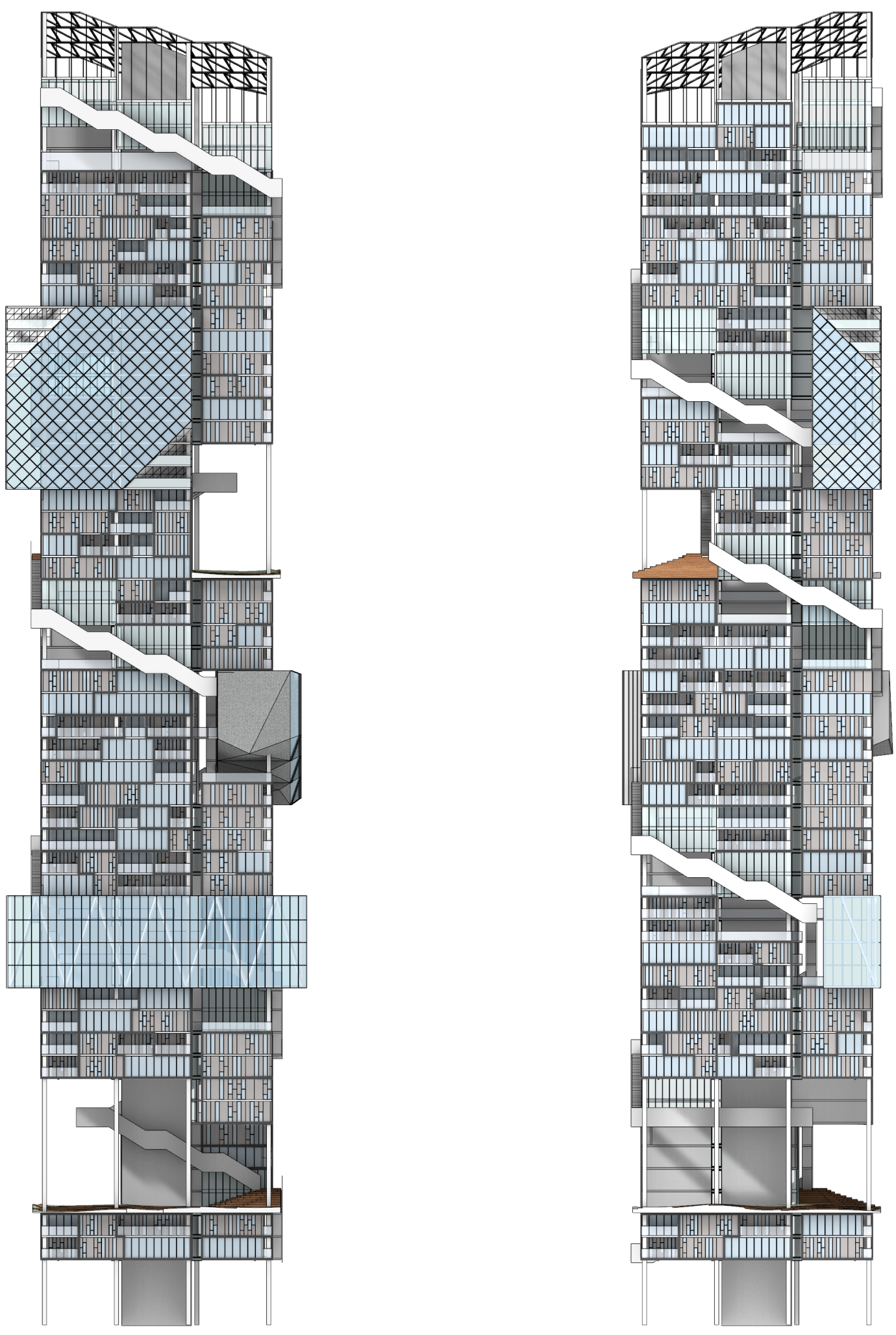


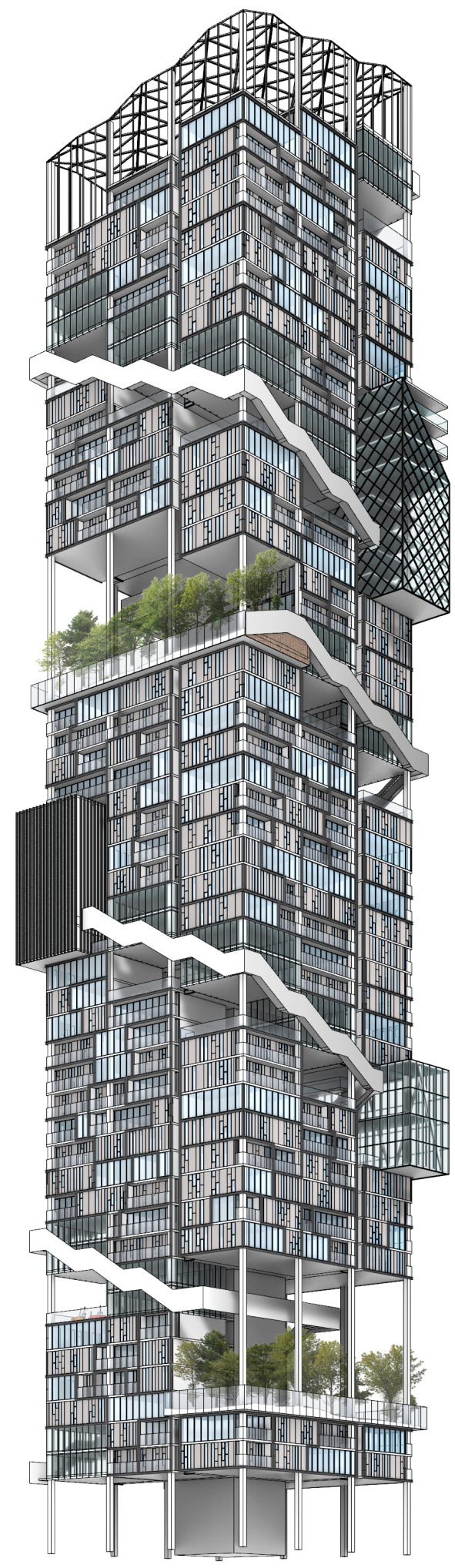



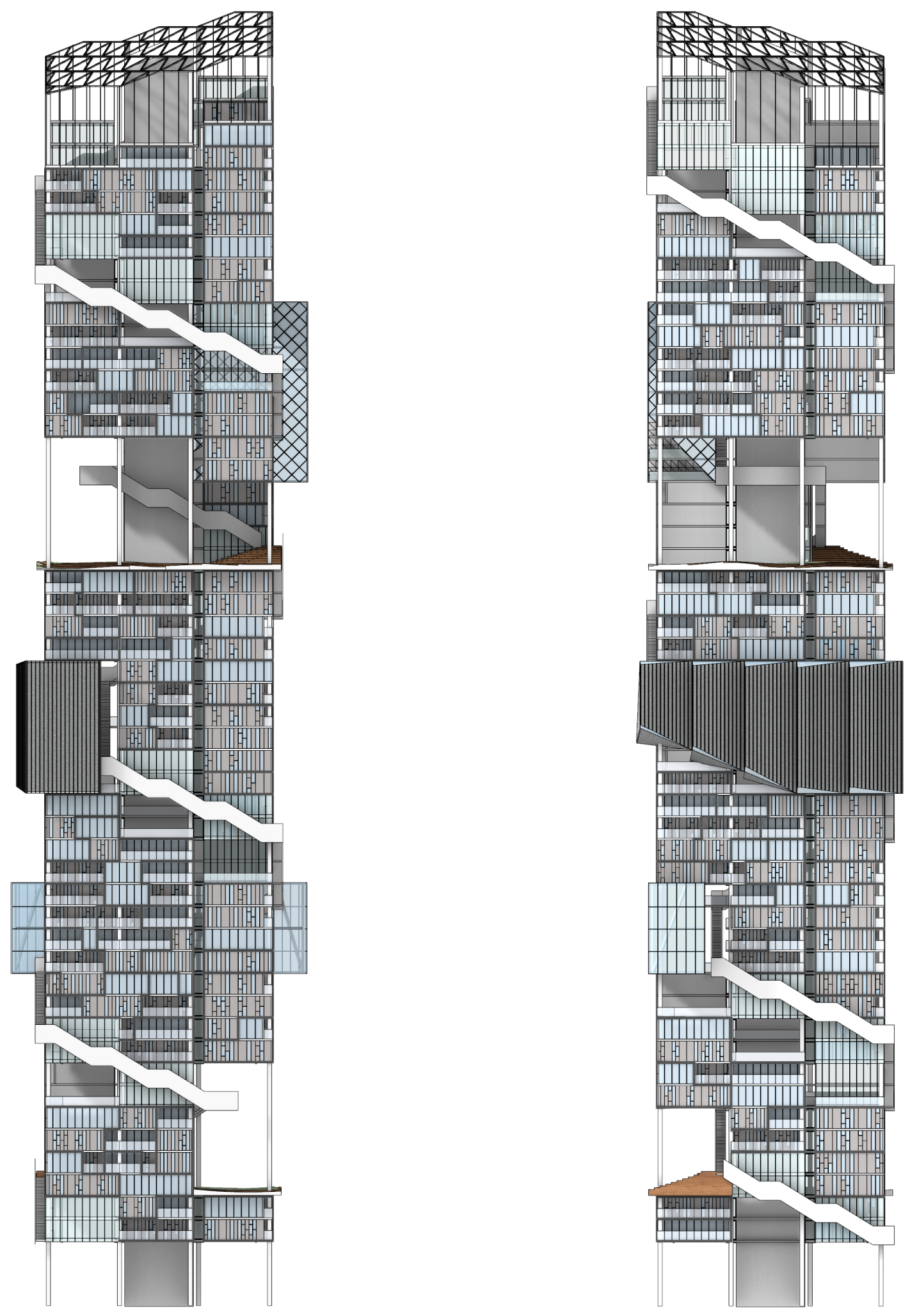


\section{Appendix B}

Other Changing Allocation Scenarios
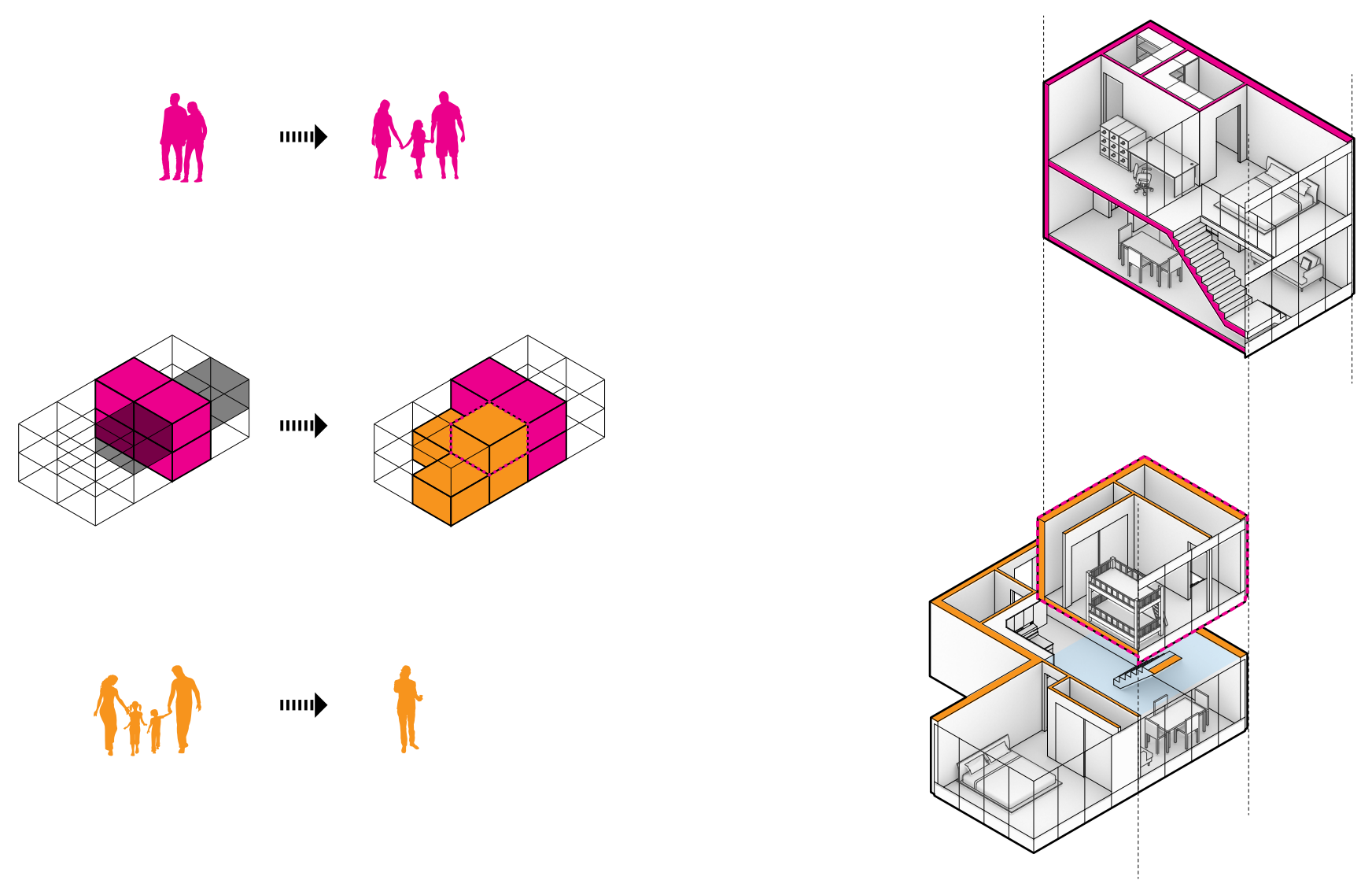

Allocation Level transformation between devoiced

Prior to Allocation Level Transformation

family (contraction of space) and family with a new child (space addition). 

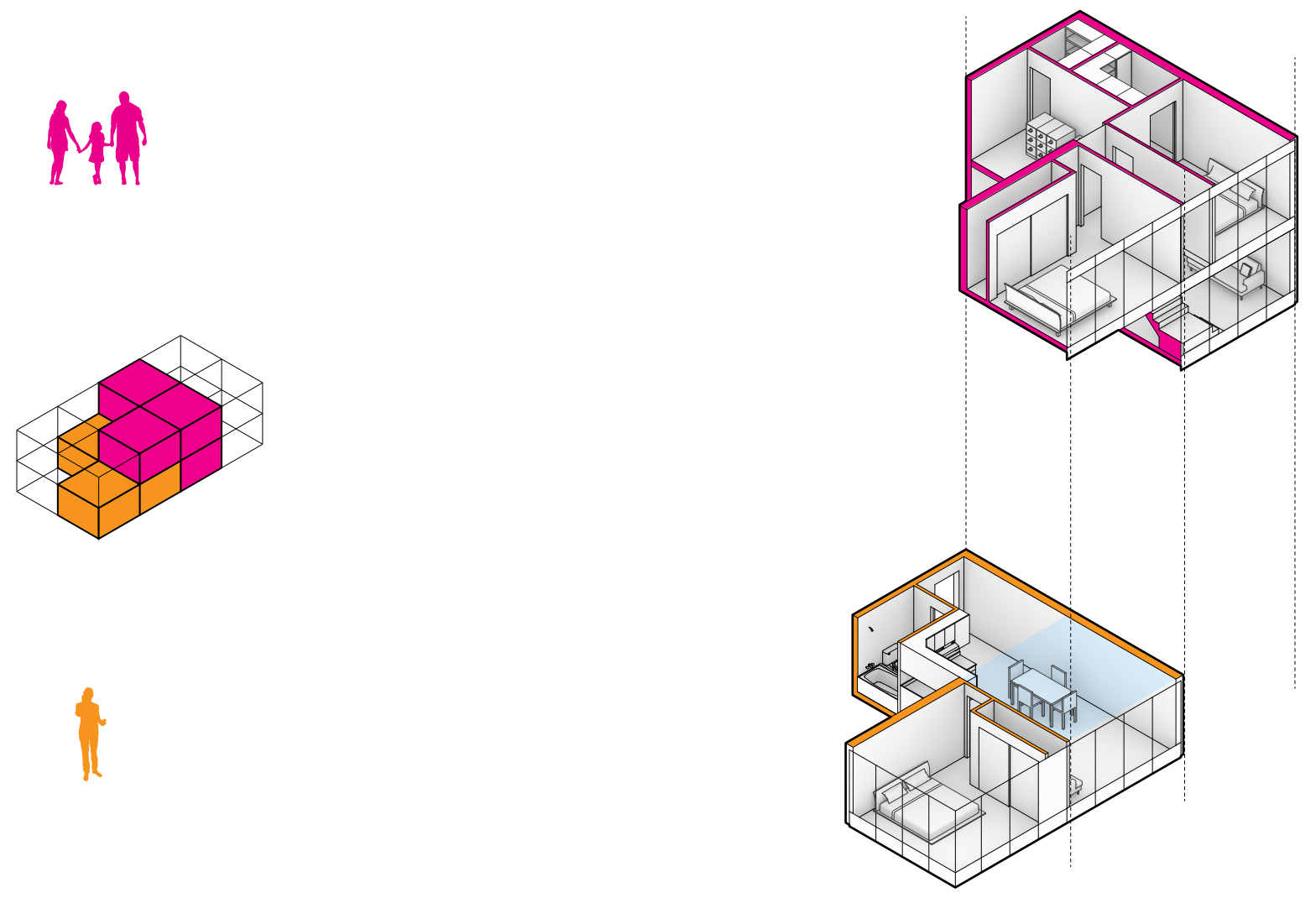

After Allocation Level Transformation 


\section{Appendix C}

Parametric simulation of Allocation Layer transformation over time

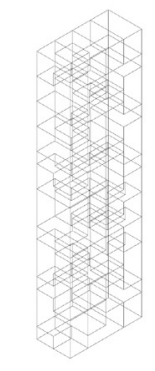

Modified space for changing Allocation Level
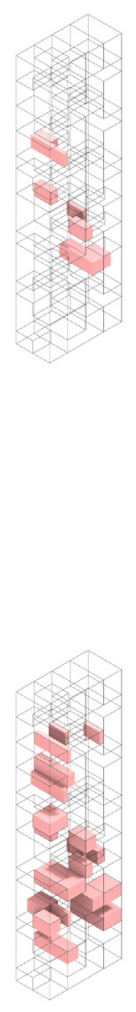
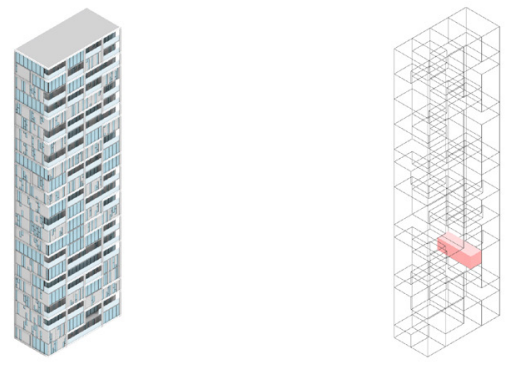

Building facade

Apartment unit massing after customization of Allocation Level
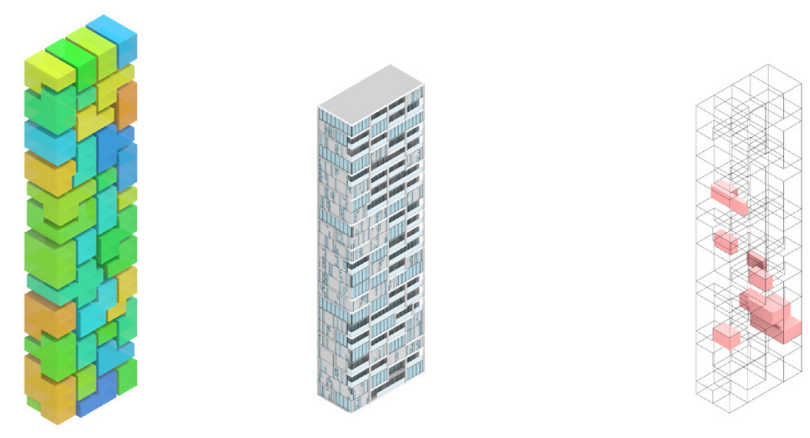
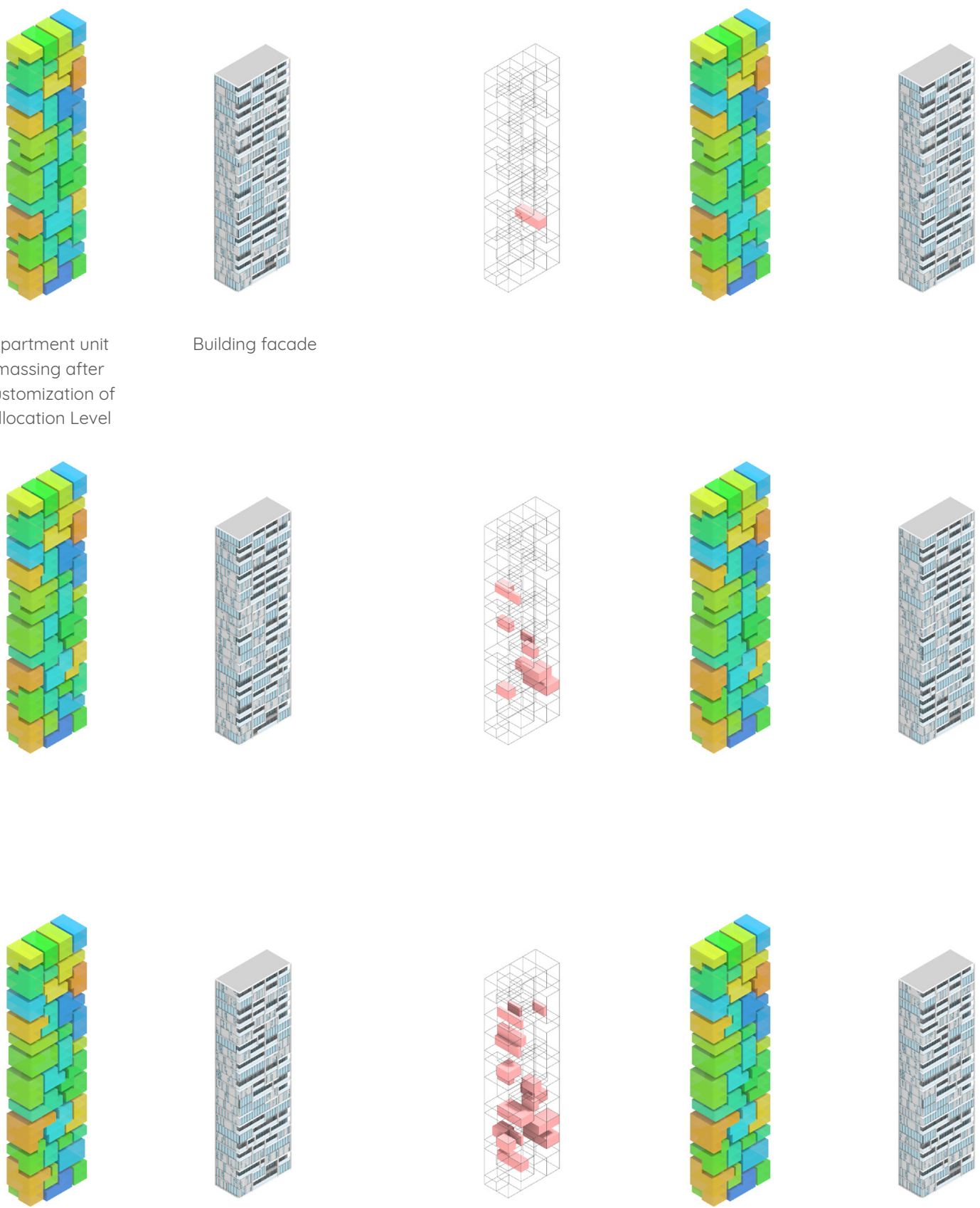
This is a simulation for the transformation of the allocation layer based on the established rules, through transferring and sharing unit space. After the parametric unit distribution, we can see that boundary lines between the modules are vertically aligned. However, as time progresses, the unit boundary will start sifting through neighbourhood negotiation, driven by users' needs, eventually developing its pattern on the façade. The interior space and the façade would continuously evolve, creating a natural relation between the users and their inhabited space.
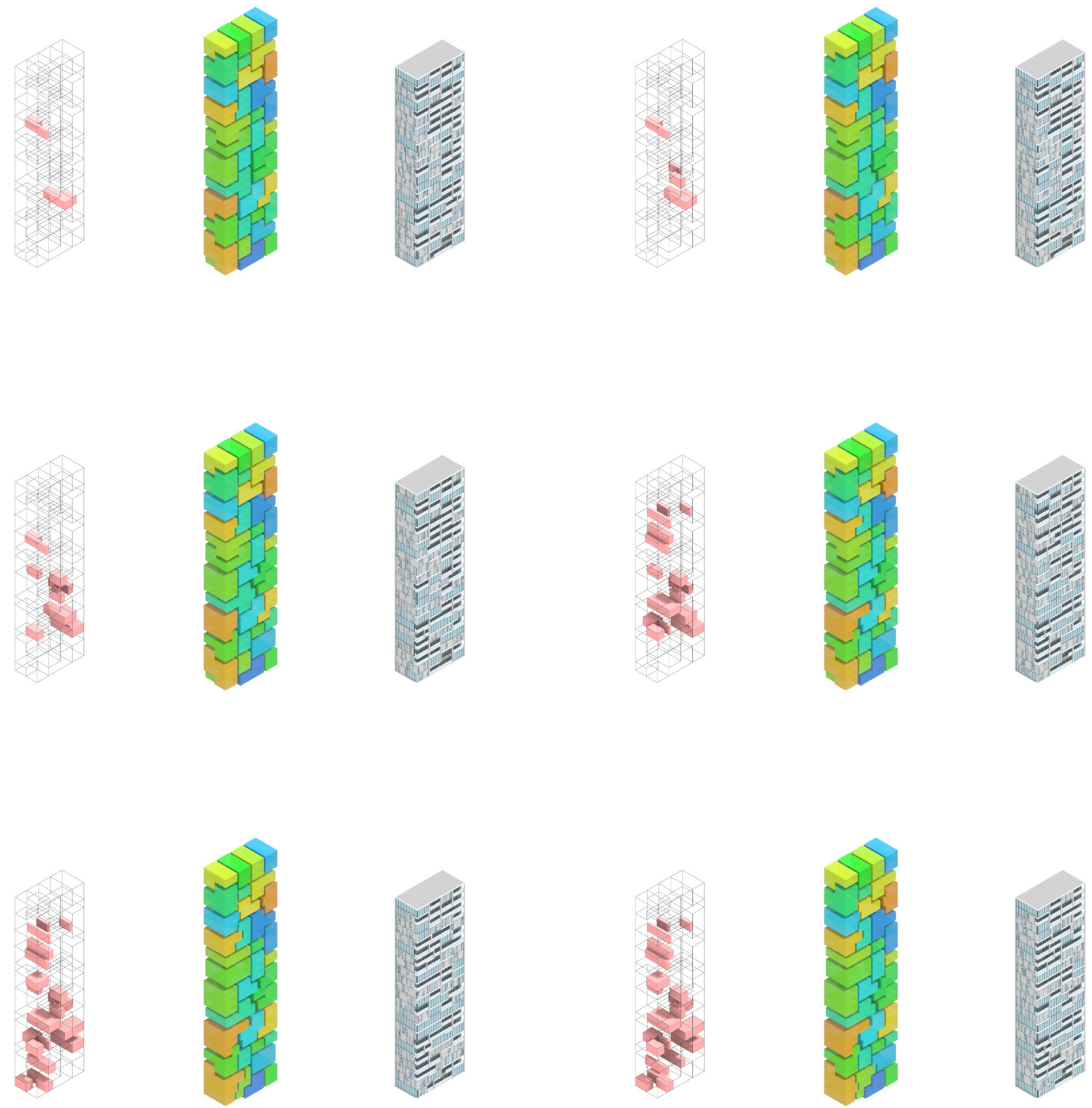